Digitized by the Internet Archive in 2008 with funding from Microsoft Corporation 


THE THEORIES OF EVOLUTION 



\section{THE THEORIES OF EVOLUTION}

BY

YVES DELAGE, M.D., Sc.D.

Professor of Comparative Zoology, Anatomy and Physiology at the University of Paris, Member of the Institute

AND

MARIE GOLDSMITH, M.Sc.

Editor of l'Annee Biologique

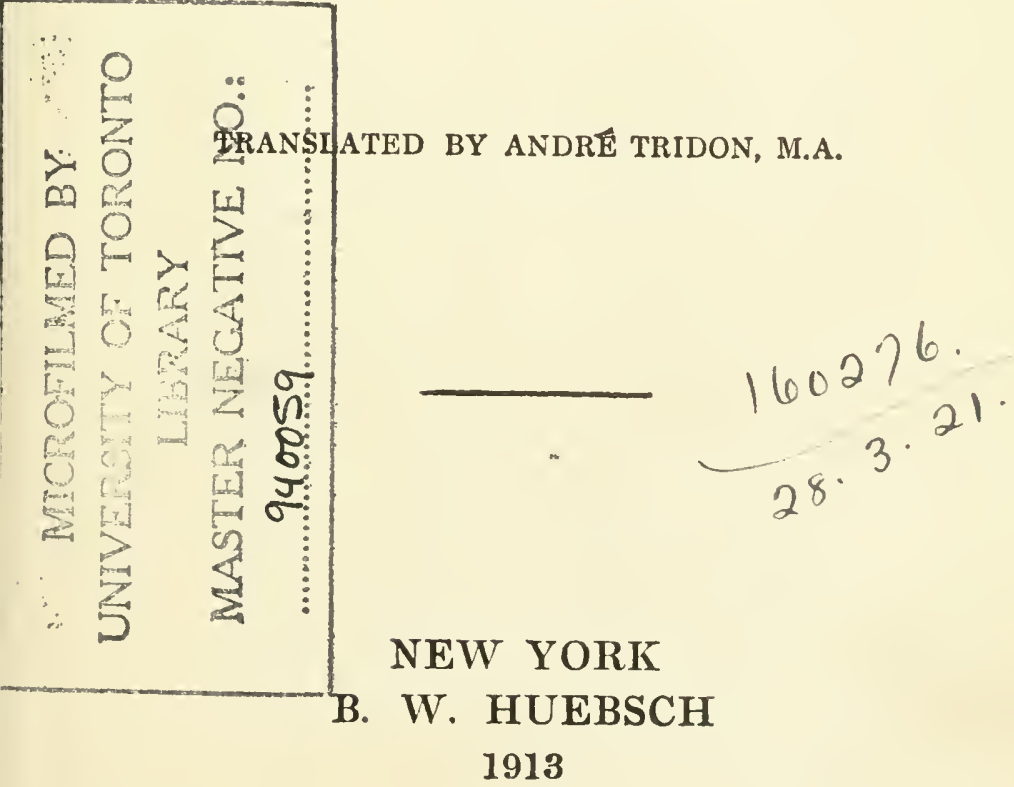


Copyright, 1909 , by

ERNEST FLAMMARION

Copyright, 1912, by

B. W. HUEBSCH

First printing, March, 1912

Second printing, January, 1913
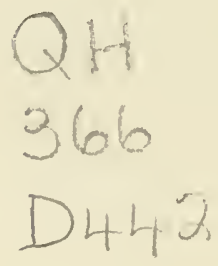

PRINTED IN U. S. A. 


\section{Introduction}

The idea of evolution.-Its application to inorganic things, to organisms, to the origin of man and to man's psychical life.-Its bearing upon ethics and social science.-Its special province: natural science.

THE present generation is so familiar with the 1 various doctrines which constitute our modern scientific creed, in particular with its fundamental tenet, the idea of evolution, that it is apt to forget entirely how very recently this idea became current, and through what struggles it has forced its way into science.

The idea of evolution has come to be one of the most, if not the most inclusive of generalisations at the present time; it extends far beyond the boundaries of the sciences in which it had its inception and covers every department of human thought not excluding even the most obscure and arduous problems of philosophy.

Taken in its broadest sense, it is closely allied with the idea of causality: nothing can happen without a cause, nothing can disappear without leaving traces; all things have their origin in the things which precede them and engender the things which follow 
them. The law of the conservation of energy merely expresses the same truth in different words. The theory of causality has a tremendous importance, both in science and in philosophy, as it eliminates from human speculations the supernatural or marvellous element, and compels man to seek explanations which admit of none but natural factors. It obliges him to create conceptions of the world which presuppose no miraculous act of creation, of creation from nothing.

It has led man to abandon, in the first place, the geocentric conception of the planetary system and secondly, the anthropocentric viewpoint in the study of animal nature. Likewise it has compelled him to reject the too facile explanations offered by teleological systems and to consider causal explanations as the only satisfactory ones.

Our mind is not ripe yet for drawing from the idea of causality all the conclusions to which it may lead; the intellectual bequests of the past are weighing too heavily upon us and too many obstacles are retarding the development of our thought along that line. We may say, however, that in many branches of knowledge, and especially in the study of the inorganic world, this idea prevails absolutely.

The next step forward consisted in applying to the study of the organic world the methods and generalisations adopted in the study of the inorganic world. The task was an arduous one, the more so as the scant 
information at hand and the complexity of the question, increasing as soon as it bore upon living things, were not by any means the most formidable obstacles: the new theory encountered on its path powerful prejudices and deeply rooted convictions, not to mention man's intellectual inertia.

The upholders of religious traditions and the recognised scientific authorities joined forces against it, for it overthrew all the idols which mankind had been taught to worship for several centuries.

More than anything else did the study of life foster the growth of the evolutionary idea proper, the idea, namely, of a processus whose various stages are not only linked by a bond of causality, but constitute an uninterrupted and unreversible sequence, in which a step backward or the exact recurrence of whatever has become the past, is impossible.

This is what we mean when we speak of the evolution of a living thing in the course of its embryonic development (it was to this derelopment that the term was first applied); this is what we mean when we speak of the history of all living things taken in its entirety.

Finally, the idea of evolution leads to the idea that all organic forms are descended from other organic forms, the more complex forms evolving out of simpler ones; thus we go back to the beginning of the history of the organic world, as far back as the origin of 
life itself; thus we arrive at the theory of transformation, the only theory which seems capable of solving satisfactorily the problem of the origin of all living things which now people the earth.

That the different species were bred one from the other is not merely a deduction based on a few facts, for facts can be either disputed or interpreted differently, but a conception which imposes itself on our mind as the only acceptable one, as soon as we reject the doctrine of a supernatural act of creation.

After winning their point as to the origin of the animal and plant species, evolutionists took another step forward and busied themselves with the origin of man. In the mind of the primitive savage, man is not dissociated from the world; everything is considered from the point of view of man, nature is peopled with beings similar to man and leading a life similar to his life; the origin of the human race is not any more mysterious than the origin of nature herself.

At a later stage of development, subtler religious conceptions and a metaphysical philosophy open a chasm between nature and man. Man's destiny rises far above all other natural phenomena, far beyond the reach of the sciences dealing with them. This chasm was never bridged until the modern idea of transmutation compelled us to extend its deductions to man, to embrace in one and the same generalisation man 
and nature and to adopt the same methods in dealing with both.

Before this result could be attained, the partisans of transformation had to overcome a formidable opposition; if the controversy on the origin of species assumed such a bitter character it was because the close of the debate was expected to settle the questions relative to the origin of man.

That was the burning, the painful issue between the two camps and that is why the transformists had to pay so dearly for their victory. Their victory, however, was definitive; man was to be considered henceforth as the last link in the evolution of the animal world, produced by causes as natural as those which determined the appearance of other species.

The victorious party soon faced new problems arising from the very problems which had just been solved, for instance, the origin of our psychical life. The new theories endeavoured to relate psychical phenomena with those observable in the physiology of the nervous system and especially of the brain. Sincethe human brain to-day is the result of the gradual development of the same organ in the individual series, why should not the human mind be the result of the perfect development of animal psychology?

This method of approaching the subject conflicted with all accepted ideas, with all the beliefs which not only appeared undeniable, but were held to be 
necessary if man was to be man. If the new point of view were to prevail, what would become of free-will, the indispensable basis of every ethical system? Where could we find any guidance for human behaviour if we gave up the spiritualistic faith?

It was naturally more difficult for the exponents of the evolution theory to carry the day on this point than on any other point. Even in these days, whenever controversies arise as to man's life, his physical or mental needs, this theory has to break its path anew with much difficulty.

In psychology and in ethics, we are constantly confronted by some spiritualistic notions, by some biassed tendencies bequeathed to us by metaphysical philosophy.

The same applies to social science, to history, to political economy and to the practical questions related to them: here again we have to fight superannuated views derived from methods of reasoning which natural science discarded long ago.

In spite of all, the idea of evolution continues on its forward march and will win the battle in this field as it has won it in others. The odds are more tremendous here than anywhere else: we must overcome, not only a natural lack of intellectual courage, but also the conscious hostility of those who wilfully oppose mankind's progress.

Furthermore, the thorough and logical application 
of the theories of causality and evolution to our recently acquired knowledge, insufficiently elaborated as yet, presents many difficulties: our mind has not been in possession of these new ideas long enough to know how to handle them unerringly.

It is not our province to touch upon questions to which the evolutionist method may only be applied in a more or less remote future. We have only al luded to them in order to illustrate the far-reaching import of the evolutionist idea.

For this idea we are indebted to natural science; neither transcendental philosophy, nor the exact sciences would have fathered it or assured its triumph. It is within the domain of natural science, its special province, that we will study the idea of evolution in the course of the following chapters.

There it rules without a rival and the only points raised concern the very processus of the evolution of living things and the factors which have determined the successive transformations of the various species. 



\section{TABLE OF CONTENTS}

PAGE

\section{Introduction}

The idea of evolution.-Its application to inorganic things, to organisms, to the origin of man and to man's psychical life.-Its bearing upon ethics and social science.-Its special province: natural science.

\section{CHAPTER I}

The Idea of Evolution before Darwin . .

The dawn of the evolutionist idea.- The revival of natural sciences in the seventeenth and eighteenth centuries. - Linnæus, Cuvier.- The first transmutationists: Goethe, Erasmus Darwin, Lamarck, the originator of the transmutation theory.Ernest Geoffroi Saint-Hilaire versus Cuvier.- The nature-philosophers: Oken.-A period of stagnancy.- Modern transmutation theories. Lyell; geological and paleontological discoveries. Herbert Spencer. The publication of Darwin's book.

\section{CHAPTER II}

Darwin and "The Origin of Species" . . . 35

A double element in the Darwinian theories: Transmutation and natural selection.- How the idea of transmutation first entered Darwin's mind; the journey of the Beagle.-The Malthusian 
theory and selection._- "The Origin of Species." - Evidence from geology, geography, embryology, classification.- The origin of man.- The conflict between the new and the old theories.- The triumph of the transmutation theory and its bearing on various sciences.

\section{CHAPTER III}

Darwin and Natural Selection . . . . . 44

The idea of natural selection a vital factor in the triumph of the transmutation theory.- Natural and artificial selection.- The multiplication of living things and the struggle for life.-Divergence of character.-The direct influence of environment.- Objections answered.- Natural selection a decisive argument in favor of transmutation.

\section{CHAPTER IV}

\section{Natural Selection since Darwin}

Controversies over natural selection.-A. R. Wallace; exclusive selectionism. - The Neo-Darwinians; A. Weismann.- The theory of panmixia. - A discussion of selection.-- The struggle against nature and the struggle against individuals.-Is rigorous selection an element of progress? - The part played by favourable conditions.- Chance and the individual characters.- Isolated characters and groups of characters. 


\section{CHAPTER V}

Natural Selection since Darwin (continued) .

The appearance of variations: their numerical importance; Delboeuf's law.- Frequency of variation.- Nature of variations; usefulness and degree of development of certain characters.-The neck of the giraffe and the femur of the whale.Abnormal development of characters. Butterflies that mimic leaves.-Parallel adaptation.-- Overperfected organs.- Analogy between natural selection and artificial selection.- Secondary objections.- The true rôle of selection.

\section{CHAPTER VI}

\section{Sexual Selection}

The origin of secondary sexual characters.Darwin's hypothesis; objections formulated against it.- The numerical proportion of males and females.- The æsthetic sense of the female.-Ornamental characters of animals with external fertilisation.- New theories: means of identification, desire to frighten enemies, surplus energy in the male, internal secretions of genital organs.

\section{CHAPTER VII}

Theories of Heredity-Spencer's Physiological Units

Relations between the theories of evolution and the theories of heredity. - The various hypotheses as to the structure of the protoplasm.- Micromerists and organicists.- Uniform particles and representative particles. - Physiological units typical 
of the former.- Their properties; an explanation of biologieal phenomena.- The persistence of force and the instability of the homogeneous.-Other hypotheses.

\section{CHAPTER VIII}

Darwin, Naegeli, De Vries, and Their Theories of Heredity

Theories based upon representative particles. Darwin's pangenesis; gemmules representing the cells of the body; their migration through the organism.-Objections.- Particles representing properties of the organism.- Naegeli's theory; the micellæ and their groupings; the two types of protoplasm; elementary characters.- Discussion of this system.- De Vries' theory; the pangenes, their migration through the cells.

\section{CHAPTER IX}

\section{Weismann's Theory}

The two kinds of protoplasm; germ plasm.Constitution of the nucleus; ids, idants, determinants, biophors.- Ontogenetic differentiation.-Disintegration of determinants; migration of biophors.- The continuity of the germ plasm.Hereditary likeness.- Reserve determinants.

\section{CHAPTER $\mathrm{X}$}

Germinal Selection. A Discussion of Weismann's Theory . . . . . . . 150

'A theory created in support of natural selection. - Roux's struggle between the parts; the struggle 
between determinants. - Advantages of the new hypothesis. - The idea of selection applied universally.-A discussion of germinal selection.A discussion of Weismann's system; the theory of the germ plasm, the representation of characters, the migration of biophors.

\section{CHAPTER XI}

\section{William Roux's Theory}

The organicist view and its distinctive characters. - Importance of external factors. - Exponents of the theory: O. Hertwig, Herbst, J. Loeb, Driesch. - Tropisms and tactisms.- W. Roux and biomechanics. - The theory of "the mosaic"; the struggle between parts of the organism; functional stimulation.- Evidence: the formation of spongy tissue in bones, pseudarthrosis.- A discussion of Roux's theory; its merits.- Its relation to selectionism and Lamarckism.

\section{CHAPTER XII}

The Law of Galton and the Laws of Mendel . 176

Heredity considercd from a new point of vicw. - Galton's statistical researches: the law of ancestral heredity.- Mendel's experiments. - The study of hybrids; the law of dominance and the law of segregation of characters.- Instances of the application of these laws.- Theoretical consequences of the Mendelian discoveries. 


\section{CHAPTER XIII}

Transmission of Acquired Characters: Theoretical Controversies

Importance of the question.-Evidence from daily observation.- Darwin on the transmission of acquired characters.- Modern controversies.Definition of acquired characters by Montgomery, Le Dantec, Weismann.- What the Weismannians reject.-An arduous problem.-Spencer versus Weismann; the papillæ of the tongue; the sense of touch; the degeneration of the fifth toe; seasonal dimorphism of butterflies, neuter ants and bees.

\section{CHAPTER XIV}

Transmission of Acquired Characters. Observations and Experiments . . . . 210

Experiments instituted to ascertain the hereditary transmission of acquired characters.-Mutilations and disease.- Brown-Sequard's guinea pigs.- The adaptation of living beings to external conditions. - Variations produced in butterflies by temperature and food: experiments made by Kellogg and Bell, Pictet, Fisher.-Influences producing local modifcations: facts instanced by Cunningham, Hyatt, Cattaneo.- Transmission of psychical characters such as a talent for music. How acquired characters may possibly be transmitted.-A chemical theory; the theories of $\mathrm{A}$. Gautier, Le Dantec and Montgomery.-The proper method to follow. 


\section{CHAPTER XV}

PAGE

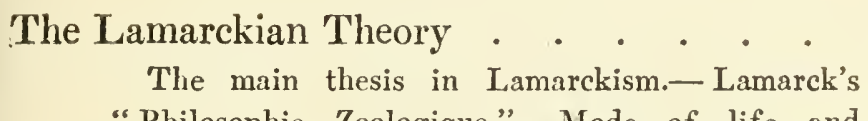
"Philosophie Zoologique."-Mode of life and habits of animals. - Lamarck's two great laws.Modern Lamarckism; its essential characteristics; the Lamarckian attitude to the main biological issues. - The growth of Lamarckism.

\section{CHAPTER XVI}

Representative Lamarckians of To-day . . . 247

Cope's theory.- Physiogenesis and kinetogenesis; the mechanical origin of certain structures:muscular tissue, the columella of gastropods, the astragalus, the vertebral column. Ontogenetic differentiation: bathmism. The energetic point of view.-Le Dantec's theories.-Functional assimilation; organic beings as units; hereditary transmission.- Lamarckians of the vitalist school.-A parallel between Darwinism and Lamarckism.

236 


\section{CHAPTER XVIII}

Isolation

Geographical isolation and physiological isolation.- Moritz IVagner's theory. - Wallace on the distribution of American butterflies and island fauna.- Gulick and Romanes.-Two modes of isolation.- D. S. Jordan.-- Physiological selection. - Vernon's theory of reproductive divergence.Discussion.

\section{CHAP'TER XIX}

\section{Orthogenesis}

Variations occurring in determined sequence.Exaggerated development of certain structures; giant reptiles; the tusks of the mammoth and of the Babirussa, the antlers of the Irish stag, the protective coloring of the Kallima.-Eimer's orthogenesis and his laws of organic growth.Cope's archæsthetism; the rôle of consciousness.Naegeli's views.

\section{CHAPTER XX}

\section{Mutation}

Continuous variation and discontinuous variation. Examples of discontinuous variation.-Theories based upon it.- Korshinsky's heterogenesis.- De Vries' experiments; the theory of mutation. Its theoretical importance according to De Vries.Formation of new varieties and species.-The mutations of Enothera.- The laws of mutation.- 
PAGE

Individual selection and interspecific selection.The origin of mutations. - Partisans and opponents of the mutation theory. - Its practical importance.

\section{CHAPTER XXI}

Résumé

The present status of the question.-Differentiation and adaptation.- Theories of differentiation: Mutation, orthogenesis, isolation.-Thcorics of adaptation: Darwinism and Lamarckism.- Natural selection, transmission of acquired characters.The limits of adaptation.- Structure and function.- Non-adaptive variations. - Increasing complexity of living things. - A possible solution of the question at issue.

Conclusion 



\section{THE THEORIES OF EVOLUTION}

\section{CHAPTER I}

\section{The Idea of Evolution before Darwin}

The dawn of the evolutionist idea.-The revival of natural sciences in the seventeenth and eighteenth centuries.-Linnæus, Cuvier.-The first transmutationists: Goethe, Erasmus Darwin, Lamarck, the originator of the transmutation theory.-Ernest Geoff roi Saint-Hilaire versus Cuvier.-The nature philosophers: Oken.-A period of stagnancy.-Modern transmutation theories.-Lyell; geological and paleontological discoveries.-Herbert Spencer.-The publication of Darwin's book.

THE idea of evolution did not dawn upon stu1 dents of natural science until the end of the eighteenth or the beginning of the nineteenth century. We could, it is true, by going back to the Greek philosophers, discover in some great intellects a glimpse of the transmutation idea; but the following centuries did not allow that seed to grow and between the mentality of the ancients and the mentality of those who took up again, centuries later, the study of the same problem, we fail to see any direct filiation. 
We can say that the revival of natural sciences dates from the seventeenth century, when the microscope was invented and the circulation of the blood was accepted as a fact. The eighteenth century witnessed a considerable advance in embryological research as well as in the study of other special subjects; records of observations on many special cases became more and more numerous. The time had come when that store of descriptive literature was to be put in order.

This was accomplished by Linnæus, who through his classification, systematic and practical though artificial, rendered science a service whose value has been to this day unanimously recognised by naturalists.

He delimited the boundaries of species, divided animals and plants into classes, classes into orders, orders into genera and genera into species. He gave every individual two names, the first one designating the genus, the other the species within the genus. Such is the origin of the binomial Latin nomenclature used at present in zoology and botany.

The idea of species assumed a considerable importance, and Linnæus, influenced by the current conceptions of the time, stated his thesis as follows: "There are as many different species as there were different forms created in the beginning by the Supreme Being." 
The act of creation itself marked off the limits of every species which was, therefore, doomed to remain constant and immutable. Linnæus' theory of the origin of living things was purely biblical and the only way in which he contributed, quite indirectly, to the introduction of the transmutation doctrine, was by assigning to man, in his classification, a place, not merely among the other animals, but in a genus including the anthropoid apes, man being merely a species of that genus.

The theory of the immutability of species increased in popularity in Cuvier's time; Cuvier considered it a necessary postulate and it became the basis of all the scientific knowledge of that period.

Cuvier's services to science are well-known. By grouping Linnæus' species in categories or types characterised by an organic unity of their own, he established the foundations of comparative anatomy; he originated the paleontology of the vertebrates and, after studying the fauna of the successive geological strata, he demonstrated that the lower the stratum lies to which a fauna belongs, the more widely that fauna differs from the fauna of the present day. 'That great discovery was, however, erroneously interpreted by Cuvier, who conducted his research work along the wrong lines.

He attributed to sudden cataclysms the complete disappearance of each successive fauna. From the 
dawn of ages, mankind, impressed undoubtedly by floods or earthquakes, has believed in world-wide cataclysms. Those "revolutions of the earth's crust" as Cuvier called them, geological upheavals of the most violent character extending orer considerable areas, were responsible for the annihilation of one fauna after another, each fauna being replaced by another fauna introduced by migration, he thought, or, as some of his disciples suggested, created especially in the same locality.

The great services rendered by Cuvier to science caused his views to prevail for many years, and the weight of his opinions delayed for many years the advent of the transmutation idea.

We find this idea expressed for the first time at the close of the eighteenth century. In his essay on the "Metamorphosis of Plants," published in 1790, Goethe advanced the contention that whenever we study organs, we must compare them with one another, determine the points they have in common, find out their original shape, and then consider the various forms observed as the result of modifications, of some "metamorphosis."

He held, for instance, that all the organs of a plant are produced by the metamorphosis of one single organ, the leaf. Applying this method to zoology, he originated simultaneously with Oken, though independently of him, the vertebral theory of the skull: 
he considered the skull as a continuation of the spinal column and as consisting of vertebræ peculiarly modified. This theory, according to which every organ developed from some other organ modified, was very similar to the theory according to which every species developed from some other species. Goethe added that this transformation must have been due to the influence of the environment:

"All members develop themselves according to eternal laws And the rarest form mysteriously presents the primitive type. Form, therefore, determines thc animal's way of life,

And in turn, the way of life powerfully reacts upon all form. Thus, the orderly growth of form is seen to hold, Whilst yielding to change from cxternally acting causes." 1

In 1794, a few years after the publication of the "Metamorphosis of Plants," Erasmus Darwin, Charles Darwin's grandfather, embodied similar" views in a book entitled "Zoonomia," in which he maintained, among other things, that the resemblance observable between the arm of a man and the wing of a bird betokened a positive relationship between the two species.

Lamarck was the first, however, to put the idea of transmutation into accurate wording. What in the mind of Goethe and of Lamarck's other predecessors had only been a rather vague and perhaps

1 From a poem, The Metamorphosis of Animals, quoted by HaEckeL in The Natural History of Creation, 1874, page 79. 
metaphysical idea (for it is not sure that, by the primordial type to which he traced back the modified forms, Goethe meant a tangible ancestral form and not an entity existing only in his imagination) became with Lamarck a generalisation based on concrete facts.

Born in 1744, Lamarck wrote at first several books on various questions of zoology and botany. He originated the division of animals into vertebrate and invertebrate; Cuvier's division into four fundamental types, vertebrate, molluscs, articulate and radiate is a more recent conception. He gave special attention to the lower animals in his course of lectures at the Paris Museum of Natural History and in his great work on "Animals without Vertebræ," but his capital work, which is also the first transmutationist manifesto, was his "Philosophie Zoologique" published in 1809.

In this book, Lamarck showed how relative and superficial the idea of an absolute species is, and how little it agrees with what we observe in nature. "If the various species appear invariable," he wrote, "it is because we observe them for a very short period of time, that is the span of our own life. In reality they are changing continuously under the influence of their environment and habits, of the climate, of the temperature and of the living environment constituted by other closely allied species." . . . "It is not the 
organs, in other words, it is not the nature and shape of the parts of the body of an animal, which determine its habits and its peculiar faculties; it is on the contrary its habits, its mode of life and the environment in which the individuals from which it is descended lived, which have gradually determined the shape of its body, the number and condition of its organs, and finally its various faculties." 2

Species are descended one from the other through the hereditary transmission of modifications due to natural causes, apparent to all. Man himself is the result of a transformation of the quadrumana and his mental faculties have no more than those of other animals a superior, supernatural origin. He is separated from them by quantitative, not qualitative, differences. Here we have the whole theory of erolution with its implied principle of causality applied to all the branches of human knowledge.

Lamarck's ideas on the mechanism of evolution, that is on the influence of the environment and the use of the organs, were considerably developed in later years, in the nineteenth century and in our days. They gave rise to a whole school of naturalists, the Neo-Lamarckians.

The idea of transmutation did not meet with any favour during Lamarck's life and did not find ac-

2 Researches on Living Bodies, p. 50, quoted in Philosophie Zoologique, pp. 237-238. 
ceptance until Darwin's time, half a century later, when Europe's scientific mentality was ripe for it.

Among his French contemporaries, Lamarck found one disciple in Etienne Geoffroi Saint-Hilaire. It was Geoffroi Saint-Hilaire who, in 1830, took his stand against Cuvier in the Academy of Sciences in a sensational debate which lasted almost six months, a duel, so to speak, between the theory of transmutation and the theory of the invariability of species. That controversy became famous in all the scientific world; Goethe, then 81 years of age, took a keen interest in it and devoted his last work, completed in 1832, to a review of the debate, pointing out its great scientific and philosophical import.

And yet the outcome of that far-famed contest was not favourable to the new ideas. In the opinion of the majority, the victory remained on the side of Cuvier, who crushed his opponent under an accumulation of facts to which his authoritative interpretation gave the weight of incontestable arguments.

In Germany the idea of evolution was advocated by the "nature philosophers." Some of them were famous naturalists, among others Oken who, like Goethe, formulated a vertebral theory of the skull and conceived, even before the discovery of the cell, the prophetic idea that all beings were descended from a sort of primordial mucilaginous matter (Urschleim), affecting originally a "vesicular" 
shape. The lowest animals are nothing else; all the others are mere aggregations of such vesicles.

Other philosophers had already pointed out the variable character of every living organism. In 1802, Treviranus had published a book on the subject. But those theories were shrouded in nebulous speculations and led to absurd conclusions; this was inevitable, considering the method adopted by that school of philosophers: instead of starting from facts observed and then working their way towards theoretical generalisations, they started from abstract conceptions and came to the conclusion that the physical world corresponded to their conceptions.

Such methods, contrary to the spirit of natural science, could not inspire any confidence; this is why the transmutation idea, misrepresented by those philosophers, was rejected by scientists. There was actually a reaction against all general ideas and the following period, from 1830, the date of the famous debate between Cuvier and Geoffroi Saint-Hilaire, until the publication of Darwin's book, was characterised by its materialistic spirit, and its indifference to philosophical research.

There were exceptions, however, notable exceptions. In 1830, Lyell published his "Principles of Geology," which paved the way for the application of evolutionary ideas to that science. The author rebelled against Cuvier's theory of catastrophes and 
contended that all the transformations our earth underwent in the past are easily explained by simple phenomena such as can be observed in our days.

Geologists following this path noticed traces of rain drops in carboniferous strata, observed the influence of streams on the configuration of their banks, the destruction wrought upon the shores by the action of the sea, the erosion of glaciers, etc. Everything confirmed the hypothesis that the earth's crust had been formed gradually by the action of natural factors and that no special creative intervention was required in order to bring about such changes.

At the same time, paleontological discoveries contradicted certain positive statements of Cuvier's relative to the origin of man. Never, he said, would we find the link between man and the other animals; never would we discover any fossil remains of prehistoric man or of anthropoid apes. And after his death, geologists unearthed fossil remains of the latter, then flint tools used by the prehistoric man and finally human skulls apparently inferior to that of the modern man. Vestiges of the prehistoric man appeared more and more frequently; more and more frequently objects were found, dating from the period when man's ancestors were being transformed gradually into men.

In another line of thought, in philosophy, Spencer 
had demonstrated in 1852, the necessity of adopting the transmutation theory. By degrees, advanced thinkers became convinced that a gradual transformation of all beings was really taking place; it only remained to ascertain by what process this transformation was being brought about.

And still, in spite of scientific discoveries, such as the discovery of the cell, in spite of the prodigious advance made in certain sciences, for instance in embryology, official teaching remained absolutely dominated by the old ideas or rather by a spirit of hostility to all general ideas.

Weismann, who could observe de visu that condition of affairs, describes it as follows in his "Theory of Evolution":

"It is impossible to estimate the effect of Darwin's book on 'The Origin of Species,' unless we fully realise how completely the biologists of that time had turned away from general problems. I can only say that we, who were then the younger men, studying in the fifties, had no idea that a theory of evolution had ever been put forward, for no one spoke of it to us, and it was never mentioned in a lecture. It seemed. as if all the teachers in our universities had drunk of the waters of Lethe, and had utterly forgotten that such a theory had ever been discussed, or as if they were ashamed of these philosophical flights on the 
part of natural science, and wished to guard their students from similar deviations." 3

We can understand what a sensation Darwin's "The Origin of Species," published in 1859, must have created in those circles.

3 The Evolution Theory, translated by J. A. and M. R. Thonson. Vol. I, p. 27-28. 


\section{CHAPTER II}

\section{Darwin and "The Origin of Species"}

A double element in the Darwinian theories: Transmutation and natural selection.- How the idea of transmutation first entered Darwin's mind; the journey of the Beagle.-The Malthusian theory and selection.- "The Origin of Species." -Evidence from geology, geography, embryology, classification.-The origin of man.- The conflict between the new and the old theories.-The triumph of the transmutation theory and its bearing on the various sciences.

\section{ARWIN'S theories are at present universally} known. So deep and far reaching has been their influence that the reading public is thoroughly familiar with them. It would be superfluous, therefore, to review them here in detail and to recite the evidence upon which they rest. Besides, there are many books in which the reader can find an excellent account of them. We will confine ourselves to pointing out those essential features which we must keep in mind in order not to be confused by later theories, and in order to draw a clear distinction between Darwin's direct legacy and the elements which, under the name of Darwinism, have been added to it.

What is generally. understood by Darwinism is a 
complex doctrine in which we must recognise two almost independent ideas: first, the fundamental theory, the general theory of transmutation as formulated by Lamarck; secondly, Darwin's original contribution, an explanation of the process through which the transformation of living beings is taking place. It must be said, that although the idea of descent had been formulated before Darwin, he conceived it independently of Lamarck or any other forerunner. We cannot help wondering why Darwin did not recognise in Lamarck's doctrine the transmutation idea which serves as a basis for his own theory.

Profound differences between his mentality and that of the French zoologist may account for this lack of perception on his part. No greater contrast-can be imagined than the contrast between these two great minds, Lamarck, who rushed to broad generalisations, Darwin, who, always afraid of drawing hasty conclusions, painstakingly gathered data whose number he never deemed large enough.

Thus Darwin arrived at his theory in an absolutely independent way, not by philosophical speculations, but by the observation of a great many facts which made his conclusions irresistibly convincing.

His first.observations were made in the course of a trip around the-world. In 1831, a youth of barely twenty-two, Darwin sailed on the Beagle, a ship sent 
by the English Government to survey, for scientific and practical purposes, the southernmost points of South America. The trip lasted five years, and when Darwin returned, the theory of descent was already ripe in his mind. He related this experience in a letter addressed to Haeckel many years later: "In South America three classes of facts were brought strongly before my mind. Firstly, the manner in which closely allied species replace species in going southward. Secondly, the close affinity of the species inhabiting the islands near South America to those proper to the continent. This struck me profoundly, especially the difference of the species in the adjoining islets of Galapagos Archipelago. Thirdly, the relation of the living Edentata and Rodentia to the extinct species. I shall never forget my astonishment when I dug out a gigantic piece of armour like that of the living armadillo." 1

Pondering over these facts and collecting analogous ones, Darwin reached the conclusion that species related to one another might very well be descended from one and the same ancestral form, modified through adaptation to different habitats and to changed conditions of life. The mutability of all living things appeared to him as a general rule; that mutability and the fact that acquired modifications

1 October 8, 1864. Quoted by HAECKEL in his Natural History of Creation, 1874, page 119. 
are transmitted through inheritance made him conceive the possibility of universal transmutation. The only questions in his mind were the origin of such modifications and the way in which they endow organisms with the means of adapting themselves to their environment.

Darwin devoted the years which elapsed between his return from his voyage, in 1835 , and the publication of his book, to meditating on those problems and collecting the greatest possible number of facts bearing upon their solution. As he did not wish to draw any far-reaching conclusions without basing them on irrefutable evidence, he did not publish a single line about his theories. He collaborated to the report on the Beagle's trip, published an essay on "Coral Reefs," and a "Monography on Cirrhipedia," but he reserved the main question at issue.

Slowly and patiently, Darwin observed domestic animals and cultivated plants, until then ignored by scientists, their varieties and the way in which they were produced. He realised then what power of selection man could wield.

Malthus' "Principles of Population," which came accidentally into his possession, suggested to him the possibility of a similar selection in the animal and vegetable kingdoms. Man tends to increase in geometrical ratio, Malthus said, while the increase of food supply is only in aritlmetical ratio. Hence a 
competition arises which must bring about the disappearance of certain individuals less gifted than certain others. The same must happen in nature, Darwin thought. Many more beings are born every minute than can ever survive, and those that survive are the best fitted for life's requirements.

This explained at last the mysterious adaptation of all living things to their environment. We will considerably enlarge elsewhere upon the mooted theory of natural selection; for the present, we only desire to show how anxious Darwin was to found his book on solid evidence and to answer all questions which might arise.

We find in his book all the objections which he could foresee at the time, presented with all their weight and refuted by the help of all the data which the various sciences could supply. Not only did he peruse all the works likely to throw light upon these questions, but he entered into personal relations with scientists, physicians, breeders and horticulturists, whose special observations could clear up some obscure point.

He was therefore able in his argumentation to review all the generalisations of the various branches of natural science and to remark that they all led to the same conclusion: that the various species are descended from one another through successive transmutations. His main arguments were suggested to 
him by paleontology and embryology. A capital datum furnished by paleontology, he said, was the close affinity existing between the fossil remains of two successive formations; nothing short of direct descent could explain it.

The same applies to the resemblance between representative specimens of the fauna of a given region, and to the important fact that the more highly organised a form is, the more recent its appearance must have been. This of course does not imply a continuous progress, for, otherwise, the lowest organisms would have all disappeared long ago. In reality, nothing prevents their survival for they can become adapted to their environment as perfectly as the most highly differentiated beings.

-It only goes to prove that higher forms of life have developed successively and gradually at the expense of parents having a very close resemblance to them. The geographical distribution of living things points in the same direction. The wide differences observed between the faunæ of regions whose geographical and climatic conditions do not differ to any great extent, for instance the fauna of the new and the fauna of the old world, can only be explained by the hypothesis of the local development of those faunæ.

On the other hand, the fact that the presence of certain animal forms presupposes the presence of 
other well-determined forms (which gives a fauna its characteristic appearance) cannot be explained either, except through actual blood relationship.

The various barriers or obstacles to migration are a very important factor. For instance, in islands located at a certain distance from a continent, certain genera of animals may be lacking entirely. No island located over 300 miles away from a continent counts in its indigenous fauna batrachians or land mammals. Generally speaking, the fauna of islands can give, in regard to descent, very valuable indications. Thus it is observable that the animal population of an island, while having its peculiar characteristics, resembles that of the nearest continent; also that the closer the islands are to one another the greater is the similarity between their faunæ.

The most conclusive evidence in favour of the theory of descent, however, is, in Darwin's estimation, that furnished by embryology. The most salient fact instanced is the resemblance between the embryos of-various animals, which is much closer than the resemblance between the adult animals themselves. The embryos of a mammal, of a bird and of a snake, for example, cannot be distinguished from one another at the primary stage of their development. Another important point is the similarity, in the various embryos, of homologous parts destined to become differentiated at a later stage. 
For all these facts there can be only one explanation: The embryo reproduces the appearance of an ancestor common to a whole group of animals; the variations which determined their differentiation only appeared at a relatively later stage of embryonic life and were, through inheritance, caused to appear at approximately the same age.

Neither can the survival of vestigial organs be explained by any theory except that of descent.

Classification itself, which was still based upon traditionalist and non-transmutationist ideas, furnishes further support to the transmutation theory. What elements do we consider when we draw the line between the various groups? Not adapted organs, nor similar organs, for we would then class the whale with the fishes, but homologous organs and vestigial organs. These are the elements which constitute the unity of type, the great principle recognised by morphologists. And unity of type merely symbolises actual relationship between the species observed.

Strengthened by all this evidence, Darwin finally published his great work. We know what discussions it brought forth, the enthusiasm of its partisans, the violent hostility of its detractors. All the young scientists athirst for progress sided with the new doctrine in its struggle against prejudice, religious traditions and the forces of reaction.

In this first book, Darwin reserved, intentionally, 
the question of the origin of man; but the conclusions he did not wish to draw were drawn by others, by Huxley in England and by Haeckel in Germany. It was only in his "Origin of Man and Sexual Selection," a book published much later, in 18\%1, that he finally decided to follow their example. But the import of his theory immediately became apparent to all without any intimation on his part, and charges of materialism, of atheism and of immorality were brought against him from the very first.

We can truthfully say that all his opponents were, in the last analysis, swayed consciously or unconsciously by one of two motires, their theological turn of mind or their hatred for all generat ideas in science.

Those years of storm and stress gave a marvellous impetus to all branches of knowledge, and will remain memorable in the annals of science. There was not one department of thought which did not then feel the influence of the new doctrine, henceforth firmly implanted. Not to mention biology, whose various branches were absolutely rerolutionised by the introduction of the comparative method, new sciences were born. Anthropology, the study of prim- itive man and of savage tribes, comparative psychol- 2 ogy, inaugurated by Herbert Spencer, a transformed philology, sociology led along a new path-such are the many conquests for which credit is due to the victorious transmutation idea. 


\section{CHAPTER III}

\section{Darwin and Natural Selection}

The idea of natural selection a vital factor in the triumph of the transmutation theory.-Natural and artificial selection.The multiplication of living things and the struggle for life. -Divergence of character.-The direct influence of environment.-Objections answered.-Natural selection a decisive argument in favor of transmutation.

THE clear and plausible explanation, based on 1 evident facts, which Darwin had given of the transformation of species, settled the dispute in his favour. The idea of evolution could no longer be considered as a mere hypothesis, but became a deduction drawn from observation. The whole Darwinian doctrine with its main tenet, evolution, and its secondary, subordinate tenet concerning the process of evolution, found acceptance among scientists. What made the fight so bitter was the fact that it was waged not about the latter idea, but about the great fundamental idea of evolution, fraught with innumerable theoretical and practical consequences.

Who cared about the processus by which species was descended from species so long as the descent was natural and did not presuppose any miraculous inter- 
vention? For the only point at issue was the principle of descent; the theory of natural selection was indeed invaluable, for it explained the very processus of descent. Whatever may befall this theory in the future, whether it is to be superseded by some other theory or not, Darwin's everlasting title to glory will be that he explained the seemingly marvellous adaptation of living things by the mere action of natural factors, without looking to a divine intervention, without resorting to any finalist or metaphysical hypothesis.

What is the real meaning of "natural selection," of the "struggle for life," two well-known terms which have been used too frequently, especially outside-of the limits of biology?

As more living things are born, according to Malthus, than the earth can support, there arises between them a competition for food and better conditions, a struggle whose outcome depends upon the superior advantages which certain individuals possess over certain others. This inequality is unavoidable, for even the young born from the same parents always present marked differences. That fact is even more frequently observed between individuals merely of the same species. Those distinctive characters are generally superficial and not very noticeable but they are, nevertheless, either useful or harmful to the individual. If useful, they impart to it a superiority over 
the others and enable it to survive when others perish.

This is what Spencer describes as "the survival of the-fittest." Darwin calls this phenomenon "natural selection." Nature selects among the various individuals, as breeders do among domestic animals or agriculturists among cultivated plants, certain specimens presenting in the highest degree the characters deemed worth preserving. Such individuals are mated and made to breed to the exclusion of others and the character desired becomes more and more accentuated and finally constant and hereditary. A new race or a new species has been created.

Darwin observed very carefully the transformations undergone by the various domestic races under the influence of artificial selection. His attention was drawn to a group of animals lending themselvespeculiarly well to that kind of observation-domestic pigeons.

Pigeon breeding is a very old science which was already practised in ancient Egypt; it was also very common in the Roman Empire and the pedigrees of certain breeds were accurately established. At the courts of some Asiatic rulers, pigeons were raised by the thousands. Thus, in the course of many centuries and through different processes, races and varieties were created which present a differentiation more deeply marked than that existing between cer- 
tain species. They differ in shape, color, size and instincts. For example, there are the carrier-pigeons, with their special topographical instinct; the tumblers, which are in the habit of flying at a great height in compact flock and then tumbling in the air head over heels; the fantails, whose tail, owing to the disposition of its feathers, resembles that of a peacock; others have tufts of feathers, peculiar creases of the skin, modified beaks or feet, etc., etc.

Darwin secured specimens of every available breed from all parts of the world. He became acquainted with the best known breeders and fanciers, joined pigeon clubs, and after years of observation, succeeded in proving that all the various breeds (which breeders believed to be derived from as many wild species) were all descended from one single species, the European rock pigeon (Columba livia).

What breeders do on purpose, Nature does unconsciously and her aim is attained through "the struggle for life," i. e., the struggle of animals or plants against certain conditions of the inorganic world (frost, heat, dearth, etc.), the struggle of the-individual against individuals of different species on which it preys or whose prey it may become, and the struggle against other individuals of the same species for a place at Nature's banquet table.

Darwin illustrates in his book the way in which certain species would surely overrun the earth if some 
factor did not destroy a large number of individuals.

When our domestic animals run wild and circumstances are favourable to them, as in the case of cattle and horses in South America and Australia, their increase is astonishingly rapid. So it is with plants. Cases could be cited of plants newly introduced which have become common throughout whole islands in a period of less than ten years.- Several of the plants which are now commonest over the wide plains of La Plata, clothing square leagues of surface, have been introduced from Europe. The elephant is reckoned the slowest breeder of all known animals. Yet if one elephant brings forth six young, then after a period of 750 years, there would be nearly nineteen million elephants alive, all descended from the first pair. If all species of animals increased at the same ratio, their numbers would become so inordinately great that no country could support them. ${ }^{1}$

The increase of living things, however, is not so easy by any means; their existence is dependent on a thousand conditions, on a thousand other living things. Every one of us could cite examples offhand. Here are two offered by Darwin: several hundred acres of a barren heath had been planted with Scotch fir. The change in the native vegetation of the planted part of the heath was most remarkable, 1 Origin of Species, passim. 
greater than that generally seen in passing from one soil to one quite different. Twelve species of plants flourished in the plantations which could not be found on the heath. The effect on the insects must have been still greater, for six insectivorous birds were very common in the plantation, which were not to be seen on the heath. . . . Certain plants require the visits of certain insects to fertilise them. Thus the visits of bees are necessary for the fertilisation of clover, and bumble bees alone visit clover. What would happen if bumble bees became extinct or very rare in England? Red clover, whose reproduction depends upon them, would also become very rare or wholly disappear. The number of humble bees depends in a great measure upon the number of fieldmice which destroy their nests, and the number of mice is dependent on the number of cats. Thus the number of cats in a district might determine the frequency of red clover in that district.

Everywhere we observe close interdependence and struggle; individuals struggle not only for life but for reproduction. The main factor in that struggle, a necessary condition of natural selection, is the competition between individuals of one given species which results in the survival of those best armed for $\angle$ the fray. This struggle is most stubborn, for all the individuals live under the same conditions, fight over the same food and invade the same grounds. And 
what determines the outcome of that competitive fight? Slight individual differences, insignificant characteristics which enable those possessing them to overcome their opponents.

"Let us take," Darwin writes, "the case of a wolf which preys on certain animals, securing some by craft, some by strength and some by fleetness; and let us suppose that one species of animals, deer for instance, had from any change in the country increased in number's, or that other prey had decreased in numbers, during that season of the year when the wolf was hardest pressed for food. The survival of the wolves would then depend upon their ability to catch deer, the fleetest of the animals on which they can prey. Under such circumstances the swiftest and slimmest wolves have the best chance of surviving and of leaving descendants which inherit their fleetness."

Another example is taken from the vegetable kingdom: Certain plants excrete sweet juice, greedily sought by insects; this is effected, for instance, by glands at the base of the stipules or at the back of the leaves. Now let us suppose that the juice or nectar were excreted from the inside of the flowers instead of from the back of the leaves: insects in seeking the nectar would get dusted with pollen and transport it from one flower to another. The flowers of two distinct individuals of the same species would 
thus get crossed, while those whose glands were not located as favourably might remain unfertilised. The advantageous location of the glands is transmitted to the next generation; from this generation of plants, those whose glands are the most developed and excrete the most nectar would likewise be favoured and the process would go on until, at a certain moment, a new species would spring into existence, characterised by nectar-excreting glands within the corolla.

This does not mean that the individuals not endowed with such farourable characteristics are necessarily doomed to disappear; for they may possess other advantages, other weapons which in life's struggle may compensate for the lack of the former.

"Take the case of a carnivorous quadruped of which the number that can be supported by any country has long ago arrived at its full arerage. If its natural power of increase be allowed to act, it can succeed in increasing (the country not undergoing any change in conditions) only by its varying descendants seizing on places at present occupied by other animals; some of them, for instance, being enabled to feed on new kinds of prey, either dead or alive; some inhabiting new stations, climbing trees, frequenting water, and some perhaps becoming less zarnivorous. The more diversified in habits and itructure the descendants of our carnivorous animals 
become, the more places they will be enabled to occupy." 2

'This is what is known as the "divergence of character" and the more marked that divergence is in a species, that is, the better adapted the individuals of which it consists have become to different conditions of life, the more chances that species has of being victorious in the life struggle.

Both divergence of character and the extinction of certain species (another very common and very J important factor in the history of the organic world) can be explained satisfactorily by natural selection and constitute, Darwin thinks, a very strong presumption in its favour, although no absolute evidence can be produced.

Natural selection was never considered by Darwin as it was by his disciples, the Neo-Darwinians, as the only and exclusive factor of evolution. He fully recognises the direct action of the environment and says expressly that we must not attribute everything to selection. He also realises the importance of characters acquired by inheritance under the influence of the environment or through use or disuse of certain organs. He believes, nerertheless, that the structure of an organism is more important than its environment and that the other factors only play an important part when natural selection can foster or 2 Origin of Species, Chapter IV. 
destroy structures produced by them, according to whether those structures are useful or harmful.

Darwin foresaw the objections which could be raised against his theory, some of which were formulated during his life. One of the cases which are most difficult to explain through natural selection is the appearance of organs of extreme perfection and complexity, consisting of numerous parts and unable to function propely unless all their parts are very accurately fitted to one another. Such is for instance the eye of the higher animals.

Without solving this difficult problem, Darwin makes the general statement that, as restigial organs of vision are found in certain animals (and numerous transitional forms can be shown to exist), it should not be hard to believe that a perfect and complex eye could be produced by a series of variations (in fact, variations of the eye have been observed), every one of which would prove useful to the species. It cannot be demonstrated that any complex organ exists which could not possibly have resulted from numerous, successive, slight modifications. The transitional grades may have become extinct but it would be erroneous to conclude that they never existed.

Another objection is that certain organs are too unimportant or too useless to have been preserved by natural selection. What purpose can the giraffe's 
tail serve with its special shape, except driving away flies, a rather insignificant use. We must realise, however, how little we know about the multiple factors which shape the life of individuals. It may be that the uselessness of tails is only apparent and that in warm countries, insects, especially mosquitoes, play in the life of the large mammals a part which we little suspect, although we know something about it as far as African cattle are concerned.

It may also be that the giraffe has inherited its tail from its aquatic ancestors which used it in swimming, and that this tail has been gradually modified and adapted to its new uses. Whatever the case may be, the principle of usefulness seems to be firmly established and there are not, nor could there be, any organs harmful to the species. We may also be mistaken when we attribute to natural selection the presence of an organ which may have been created by the action of the environment or by a tendency to revert to a long-extinct form, or by correlation, or by sexual selection, etc., etc.

Our lack of information is also responsible for one objection raised against the theory of natural selection. What of the organs which cannot render any service until they are fully developed? For instance, the giraffe can, owing to its long neck, browse on the foliage of trees. But if, at the time when the an- 
cestors of the modern giraffe had not yet acquired that character, one of them had happened to have a neck a few inches longer than that of its fellows, what advantages could it have derived therefrom?

It is possible, Darwin answers, that during dearths, the aptitude to browse on higher branches may have become a question of life or death. It is possible also that an elongated neck, enabling the animal to see at a great distance, may constitute a precious advantage, a protection against beasts of prey. A certain physical character may have many advantages which we do not suspect.

In his survey of possible objections to his theories, Darwin clearly shows his desire to prove, not that the various forms observable in the organic world are due to natural selection rather than to any other factor, but that they may be descended from one another. Darwin wishes above all to show that, however improbable certain details of his theory may appear, the theory of the independent origin of every species, due in every case to a special act of creation, is still more incredible. The objections raised against the theory of natural selection were to Darwin, and to almost everybody else at the time, the very same objections which the partisans of the immutability of species formulated against the theory of descent. The issue was between immutability of 
species on one side, and descent of species from other species through natural selection on the other side. Darwin did not foresee the possibility, of any other transmutation theory. 


\section{CHAPTER IV}

\section{Natural Selection since Darwin}

Controversies over natural selection.-A. R. Wallace; exclusive selectionism.-The Neo-Darwinians; A. Weismann.-The theory of panmixia.-A discussion of selection.-The struggle against nature and the struggle against individuals.-Is rigorous selection an element of progress?-The part played by favourable conditions. - Chance and the individual characters.-Isolated characters and groups of characters.

THE theory of natural selection could not have 1 been discussed intelligently or with good results until the transmutation idea had won a complete and decisive victory. But for the triumph of the central idea which dominated the Darwinian movement during its first years of struggle, it would have been impossible in the following years to approach the subsidiary questions raised by Darwin.

The ground had first to be cleared before the partisans of transmutation could, while ignoring the arguments pursued outside of the scientific field, discuss the various factors which bring about the descent of species. Foremost among those factors was natural selection, for Darwin's book had from the very first overshadowed the works of his fore- 
runners, the works of Lamarck among others, who attached much importance to other factors.

At that time, A. R. Wallace, who originated simultaneously with Darwin, though independently of him, the idea of natural selection, had already opposed this idea to Lamarck's conceptions.

In his essays ${ }^{1}$ (the first two written before he could become acquainted with Darwin's theories, the next under their direct influence), Wallace mentions the life struggle and the survival of the fittest as the only factors of evolution. Those essays are mostly devoted to showing how natural selection could produce certain characters such as the protective colouring and mimicry of animals. Never do we find any other factors mentioned, even as being of secondary importance.

Naturalists of the following generation exagger-

$\int$ ated (as scientists are apt to exaggerate every new theory), the rôle played by natural selection, a rôle very different from that attributed to it by the author of the "Origin of Species." The Lamarckian theories were discarded in their entirety; the direct action of the environment on the organism and the

1 A. R. Wallace. Contribution to the Theory of Natural Selection, 18\%0. In the second essay entitled: On the Tendency of Varieties to Depart indefinitely from the original Type, published in 1858, Wallace expresses his ideas concerning natural selection. One of the chapter heads in that essay reads: "Lamarck's hypothesis differs greatly from that now adranced." 
reaction of the organism through the use or disuse of organs seemed to lose their importance.

According to Darwin, natural selection preserves and fosters characters of direct adaptation and fortuitous individual characters. According to the Neo-Darwinians it acts only upon the latter characters. Neo-Darwinians were the more willing to leave the direct action of the environment in the background as they held that its effects were transitory and did not outlast the limits of one generation.

Weismann, the founder and main representative of that school, reached through his theory of ontogenesis and heredity ${ }^{2}$ the conclusion that characters acquired in the course of the individual's life are not transmissible, and he thereby divested those characters of all importance as far as the future of the species is concerned. Natural selection of fortuitous innate variations remained the only cause of all those transformations. The rery significant title of one of his books, "The All-sufficiency of Natural Selection" ${ }^{\prime \prime}$ reveals the exclusive point of view from which he considers all biological phenomena. 'To natural selection he attributes them all, with sometimes the help of a theoretical argumentation in which we de2 See Chapter IX and X.

3 Die Allmacht der Vaturzüchtung. Eine Erwiederung au Herbert Spencer, 1893. 
tect the author's prejudiced and consciously narrow. ideas.

In his later works, Weismann, influenced by frequent and searching discussions, which cast doubt upon many of the statements of the Neo-Darwinian school, made a number of important concessions; he added to his system some ideas which allowed the much-despised Lamarckian theory of environmental influence to penetrate it gradually. But all these new ideas, all these improvements of the original edifice, are in some way related to the theory of the life struggle and the theory of selection.

In the last published of Weismann's works ${ }^{4}$ which sums up all his scientific writings, we still find the $\checkmark$ one idea of natural selection applied to all biological phenomena, especially to those on which its action is considered as most doubtful: colouring of animals, mimicry, development of instincts, etc. The direct $>$ action of environment, the Lamarckian theory of use and disuse are still emphatically rejected. At the same time, Weismann upholds the principle of the usefulness of all existing characters, even when that usefulness is not apparent.

Natural selection appears to him not only the sole factor but an unfailing factor. At the same time the life-struggle and selection which in the "Origin of Species" are simply an explanation of well 4 The Evolution Theory. 
known, familiar and concrete facts, become in Weismann's works real abstractions, metaphysical entities. The various parts of Weismann's huge system, which covers all the problems relative to the development of the individual and of the species, are connected with one another by the idea of selection and life-struggle. This idea, however, is made to fit so many cases and is interpreted in so many different ways that it gives the impression of the same label affixed to the most dissimilar objects.

The only thing which Darwin's natural selection, Roux's histonal selection (the struggle between parts of the organism) and Weismann's germinal selection have in common is the word selection which reveals similar tendencies in three different theories. - We treat elsewhere in detail of Weismann's theory; at present, we only wish to mention that his works contain the most complete exposé of the Neo-Darwinian doctrine with its overemphasis of innate characters as against acquired characters, of predetermination as against environmental action $\sim$ and with its too precise explanation of the evolutionary process and of its only factor, the life-struggle.2

In order to explain through natural selection a fact which Darwin had not clearly elucidated, namely, the presence of vestigial organs, Weismann resorted to a special theory, the theory of panmixia.

Of vestigial organs there are many examples 
in the animal kingdom: atrophied eyes of animals living under ground, hindlegs of cetaceans, the vermiform appendix and caudal vertebrre of man, etc. Those organs are vestiges of more developed organs which were once useful to the ancestors of the animal and have now become useless or harmful. How did they become attenuated? Cases may differ. If a once useful organ, for instance, should become harmful, it could be attenuated through a reversion of the regular processes of natural selection: those individuals alone in which that organ would be least developed would survive and transmit that character to their offspring. When, on the other hand, the organ is merely useless and its disappearance does not present serious advantages, we must find some other explanation for its atrophy.

The explanation given by Weismann is a cessation of selection as far as the organ is concerned. Not only does selection develop an organ, but it maintains it at the height of its development. When its action ceases, the animals that possess the organ as well as those that do not possess it, have an equal chance to survive and to beget offspring. Hence the word panmixia. The average development of the organ is lower in every new generation until the organ becomes atrophied or disappears completely.

The theory of panmixia was the first subsidiary theory which Weismann formulated in order to ap- 
ply logically the principle of selection to all phenomena. It fails, however, to explain why an organ may fall below a certain level of development and it does not explain the physiological method causing this retrogression. A theory created later and of which we will speak elsewhere, the theory of germinal selection, filled this want.

Before we review the various criticisms passed upon the selection theories, we must first examine an important question: is the intraspecific competi- $\nu$ tion as general as Darwin thought it to be? Is that competition a harsh, merciless struggle, a life and death struggle? Many naturalists, Russian scientists especially, who have studied regions in which animals have to contend with unfavourable conditions, think that this struggle against the environment is much fiercer than any intraspecific struggle.

A writer, who for theoretical reasons to be mentioned later, has laid stress on this argument, Kropotkin, ${ }^{5}$ had opportunities to observe animal life in regions where the climate is very severe and the ground barren, namely, Northern Asia. There the life struggle is fierce, but it is directed against nature, which wreaks terrible destruction and constitutes a stronger obstacle to overpopulation than competition among individuals.

The Russian zoologists, Menzbir and Brandt, 5 P. Kвороткix. Mutual Aid a Factor in Evolution. 
reached the same conclusion from their own observations. As early as 1871, one of the first Darwinians, G. Seidlitz, ${ }^{6}$ pointed out the difference between the intraspecific struggle and the struggle against natural obstacles or common foes.

Certain naturalists go so far as to state that they

Dever knew of any competition between adult animals. V. L. Kellogg, who has given much attention to the life of insects and observed their variations, writes as follows:

"I find just as much variation represented in series of mature individuals collected miscellaneously after having lived for more or less time a free life exposed to all the dangers of this life, exposed, that is, to the rigour of the individual struggle for existence, as among series of similar extent of individuals of the same species collected just at the time of reaching maturity but before enjoying any opportunity to be weeded out by the rigour of the life-struggle." 7

From which he concludes that no rigorous natural selection, such as the selection theory presupposes, has exerted its influence in this case.

Another objection has been raised against the selection theory. Darwin says very justly that "the $\checkmark$ more diversified in structure animals become, the more places they will be enabled to occupy," but the

- Die Darwinische Theorie, 1871.

7 V. L. Kelloge, Darwinism To-day, p. 83. 
question is: do they become diversified through a bitter struggle between individuals, through a rigorous selection?

Are we not justified in thinking, on the contrary, that it is favourable conditions and a relatively easy life, which create and preserve new variations? This opinion is shared by several authors. Kropotkin, speaking of the bleak regions of Northern Asia, points out that there is little life there, and that after a protracted dearth, all animals, the half-wild horses and cattle of Transbaikalia, squirrels, etc., are so weakened by privation that competition between them could not result in any progressive evolution of the species.

The perusal of certain vital statistics tends to prove the same thing. Unfavourable conditions not only eliminate the weak but jeopardise the health of the survivors; they therefore serve no useful end. In an essay on the infantile death rate $^{8}$ Koeppe demonstrates that in years of rigorous selection, when on account of inclement weather or epidemics many children die, a weaker generation survives whose death rate is higher in the following years.

Among the naturalists who have adopted this point of view we must mention two who not only started from entirely different premises but who devoted themselves to the study of absolutely different sub-

8 Münchener Medizinische Wochenschrift. Vol. II, p. 1547. 
jects. One is the Russian botanist, Korshinsky, whose theory of heterogenesis preceded by several year's De Vries's ${ }^{9}$ theory; the other is not a theorist but a practical scientist, Luther Burbank, the wellknown California horticulturist. His work is of capital importance and his conclusions are the more interesting as he has had opportunity of experimenting on a larger scale than had ever been done in that department of research. ${ }^{10}$ Luther Burbank states that it is invariably a rich soil and favourable conditions which determine the appearance of new variations, whereas underfertilised or overfertilised ground induces reversion.

Burbank refuses to draw any definite conclusions, but we can easily draw our own: new variations \rfloor appear, not where the life struggle is the fiercest, that is, as Darwin believed, where conditions are most unfavourable, but where the struggle is mildest, and where all the wants of living things are filled.

Starting from rather theoretical considerations, Korshinsky arrives at the same conclusion as Burbank. No new forms appear, he writes, under dif-

P ficult conditions of life, or if they do appear, they very soon become extinct. Their appearance is due to certain organic disorders, especially to disorders of 9 See Chapter XX.

10 See V. L. Kellogg's article in Popular Science Monthly, 1906, Vol. LXIX, pp. 363-374. See also Kellogg's Darwinism To-day, p. 310 and following. 
the reproductive organs, and very rigorous conditions hamper the procreation of offspring.

The more favourable conditions are, the better protection a species receives and the more easily will it evolve. And it is precisely under unfavourable conditions that the life struggle and selection are most rigorous. Here are, therefore, two factors which, instead of fostering evolution, impede it, by preventing variation and eliminating new forms just ready to come into existence. ${ }^{11}$

Korshinsky's attitude to the rather negative and preventive rôle of natural selection and of the life struggle is justified to a great extent; unfortunately when Korshinsky attempts to give another definition of evolution (which he is careful to distinguish from adaptation, the latter being apt to assume a retrogressive appearance), he seeks to find it in a certain inborn tendency of all things towards progress and thus loses himself in a maze of metaphysical speculations.

Another argument frequently brought up against the theory of selection is the following: do some peculiar organic characters which give the individual $v$ a better chance in the general competition, cause certain individuals to survive to the exclusion of others?

11 Konshinskr. Hétérogénèse et Evolution. Contribution à la théorie des espèces. Mémoires de l'Académie de Saint-Petersbourg, Vol. IX, 1899. 
If innumerable individuals perish under the influence of an inclement nature, is it because they are ill-fitted for the struggle? We must note that nature does not destroy adult individuals able to struggle or to compete among themselves, but rather eggs or larvæ. And what determines their life or their death is not individual characters but conditions independent of these characters? It is by mere chance that they are not devoured by other animals, because they are more or less sheltered by certain objects, or are more or less noticeable, etc. Such conditions are by no means dependent upon the peculiarities of each and every egg.

In the survival of adults, chance also plays a very important part. As Kellogg writes:

"What shall decide when the big whale opens his mouth in the midst of a shoal of myriads of tiny Copepods floating in the pelagic waters of the $\triangle$ Aleutian seas, what Copepods shall disappear forever? Mainly, we say, the chance of position. A bit more or less of size, or strength, or redness, or yellowness, or irritability or what not of form and function is going to avail little when the water rushes into the yawning throat." 12

The same thing happens when the summer heat dries up certain streams or lakes; thousands of fishes or aquatic insects perish and the slight differ12 V. L. Kellog. Darwinism To-day, pp. 80-81. 
ences observable among them do not help them in any way. We could cite many more instances proving that it is not the fittest which survive but those which, by a fortunate coincidence happen at a critical time to find themselves far enough from whatever destructive factor brings death to the others.

Thus it appears that the action of natural selection is more limited than the orthodox Darwinians as- $r$ sumed and that, at any rate, natural selection is not the only positive factor/, it is even questioned whether within its own limits it has the influence attributed to it by selectionists. Opponents of the selection theory declare that the facts are presented in a too dogmatic way. To make things simpler, they say, it is supposed that one character varies in one individual and that natural selection bears exclusively upon that character while all the other characters remain unchanged. In fact, variations as considered by Darwin and especially by the Neo-Darwinians, are accidental and spontaneous and independent of any predetermined and exclusive cause/ One is not justified, therefore, in assuming that they could not appear in different forms and thereby compensate one another. Herbert Spencer cites the following case in support of this view: "Keenness of $\checkmark$ scent in a deer, by giving early notice of approaching enemies, subserves life so greatly that, other things being equal, an individual having it in an 
unusual degree is more likely than others to survive. Clearly this highly useful power may be developed by natural selection. So also, for like reasons, may quickness of vision and delicacy of hearing; though it may be remarked in passing that since this extra sense-endowment, serving to give early alarm, profits the herd as a whole, which takes the alarm from one individual, selection of it is not so easy, unless it occurs in a conquering stag. . . . The advantages which other members of the herd gain from other slight variations may be equivalent. This one has unusual agility and leaps a chasm which others balk at. That one develops longer hair in winter, and resists the cold better. Another has a skin less irritated by flies, and can graze without so much interruption. Here is one which has an unusual power of detecting food under the snow; and there is one which shows extra sagacity in the choice of a shelter from wind and rain. . . . If these other individuals severally profit by their small superiorities, and transmit them to equally large numbers of offspring, no increase of the variation in question can take place; it must soon be cancelled." 13

In other words, no individual possesses on account of certain advantages due to one character any actual and complete superiority insuring its success at every 13 The Inadequacy of Natural Selection, Contemporary Reriew: Feb. and Mich., 1893. 
stage of the life struggle; advantages are not grouped together and they may be compensated by certain drawbacks. This argument carries weight and shows that in the discussion of this question the issue must not be too simplified and that we must beware of reasoning mathematically, assuming all other things to be equal. This method of reasoning can be applied in experiments well prepared and conducted with the utmost care, but it cannot be applied to phenomena such as we observe in living nature. 


\section{CHAPTER V}

\section{Natural Selection since Darwin (continued)}

The appearance of variations: their numerical importance; Delboeuf's law.-Frequency of variation.-Nature of variations; usefulness and degree of development of certain characters. - The neck of the giraffe and the femur of the whale.Abnormal development of characters.-Butterflies that mimic leaves.-Parallel adaptation.-Overperfected organs. -Analogy between natural selection and artificial selection. - Secondary objections.-The true rôle of selection.

A F'TER reviewing the objections relative to the A. modus operandi of natural selection, we come now to two very important objections that bear upon the very basis of operation of natural selection: the appearance of variations and their hereditary transmission. The first is worded as follows: Causes of variation being weaker than causes of immutability the latter must necessarily prevail.

According to Delboeuf's law, however small the number of varying individuals compared with the number of constant individuals may be, the varying will increase steadily until they outnumber the constant. This statement is based upon the following calculations: Let us designate by $\boldsymbol{A}$ the initial type 
of a species and by $A \pm 1, A \pm 2$, etc., the variations differing in degree from the point of view of a certain character which they all possess. Let us suppose that in the course of every generation each individual gives birth to $n$ similar individuals and to 2 individuals differing slightly, one in a negative and one in a positive direction. After the second generation we shall find:

$$
n \mathrm{~A}+1(\mathrm{~A}+1)+1(\mathrm{~A}-1)
$$

Now if we figure out the descendants of $A+1$, we will find in the third generation:

$$
n(\mathrm{~A}+1)+1(\mathrm{~A}+2)+1 \mathrm{~A}
$$

Whatever the number of generations considered may be, variations will always outnumber constant individuals. The ratio of variations to constant types is at the beginning $2 / n$; if the two variations $(A \pm 1)$ and the $n$ constant types produced only individuals identical to them, the ratio would remain the same; but such is not the case.

Let us consider separately the descendants of the variations and of the constant types. If for a generation the number of constant types is $n$ and the number of variations 2 , the $n$ constant types will, according to Delboeuf, produce $n^{2}$ similar individuals and $2 \times n$ dissimilar individuals, which will then increase the number of variations. On the other hand, 
the 2 variations, after procreating $2 \times n$ similar individuals, which will remain in the varied class, will only produce $2 \times 2$ dissimilar individuals. From these 4 variations the majority will remain different from the initial type and will increase the previous number of variations; only a small minority will revert to the original type and increase the number of constant types. Even if they should all revert to the original type, the initial ratio of the variations to constant types, $2 / n$, would increase, for we would then have: $2 n \frac{2+2 \times n}{n+2 \times q}$. We know that when we add the same figure to the numerator and to the denominator of an irreducible fraction, the fraction increases; a fortiori it increases when we add a larger figure to the numerator than to the denominator, as is presently the case, since $n$ is greater than 2 .

This is an unavoidable corollary of the formula proposed by Delboeuf, but it is only a mathematical corollary.

The reality is quite different. It is not true that if, in the first generation, there are 2 variations and $n$ constant types every one of them must in the second generation, procreate $n$ similar types. Individual variations are not by any means transmitted so completely to such a large progeny. If they were, new forms would appear much more frequently than they really do and all the petty anomalies such as extra 
fingers or hare lips would have long ago become the specific characters of entire races.

Observation shows on the contrary that frequency of reversion to the normal type is in inverse ratio to the degree of variation. Breeders and agriculturists have noticed that, while it is relatively easy in the first generation to make certain characters constant through selection, the task becomes harder in the succeeding generations when the character seems to reach the limits which have been assigned to it by nature. Galton, a naturalist who gathered statistical data as to variations and their laws, and who originated the new branch of biology known as biometrics (application of statistical methods to biological studies), formulated a law according to which when parents diverge to a certain degree from the average (from the "mode," in biometrical parlance) the offspring diverge in the same direction but to a lesser degree; the result is that, after several generations, a species, instead of engendering an entirely new species reverts to the original average type.

We must also note that in amphimixia, the mode of reproduction which requires two parents for the procreation of offspring, the characters inherited by both sides become blended and the variation is generally attenuated in the first generation in which it appears. 
Delboeuf's law would only hold true if variations were due to a permanent factor of modification whose action would only bear upon certain individuals which would remain affected forever. In fact, instances of such a processus have hardly ever been observed.

The question at issue was then as to whether a species would in the course of time give rise to more and more variations or whether, on the contrary, conservative influences would predominate and preserve the purity of the original type. Still, when a variation appears, it must, as it is at first a slight and individual one, increase gradually in the course of several generations until it assumes the character of a new species. This is the way Darwin conceived that processus; slight accidental variations accumulating in the course of generations which transmit them to other generations. This processus of accumulation is one of the postulates of the selection theory and does not seem ever to have been questioned by any of its opponents. And yet, why should a character, whatever useful purpose it may serve, be more deeply marked in the offspring than in the parent? Unless we explain the fact by the inheritance of the effects of use or disuse and thus introduce a Lamarckian idea well beyond the limits of natural selection, we cannot understand why it should be so.

Let us suppose that among the short-necked an- 
cestors of the modern swan there could have been individuals whose neck, having one extra vertebra, was slightly longer, and that such a peculiarity had proved beneficial to the species, so that only the individuals thus favoured could have survived and transmitted this character to their offspring. Their offspring would then have had the same number of cervical vertebræ, a number greater than the original number. Why then should a following generation have two more and a third generation three more vertebræ? The fact is, on the contrary, that after countless generations, this character will remain constant and the neck will retain (leaving aside possible causes of reversion or the consequences of crossing with normal individuals) the original number of vertebræ.

This appears self-evident and it is hard to understand why, among so many objections to natural selection, this one should not have taken the first place. There is only one explanation for it. From the very beginning the theory of selection has dealt with abstractions rather than with facts. What was supposed to be transmitted was not a certain structural character but a tendency to vary in a certain direction. In the case of the swan, it was a tendency toward the elongation of the neck which caused the number of vertebræ to increase with each generation. A tendency, however, has no existence of its own; it is an abstraction which merely expresses the 
fact that one thing is developing in one direction or another.

No tendency can be inherited any more than any other abstraction can be inherited; what can be inherited is a certain chemical combination, a certain morphological structure, and such characters are acquirable as they are and not as they might be.

The workings of natural selection can therefore explain the persistency of a useful character through several generations but they fail to explain the gradual development of that character. For this purpose other factors must be called into play; heredity of the effects of use and disuse and the uninterrupted action of the environment working steadily in one and the same direction.

The preceding objections bear only upon details; there are a number of others of a more general character, formulated from different points of view and very different in their importance. We can divide them up into two classes: Those relative to the nature of variations upon which natural selection can exert its influence, and those relative to a comparison between natural and artificial selection and to the close bonds which unite natural selection and sexual selection.

If natural selection is to favour an animal or a plant, owing to its possessing certain characters, these characters must fulfil a certain condition; they, must 
be useful. Among the characters which differentiate one species from another, very few serve any useful purpose, most of them being absolutely neutral. Darwin admits this point and adds that, in certain cases, usefulness is not apparent and that, in certain others, those neutral characters are due to the influence of the environment or to certain correlations in accordance with what he calls the law of growth. This explanation, however, oversteps the limits of natural selection and rather exposes its shortcomings. Many examples of those neutral characters (which happen to be the most immutable ones in every species) have been cited: The opposite leaves of the Labiatæ, the vorticellate leaves of the Boraginacæ (Naegeli) ; the various markings on the wings of certain insects, so fine that they cannot be detected without a magnifying glass, although they serve to differentiate one species from another (Kellogg and Bell); callouses on the legs of all the equines, four on the horse's, two on the ass's legs (Conn) ; the spiral whorls of certain mollusc's shells rolled one way or another (also a specific character); the colouring of concealed parts of birds' bodies, etc. The last case was mentioned by Romanes, whose testimony is most valuable, as he was one of the most authoritative and one of the earliest Darwinians.

The extreme partisans of the selection theory (Wallace and the Neo-Darwinians) defend it from 
Darwin's own point of view, contending that all specific characters serve some useful purpose and that it is only our ignorance as to the life and habits of animals which prevents us from discovering that purpose. It must be said that researches in this direction have revealed many uses which were not apparent at first glance. Still we must beware of the influence that preconceived ideas may have upon such observations and avoid the anthropomorphic construction which we might be tempted to place upon all natural phenomena.

Weismann endearours, for instance, to demonstrate that not only a colouring similar to that of the environment (white fauna of polar regions, transparent aquatic specimens, green-coloured animals living in the grass or on the leaves, etc.), but also the varied markings on the wings of butterflies, have their usefulness, as they tend to protect the animal by mak-

$\checkmark$ ing it unnoticeable or by causing a species to look like another better-protected species (mimicry). or to frighten away its foes.

"Among Lepidoptera, too, eye-spots often occur on the wings, and to some extent, at least, they have in this case also the significance of warning marks. Take, for instance, the large blue and black eye-spots on the posterior wings of the eyed hawk-moth (Smerinthus ocellatus). When the insect is sitting quietly the two spots are not visible, as they are covered by 
the anterior wings, but as soon as the creature is alarmed, it spreads all four wings, and now both eyes stand boldly out on the red posterior wings and alarm the assailant, as they give the impression of the head of a much larger animal." 1

And this is not an isolated case; there is no structure, no function, which Weismann can not account for by attributing to it some plausible purpose. Such hypotheses necessarily presuppose an anthropomorphic view of the world; a man might be frightened when suddenly confronted by the head of a large unfamiliar animal; but would the butterfly's foe, with its life habits and its mentality, have the same feeling? Fear in man and in animals is due to widely different causes. Why should a bird, for example, be afraid $\checkmark$ of a horned devil?

The defects of this conception are glaring. Once more we see finalist explanations smuggled into a domain in which Darwin had had the merit of replacing them by purely causal explanations. Another ever present danger is that our mind, too easily satisfied with fictitious explanations, may be induced to discontinue its investigations.

Let us now consider characters whose usefulness is apparent and incontestable. Would usefulness in any degree suffice to make the presence or the absence $\checkmark$ of one certain structural character a question of life or

${ }_{1}$ The Evolution Theory, Vol. I, p. 69. 
death? This question is closely related to another objection to the selection theory. As the variations we mentioned are not very important, the cases in which they can play such a part must be very few. The famous example of the giraffe's neck has been cited frequently. It was discussed by Darwin himself and we know his hypothesis according to which a few extra inches in length, enabling an animal to browse on the foliage of higher branches, may become in time of dearth a question of life or death, and moreover a more elongated neck may present other notable advantages even when that extra elongation is almost insignificant. To this Naegeli answers that the elongation which takes place in the course of one generation is not important enough to constitute a decided advantage and that even if this advantage were real, one could not be assured that all the individuals deprived of it would die in time of dearth; it is more probable that they would simply become weakened.

This applies to parts of the body showing an increase in size. It should apply also to organs which have disappeared. If we attribute their disappearance to natural selection alone and not to the inherited effects of disuse, we must demonstrate that their progressive disappearance was useful in every one of its phases.

The atrophy of the whale's femoral bone is another 
case very frequently cited. Herbert Spencer mentions it in his controversy with Weismann over the comparative importance of natural selection and inheritance of acquired characters as factors in evolution. In the various species of whales in existence at present the hind legs are missing; vestiges of them can, however, be found in the shape of certain bones, (the pelvic bone in some varieties, the femoral in others), hidden under the skin. Their weight is not over $1 / 900000$ of the total weight of the animal. As whales are descended from terrestrial mammals, their limbs must have become progressively atrophied. Was their atrophy due to natural selection? Or is it to the advantage of the animal that the useless bones should decrease in size? Possibly, if we consider that a saving in nutrition would thus be effected.

When the terrestrial ancestor of the whale was slowly evolving toward its present state, there must have been, Spencer thinks, an enormous increase in the size of the body, caused by habitual overfeeding. In the embryo, as in the growing animal, there must have been chronic plethora. Why, then, should not the disused parts have profited by this oversupply of nutritive materials? Even if we admit that a saving in food became imperative at a certain time, this advantage could not have been noticeable except in the primary stages of this gradual decrease. In the present age a whale's femoral bone weighs one ounce; 
( what advantage could the individuals in which it has been reduced to this weight possess over those in which the same bone would weigh a little more, say, two ounces? When we remember how insignificant the saving in food thus effected is, relatively to the total bulk of the body, we realise that mere natural selection could not have accomplished such results. It would be even more absurd to imagine that such a slight advantage could ever become a question of life or death to the animal. Herbert Spencer concludes from this that disuse of organs and hereditary transmission of gradual retrogression alone can give a reasonable interpretation of such phenomena. ${ }^{2}$

Another objection closely related to the preceding one had already been formulated in Darwin's days. Certain characters cannot be useful to the animal nor be subject to selection until they are completely developed or have at least reached a certain degree of development. 'For instance, it would little avail an animal living in the Polar regions to present a little white spot or a hide a trifle lighter in shade; in order to escape detection easily, the animal should be completely white. This holds true in all cases of protective colouring and mimicry; in their incipient stages, when no deceptive resemblance is noticeable as yet, such modifications render no service to the ani-

- A Rejoinder to Professor Weismann. Contemporary Review, Dec., 1893. 
mal. Kellogg draws the same conclusion from his observations on insects:

"In my own eyes has for long stood the familiar case of the mimicry of our common American monarch butterfly (Anosia plexippus), by the vice- $L$ roy butterfly (Basilarchia archippus). . . . Anosia is distasteful to birds; after a few experiments with Anosia a bird recognising this ill-tasting morsel - - leaves the monarchs alone. Not only monarchs, however, but also viceroys which are to all external seeming only slightly smaller monarchs." s

Both butterflies belong to groups whose typical representatives have nothing in common as far as marking and colouring are concerned; of all Basilarchia, the viceroy alone resembles Anosia, and one may suppose that this resemblance is constantly fostered by selection.

"But of what avail for this purpose of deceit was the first tiny tinge or fleck of red-brown on the staring black and white wings of the ancestral viceroy?" Kellogg asks.

Many similar examples could be brought forward; natural selection seems to regulate in a vague way existing variations rather than to create or develop any new ones.

The usefulness of a character seems, after all, to be limited to a certain degree of its development. Be3 V. L. Kellogg. Darwinism To-day, pp. 49-50. 
low a certain level, it is not evident; above that level, the development may be exaggerated and even defeat its own purpose. We have cited examples in which an inadequate resemblance could render no service; in other cases it is too perfect and involves a wealth of superfluous details. A large number of South American and Indian butterflies, living in the

$\checkmark$ forests, mimic very closely the leaves of the various trees. Their mimicry of colouring is remarkable; more remarkable, however, is their mimicry of the general shape and venation of leaves. The wings are relatively more developed than the body which, at rest, is hardly visible. The tips of the wings taper down to a petiole, the venation is very delicate and concealed by a sort of artificial venation much coarser in appearance and streaked to imitate the ribs of a leaf. The resemblance is only noticeable when the insect is at rest; for the markings do not extend to the part of the wing which is hidden in this position. They look as though they had been painted over the folded wing with one stroke of a brush. From the many cases of mimicry observable we will select two very striking ones.

In the Coenophlebia Archidona, a Bolivian butterfly, the petiole is formed by the tips of the anterior wings; a long middle rib and two lateral ones divide the surface of the wings. In the Kallima parallecta, a butterfly of the Malayan Archipelago, frequently 
mentioned as illustrating perfect mimicry, the resemblance to a leaf is even more extraordinary. At rest and with folded wings, this butterfly reproduces in every detail the dry leaves among which it lives. The real ribs of its wings, its head, and its body are almost invisible; the ribs of the leaf it imitates are, on the contrary, very clearly drawn. The resemblance does not end there; it goes so far as to show almost affectation. The wings frequently bear reddish or yellowish flecks imitating fungous spots, and are in places transparent and scaleless, thus reproducing exactly the perforations of a leaf by worms or insects. These precautions appear almost exaggerated and it is very probable that in our description we substitute our own visual impressions for those which this butterfly produces on its enemies. A rough general likeness as to colouring or shape would undoubtedly suffice to enable the butterfly to remain unnoticed among the leaves.

We could make the same remark about other cases of exaggerated development such as the tusks of the Babirussa (a boar of the Malay Islands), which, being rolled spirally can no longer be used for fighting. $L$ For these facts, some explanation must be found other than natural selection.

In the arguments which we have presented, the different variations were considered as isolated, as independent, so to speak, from the rest of the organ- 
ism. The truth is, however, that such is rarely the case, and that every modification of an organ corresponds closely to other modifications bearing upon all the parts which co-operate with it in its physiological functions. Hence, another objection against the allsufficiency of natural selection, and which Spencer has formulated as follows:

"If there occurs some change in an organ, say, by increase of its size, which adapts it better to the creature's needs, it is admitted that when, as commonly happens, the use of the organ demands the co-operation of other organs, the change in it will generally be of no service unless the co-operative organs are changed. If, for instance, there takes place such a modification of a rodent's tail as that which, by successive increases, produces the trowel-shaped tail of the beaver, no advantage will be derived unless there also take place certain modifications in the bulks and shapes of the adjacent vertebræ and their attached muscles, as well, probably, as in the hind limbs, enabling them to withstand the reactions of the blows given by the tail." 4

Likewise a certain mode of locomotion supposes co-operation and co-adaptation of the forelimbs and hindlimbs. How could this co-adaptation have been brought about by natural selection? There is no rea-

4 The Inadequacy of Natural Selection. Contemporary Review, March, 1893. 
son for supposing that an accidental asd insignificant variation is always accompanied by other variations which lend it usefulness; and therefore an isolated variation could become not only useless but even harmful.

If to the mighty antlers of a stag there did not correspond a special development of the skull and of the muscles of the head and neck, those antlers would only prove an impediment to the animal. Spencer dwells upon the question at length, giving many illustrations, and concludes that whatever the hypothetical processus of parallel modifications may be (simultaneous increase or decrease preserving the original proportions between parts; independent increase or decrease modifying those proportions; variations of such nature that in the end the various structures are adapted to a new purpose) mere natural selection cannot be considered as a satisfactory < solution of the problem.

Unless we believe in a pre-established order of things, we are compelled, Spencer believes, to adopt the one plausible explanation: structural modifications caused by functional modifications in each individual and transmitted to a certain extent to its descendants. Then all co-adaptations, from the simplest to the most complex, become intelligible. In certain cases, inheritance of acquired characters suffices to explain all facts; in other cases it explains them only 
with the help of selection fostering favourable variations.

Certain cases of parallel adaptation are even more difficrit to explain; cases in which variations must affect two different individuals, when for instance the reproductive organs of the male must fit very exactly those of the female to make fertilisation possible; Scases in which the organs and instincts of an insect insuring the fertilisation of a plant must correspond closely to the plant's mode of reproduction, and other cases of mutual adaptation.

Upon the publication of the "Origin of Species" many naturalists formulated similar criticisms, mentioning extremely complex organs, like the eye of the vertebrates which presupposes many co-ordinated variations. We remember what a general answer Darwin gave to them, an answer addressed only to the partisans of the invariability of species. Wallace reasons differently and contends that those parallel f changes can very well be due to natural selection, since we see them produced by artificial selection. And thus we are led to discuss the analogy between these two factors of evolution.

This analogy, a fundamental idea of Darwin's doctrine which he admitted without discussion, did not meet with any opposition during the first years which followed the publication of his book. It was not until many years later, in 1893, that Spencer attacked 
it in the Contem porary Review. According to Spencer, there is no such analogy except within very narrow limits, and natural selection is, in the majority of cases, unable to do what artificial selection does. For instance, a breeder can select one character to the exclusion of all the others and thus modify the species as far as this character alone is concerned. Nature can not exert such a choice. If an individual possesses a character useful from a certain point of view, another individual may possess a character useful from another point of view. Only a dominant character can attain a high development in the natural state; and this is not what we mean when we speak of slight individual variations. 'The only thing natural selection can do is to maintain all faculties at a certain level of development, destroying all the individuals which fail to reach that level.

In later years other naturalists, Morgan, Plate, and De Vries, carefully studied the analogies and the differences between these two modes of selection and came to the conclusion that they had fewer features in common than Darwin had-originally supposed. 'To them the main difference lies in the fact that races and varieties created by artificial selection are unstable and revert to the original type as soon as they are left to their own devices, while the new forms produced by natural selection remain constant as long as the conditions of their existence are unchanged. 
De Vries goes a step farther and thinks that whatever of slight individual variations is created by selection, whether the selection is natural or artificial, is doomed to immutability; consequently, constant natural varieties cannot be produced by the same factors as cultivated varieties, which are due to selection directed by man. De Vries based upon this difference a new theory of species which will form the subject matter of Chapter XX.

What general conclusion can we draw from this lengthy exposé of the objections raised against the Darwinian or rather the Neo-Darwinian theory? We have not mentioned all of them, we have merely selected the ones which seemed to carry most weight and which have not yet been answered. For instance, a criticism frequently made against the theory of natural selection is that it does not reveal the origin of the different variations but takes them for granted, while their origin is precisely the most puzzling problem. To this we can answer that no theory is expected to solve any problems but those which it raises, and that it has a right to select its own problems. Darwin considers the variations after their appearance and believes them to be accidental. It is only there that his explanations begin and it is only within the limits he assigned himself that we may criticise him.

Other objections are based upon the period of time 
(too long for some critics, too short for some others) which the development of the organic world would require, if it were due to the selection of slight individual differences. It has taken many million years for the organic world to develop itself, while the earth, according to physicists, has only existed a few million years. In 1862, William Thompson (the late Lord Kelvin), estimated the earth's age (basing his calculations on the cooling of the terrestrial crust and the high temperature in the depths), as not exceeding forty million years. According to Geike the solid crust of the earth is almost a hundred million years old; other calculations made by other physicists have given about the same figures. We cannot help noticing the arbitrariness of these calculations; physicists may make them, for they have in their possession exact data as to the cooling off of the earth within a given time, but what basis of calculation has the biologist who has never seen any new species spring up and cannot guess even approximately how long the processus would require?

The conclusion to be drawn from this controversy is, that the meaning of the word "life struggle" has been wrongfully narrowed down and limited to competition between individuals. The life struggle assumes much greater proportions between species and also between the living things and their organic environment. Purely individual peculiarities are insuf- 
ficient in the majority of cases to assure decisive advantages in the struggle. This can only be done by more general variations observable in a large number of individuals and responsible for new adaptations. Natural selection exists beyond doubt; only, when it takes place within one given species, it rather tends to eliminate whatever is below the average level than to foster the upward evolution of whatever is above it. Its rôle appears to be regulative rather than creative.

Darwin's theory of selection was, so to speak, an attitude of mind made necessary by the state of scientific knowledge at his time. Later research work has reduced to more reasonable proportions his original hypothesis which was too absolute. The services, however, which this hypothesis has rendered to science are of inestimable value. 


\section{CHAPTER VI}

\section{Sexual Selection}

The origin of secondary sexual characters.-Darwin's hypothesis; objections formulated against it.-The numerical proportion of males and females.-The æsthetic sense of the female.-Ornamental characters of animals with external fertilisation.-New theories: mcans of identification, desire to frighten enemies, surplus energy in the male, internal secretions of genital organs.

CERTAIN animal characters proved quite a puzzle to Darwin; they could not be explained by natural selection as they are not apparently useful for the preservation of the species. Such are the many characters which constitute the outward differences between sexes and are not directly useful, either for the act of reproduction or for the bringing up of the young.

These characters depend sometimes upon the difference between the male's and the female's mode of life, the one leading a roving, the other a sedentary life (f. e. certain parasitic crustaceans) ; in such cases, sexual dimorphism can be explained by natural selection. On the other hand, the bright colouring of many birds (parrots, peacocks, humming-birds), but- 
terflies or fishes, the manes, tufts of hair of certain mammals, the song of birds, their dances and their strutting, the ornaments of all description observed in many animals serve no apparent purpose. The fact that they generally appear in one of the sexes alone, in the male, while the female is deprived of them, and that, in many cases, they do not appear except at breeding time, suggested to Darwin the idea that their usefulness is related to the sexual function and has been developed through selection of a special kind.

Selection based upon sexual characters was designated by Darwin as sexual selection. Its purpose is no longer to insure the survival of the fittest but to give certain individuals of one sex a definite advantage over other individuals of the same sex, enabling them to reproduce themselves to the exclusion of the others, or, for reasons to be explained later, to reproduce themselves under conditions favourable to the procreation of a more numerous and more vigorous progeny. As the males contend for the females, sexual selection exerts its action upon them and they are provided with fit weapons for this peaceful contest, bright colours and harmonious voices being likely to appeal to females.

Still these ornamental characters alone cannot determine which males shall gain possession of the females; the male also wields real weapons of warfare 
such as the spurs of the cock, the antlers of the stag, etc. Although these can be of use also in the life struggle, Darwin classifies them with ornamental characters and attributes to them an equal importance from the view point of sexual selection.

Here a slight difficulty is encountered: Whenever the males outnumber the females the process of sexual selection is easily imagined; none but the fittest or strongest individuals secure females and transmit their fitness to their offspring. Darwin remarks that this is the case with a few mammals, many birds, certain fishes and insects. Polygamy leads to the same results, for if one male takes sereral females, many males will be prevented from mating. In most species, however, the number of individuals of both sexes is about even. This is the way, therefore, in which, according to Darwin, sexual selection exerts its influence in order to attain the same results:

"Thus with migratory birds, the males generally arrive before the females at their breeding place, so that many males are ready to contend for each female. . . Throughout the great class of insects, the males almost always emerge from the pupal state before the other sex." On the other hand, the strongest and most vigorous females are the first to breed, and as the males fight for them, the strongest, and with some species, the best armed, drive aray the weaker males and mate with these most vigorous 
females. The weaker ones that follow would have to share the conquered and less powerful males; their offspring would thus be less numerous and less powerful than that of the first couples. "And this is all that is wanted," concludes Darwin, "to add in the course of successive generations, to the size, strength and courage of the males, or to improve their methods." 1

But in many cases the female seems to exercise a choice in favouring the most ornamental males, or those which are the best songsters, etc. Darwin cites a great many examples (of birds especially) where the male seeks really to seduce the female. Thus, nightingales do not seek the females, but sing together, many of them at the same time, and the females drawn towards them choose among them. Other birds execute dances and various love antics. "In North America," Darwin writes, "large numbers of grouse (Tetras phasianellus) meet every morning during the breeding season on a selected level spot and here they run round and round in a circle of about fifteen or twenty feet in diameter, so that the ground is worn quite bare. In these partridge dances, as they are called by the hunters, the birds assume the strangest attitudes, and run round, some to

1 Darwix. Descent of Man and Selection in Relation to Sex, Vol. II, pp. 280-283. 
the left and some to the right." 2 Here are some other examples where the males seek to charm the females by displaying their ornaments. "With birds of paradise, a dozen or more full-plumaged males congregate in a tree to hold a dancing party, as it is called by the natives; and here they fly about, raise their wings, elevate their exquisite plumes, and make them vibrate, and the whole tree seems, as Mr. Wallace remarks, to be filled with waving plumes. . . . When the peacock displays himself, he expands and erects his tail transversely to his body, for he stands in front of the female, and has to show off, at the same time, his rich blue throat and breast." Another bird whose ornamentation resembles that of the peacock, the Polyplectron, takes a slightly different attitude. "His breast is obscurely coloured, and the ocelli are not confined to the tail-feathers. Consequently the Polyplectron does not stand in front of the female; but he erects and expands his tail feathers a little obliquely, lowering the expanded wing on the same side, and raising that on the opposite side. In this attitude the ocelli over the whole body are exposed at the same time before the eyes of the admiring female in one grand bespangled expanse." 3 Many similar cases could be

${ }_{2}$ Darwin. Descent of Man and Selection in Relation to Sex, Vol. III, p. 492.

3 Ibid., Vol. III, pp. 511-513. 
instanced of male birds (bullfinches, goldfinches, finches, linnets) which try to attract the female by assuming attitudes in which their ornaments, whether scanty or plentiful, are seen to good advantage.

Such characters, either attractive or useful in fights between males, transmitted to the offspring and accumulated as other characters would be, under the influence of natural selection, constitute finally the marked differences which we observe between males and females.

Darwin's theory of sexual selection, formulated in order to supplement the theory of natural selection, found immediate acceptance with naturalists and for many years was admitted without discussion. It is still adhered to by many exclusive selectionists like Weismann. Weismann, however, has introduced into it several modifications and made a few reservations. For instance, he draws the line more strictly between what can and what cannot be explained by ordinary natural selection (for example, the weapons used in the fight between males) and thus restricts the sphere of influence of sexual selection. Furthermore, he does not always believe in an intelligent choice on the part of the female, nor in a choice based upon æsthetic considerations, but he thinks that certain symptoms of sexual excitation in the male may simply influence the female and produce in her a similar excitation. This is the way certain odours prob- 
ably act. At the same time Weismann points out that secondary sexual characters, which at first appear in one sex only, may be transmitted later on through inheritance to both sexes and thus become the essential characters of a new species. Sexual selection would then seem to be a more powerful factor than is commonly believed. ${ }^{4}$

At the present day, however, this Darwinian hypothesis is being submitted to harsh criticism and has even been abandoned by many naturalists. We will review briefly the principal objections raised against it by various scientists.

Some of them attack Darwin's statement as to the numerical predominance of the males, a necessary premise of the theory of sexual selection. As in most species, at least among the vertebrates, males and females exist in about equal numbers, the individuals endowed with attractive characters, the opponents of this theory say, do not reproduce themselves to the exclusion of the others; even if they should be favoured at first, the others would always manage to secure a female. Under such conditions it is difficult for a character to become developed and constant, as the number of individuals which possess it cannot be greater in the second than in the first generation.

We know that Darwin himself did not by any means take an original numerical inequality of the 4 A. Weismaxs. The Evolution Theory, Vol. I, Chapter XI. 
sexes as a basis for his deductions and that he merely took into account a numerical inequality due to temporary conditions. Whether the solution he offers is satisfactory or not, this criticism misses the mark.

It could be imagined, other critics say, that the males endowed with ornamental characters are also the strongest and beget a more numerous and more vigorous progeny. This is a gratuitous assumption, as no correlation of this kind has ever been observed. Even if we should suppose that, for some reason or other, the results of sexual selection are permanent and that all the males lacking in ornamental characters are actually eliminated by the females at the time of mating, the process would be, as some critics point out, not only useless but harmful to the species; it would therefore yield to the action of natural selection and cease altogether.

Selection by the females, some scientists say, has never been observed scientifically. Darwin grants this point in advance. He gives many examples of efforts made by the male to attract the female, but very few examples of females signifying their preferences. He admits this choice for various reasons of a general order: Animals can distinguish between colours, sounds and odours; we may well suppose that they have their preferences, and also a rudimentary æsthetic sense, which must have grown grad- 
ually in animals before it could attain its present stage of development in man.

This is certainly true, but we run the risk of erring greatly when we attribute to animals, especially to the lower animals, xsthetic feelings similar to ours. In some species (in spiders for example) the eye is too imperfect to perceive essential differences.

"In numerous cases the so-called attractive characters of the males," such as the dances of certain insects attributed to sexual selection, "have been found, in actual life, to be of such a character that they cannot be noted by the female. . . . The dancing swarms of many kinds of insects are found to be composed of males alone with no females near enough to see. . . Of many male katydids singing in the shrubbery, will not for any female that particular song be the loudest and the most convincing, that proceeds from the nearest male, not the most expert or the strongest stridulator?" 5

Ornamental character's are not always the exclusive privilege of one sex; they are so in the majority of cases, but not in every case, and the theory of sexual selection is at pains to explain the cases in which both sexes possess those characters to the same extent or the cases in which the female is more favoured than the male. The strongest argument against the theory of sexual selection based upon the ornamental 5 V. L. Kellogg. Danvinism To-day, p. 115. 
characters of the male is the vivid coloration of the nale during the breeding period in animal species with external fertilisation. The female fish, for instance, lays her eggs in the water and never even sees the male who is to fertilise them. Cases like this preclude the idea of selection; should they be explained satisfactorily in some other way, the explanation offered would cover the other cases and the theory of sexual selection would have to be abandoned.

Experiments performed on insects have also supplied interesting evidence against it. Mayer and Soule dyed the wings of a male butterfly (Porthetria dispar), and the change in colour did not modify the attitude of the females; on the other hand, the females were aware of the presence or absence of wings and resisted the approach of males whose wings had been cut off. ${ }^{6}$ Ornamental characters are therefore beyond the sphere of action of sexual selection which seems to be based upon one character, the wings, for which nobody has ever held it responsible. Mayer made another, even more conclusive test. He took another species of butterflies (Callosamia promethea), the male, dark coloured, the female, reddish-brown, cut off their wings and glued on a male the wings of a female and reciprocally. This did not affect in any G A. G. Mayer and C. G. Sovte: Some Reactions of Caterpillars and Moths. Journal of Experimental Zoology, Vol. III, 1903. 
way the attitude of the sexes to each other. ${ }^{\top}$ Even the complete absence of wings failed to produce any impression; at the same time it was shown by experiments made on those butterflies and on the Porthetria, that the males were attracted by a certain odour emanating from the females.

There have been other objections to the idea of sexual selection. T. H. Morgan ${ }^{s}$ lists as many as twenty, the most important of which we have already mentioned. The strength of those objections compels us to conclude that a different explanation must be found for the majority of cases in point. Darwin's theory rendered a signal service, as it offered a natural explanation and exchuded all finalist considerations. It retained its prestige long enough to accustom thinkers to accept only explanations of this nature. It may now make room for some other theory more in conformity with experimental data and taking into account the discoveries made since Darwin's time.

Many solutions have been offered for this problem. Certain naturalists have expressed the opinion that the colouring of males is a means of identification, but we fail to see why males alone should need it; it would seem, on the contrary, as though the females, being generally passive and sought by the

${ }^{7}$ Cited by KenLogg, Darwinism To-day, p. 122.

8 T. H. Morgan. Evolution and Adaptation, pp. 167-221. 
males, were more in need of distinctive characters which would enable the males to recognise them.

There is also a theory according to which certain useless characters like the huge antlers of old stags, result from a desire on the part of the males to appear more dangerous to their rivals than they are in reality, but this is an assumption at least as gratuitous as the theory of the selection by the females.

Another idea, more plausible, and suggested incidentally by Darwin, is that those males which bear ornamental characters possess a surplus of energy which reveals itself through certain structures such as a deeper pigmentation or an abundance of feathers. Their various special motions or dances would only be the consequence of a marked sexual excitation. This explanation is unconvincing for it does not explain how a surplus of energy could produce, for instance, a brighter colouring.

According to another theory which seems to point at last in the right direction and which has many points in common with the preceding one, secondary sexual characters can be traced directly to certain conditions of the sexual organs, being due to internal secretions which act upon the tissues of the organism. Emery was the first to offer this explanation. ${ }^{9} \quad \mathrm{Va}$ rious experiments have demonstrated the fact that the

9 Cedanken zur Descendenz-und Vererbungtheorie. (Biologisches Centralblatt, 1903, pp. 397-420.) 
excision of the sexual organs or of certain of their parts brings about the disappearance of those characters. We only need to recall the experiments of Bouin and Ancel on the interstitial gland of the testicles of mammals, which prove that the secretion of that gland is responsible for the secondary sexual characters and for the sexual instinct itself. It has also been demonstrated experimentally that chemical changes arise in the tissues of certain animals, fishes for example, at breeding time.

Although the theory of sexual selection is to be discarded in its entirety, we must not exaggerate the bearing its passing away will have upon the Darwinian theory in general. Certain naturalists see in it such an important corollary of the theory of natural selection, that if the theory of sexual selection was abandoned, they would consider the theory of natural selection as doomed. We refuse to share this extreme view.

There were facts which Darwin could not explain without calling into service a special theory. This special theory may be replaced by another special theory but the value of the theory of natural selection, as far as it supplies an explanation for a large number of facts, remains unimpaired. The inadequacy, now fully recognised, of the theory of sexual selection should not be used as a weapon against the theory of natural selection. 


\section{CHAP'TER VII}

\section{Theories of Heredity.-Spencer's Physiological Units}

Relations between theories of evolution and theories of heredity.-The various hypotheses as to the structure of the protoplasm.-Micromerists and organicists.-Uniform particles and representative particles.-Physiological units typical of the former.-Their properties; an explanation of biological phenomena.-The persistence of force and the instability of the homogeneous.-Other hypotheses.

HROM the foregoing we can see how closely the 1 question of the phylogenetic evolution of living things is related to the question of their individual development, of the transmission of their characters to their progeny and of the appearance in them of new characters. It is through inheritance that variations become constant and characteristic of a species instead of remaining individual and temporary. Certain theories of evolution are therefore indissolubly allied with certain conceptions of hereditary transmission.

A noteworthy feature of the various hypotheses advanced on the subject of heredity is that they solve at the same time two radically different problems, the 
solution of the one depending absolutely upon the solution of the other. On one hand there is the problem of heredity, that is, the problem of the resemblance between parents and offspring, and of the process by which the different characters are transmitted; on the other hand there is the problem of embryonic development.

How can all the parts of a complex organism have their origin in an apparently simple egg-cell? What are the factors of ontogenetic differentiation? As any theory offering a solution of the first problem also offers a solution of the second, we will examine both at the same time, laying special stress, however, on the former problem.

The various theories of generation and heredity need not be reviewed here. The controversy between spermatists and ovists, the theory once known as the "evolutionist theory," a misnomer at the present day, and according to which the whole individual was "preformed" in the ovum or in the spermatozoon, gradually shed its sheath and developed, the opposite theory of epigenesis, etc., etc.,--these can only interest us from an historical point of view. And yet there is no absolute divorce between those superannuated doctrines and modern ideas. Certain theories of heredity, acceptable to modern scientists, reveal a state of mind akin to that of the old evolutionists. Weismann himself says that his doctrines would have 
found many partisans among the representatives of the "evolutionist school."

The problem of heredity can only be solved through the study of the living matter, or protoplasm, constituting the cell. Its properties, whether hereditary or not, must necessarily depend upon its physicochemical composition.

The chemistry of albuminoids and the properties of colloids, the study of which is making great strides and bids fair to explain many phenomena observed in the living cell, are still very imperfectly known. Most theories formulated in order to explain vital phenomena, among them heredity, are based upon the assumption that between the chemical molecules and the organs of the cell, as revealed by the microscope, there is another category of units, initial protoplasmic particles, which, by their characters and their groupings, determine the various properties of living matter. This idea is not new, for we can trace it back to Buffon's theory of immortal particles which become dissociated at death and can again form new living combinations. It is now accepted by modern thinkers and is apparently confirmed by Mendel's experiments which were made some years ago, but have only of late attracted the attention of the scientific world.

This theory, while it counts among its partisans the great majority of scientists, has not yet been adopted 
unanimously. Certain naturalists refuse to believe that the shape of the body and the properties of its different parts depend merely upon the one particle of the cell in which they originate. In their opinion, they depend upon "the whole," they result from the co-operative and competitive workings of all the elements, cells, tissues, organs, all of which live their individual life and finally produce a complex which apparently reveals a pre-established harmony, but which is due in reality to independent phenomena. This conception first originated with Descartes, but it has been so deeply modified that hardly anything is left of the original hypothesis, and that, under its present name of "organicism," it can be considered as a truly modern theory.

According to the former theory known as the micromerist theory, the hypothetical particles of protoplasm are all identical in every organ and in every part of an organism; the differences between them result from the way in which they are grouped, from the forces of attraction which influence them and from their special motions. Spencer who was the first to formulate a theory based upon the existence of protoplasmic particles gives the following explanation of the process: The small particles of living matter, which he designates as physiological units, are intermediary between the chemical units, or molecules, and the morphological units, or cells; they are made 
up of molecules, and clusters of them make up the cells. The shape of the organism depends upon the shape of the cells; Spencer holds that there are as many categories of these elementary units as there are species of living things, as each category produces one certain organic form. In order to make the process more readily understood, Spencer compares the physiological units to the chemical molecules of a crystalloid body. Like chemical molecules, which always group themselves so as to produce one definite shape, cube, prisn, or rhombohedron, the physiological units group themselves so as to constitute an organism whose shape, however complicated it may appear, is invariably the same for all the individuals of one single species.

Under the influence of polarity, every individual has to assume the shape of the species to which it belongs. A bird must have feathers, a beak and certain internal organs, just as a certain substance when crystallised must present facets inclining to each other at definite angles and invariably reproducing one and the same form.

And yet there is, as Spencer points out, a certain difference: The aggregation of units constituting a living organism is more complex than any combination of chemical molecules; it is therefore less stable, and its equilibrium can be more easily disturbed by the pressure of various incidental forces. The shape pro- 
duced by the crystallisation of one given substance is invariably the same and nothing could cause a substance which crystallises in straight prisms to crystallise in oblique prisms. The polarity of physiological units is more delicate, more easily affected. It presupposes very definite conditions and can be influenced by many factors. Those factors may produce some slight modifications in the whole without destroying it, without even altering its general plan.

The result is that, while only one physiological unit corresponds to one species, differences may be observed between the individuals constituting that species. Organic plasticity explains individual variations and there is no need of supposing that to each and every individual there corresponds a physiological unit.

Apart from the differences observable between individuals, there are differences between histological characters. They arise from the fact that the units, all alike in polarity (specific characters) and in variability of polarity (individual characters), are affected differently while in the embryonic state by the action of incidental forces (from the fact of the location of each cell in space) and thus slightly modified in their nature. The units which constitute muscular tissue are not identical with those constituting osseous tissue. They present the same shape, but they are like the crystals of two different substances which al- 
ways assume the same crystalline type. Those differences in nature do not extend, however, to the anatomical characters of the organs; from one end of the body to the other, the physiological units of one given tissue are identical.

Thus heredity is easily explained: the reproductive element, ovum or spermatozoon, is merely a little cluster of physiological units endowed with the characteristic polarity of the species. When those units are found under conditions favourable to their development, they group themselves naturally as their parents did. This explains the transmission of specific characters; in cases of amphimixia, certain individual idiosyncrasies result from differences between the physiological units of the two parents; there arises between those units a sort of conflict which blends in the offspring the characters of the parents.

It is more difficult to explain the transmission of characters which are not innate but were acquired in the course of life under the influence of external conditions. How can such a modification of the adult so affect its physiological units as to influence the sexual product and thereby the offspring? Spencer explains that an organism is a combination of parts, which, taken collectively, are in a state of unstable equilibrium; when the equilibrium is disturbed at any one point, the disturbance spreads to the whole organism and the offspring of the organism thus modified 
is different from what it would have been before the modification ever occurred.

"On the one hand," says Spencer, "physiological units will, because of their special polarities, build themselves into an organism of a special structure; so, on the other hand, if the structure of this organism is modified by modified function, it will impress some corresponding modification on the structures and polarities of its units. - . . If the aggregate is made by incident actions to take a new form, its forces must tend to re-mould the units into harmony with this new form. And then, these units, when separated in the shape of reproductive centres, will tend to build themselves up into an aggregate modified in the same direction." 1

This explanation is purely theoretical. What Spencer tries to do is not so much to determine through what physiological process such a repercussion becomes possible, as to make this repercussion tally with certain fundamental principles like the principle of the persistence of force. He explains that in the course of one individual's life "any functional and structural divergence produced by a new incident action, would increase until the new incident action was counterpoised; but nothing changes the fact that the replacing of a continuously existing individual by a succession of individ-

1 Principles of Biology, Vol. I, p. 319. 
uals, each formed out of the modified substance of its predecessors, will not prevent the like effect from being produced." 2

Variation is accounted for through the principle of the instability of the homogeneous, a very important principle in Spencer's philosophy. Although two germ cells or two individuals of the same species were originally identical, they must at a certain time become different from each other, owing to the fact that they occupy different locations in space or are influenced by dissimilar forces; different causes acting upon similar objects must necessarily produce different effects or else the principle of the persistence of force must be rejected.

Spencer's theory was formulated in 1864 and all modern theories, not excepting Darwin's pangenesis, are derived from it. Its weak point is that it advances principles of a general character like the persistence of force or the instability of the homogeneous, instead of offering precise physiological explanations. When Spencer states, for instance, that no influence exerted on the organism goes for naught but has its after-effect on the offspring, one could answer that the original force bearing on the parent may very well expend itself in some other way and in another direction, and that, even if it should bring about a modification of the offspring, there is no reason why the 2 1bid., p. 522. 
modification of the offspring should be similar to the modification undergone by the parent. All the facts known concerning the transformation of energy contradict Spencer's statement, as mechanical energy can be transformed into heat, heat into light, etc., etc.

As far as physiological units are concerned, we hold that those units do not possess from the mere fact of their polarity (their only specific character, according to Spencer), the capacity of producing forms as complex as living organisms. Moreover this theory only solves the problem of heredity in so far as we concede to the physiological units all the properties Spencer attributes to them; and it solves the problem only in the case of innate characters; the inheritance of acquired characters remains unaccounted for, as the persistence of force is not in itself a convincing argument.

The conception of initial particles identical in their nature has been the basis of many other theories. Some attribute their properties to their geometrical form, others to their motions (Haacke, Dolbear, Haeckel, Cope) but this does not constitute a distinct advance upon Spencer's theory, and in all those systems we find heredity explained in the same manner: the offspring resembles the parent because it proceeds from a cell of the parent, and because the particles making up that cell (biological units, plastidulæ, etc.) possess properties (polarity, mode of mo- 
tion), characteristic of a certain organism and, therefore, can only produce a similar organism. Between the whole and its parts there is not only a bond but a deep identity; differences are only quantitative.

However interesting these theories may be in their bearing upon the constitution of the protoplasm and the nature of vital phenomena, they account but vaguely for the transmission of characters.

For more definite explanations we must turn to theories according to which the hypothetical particles are not only endowed with mere molecular energy or with general properties, but are supposed to represent distinct parts or distinct properties of the organism. In such theories we will find the most inclusive, accurate and fruitful ideas about heredity. Foremost among them are the old Darwinian theory, the origin of all modern theories and Weismann's more recent theory. 


\section{CHAPTER VIII}

\section{Darwin, Naegeli, De Vries, and their Theories of Heredity}

Theories based upon representative particles.-Darwin's pangenesis; gemmules representing the cells of the body; their migration through the organism.-Objections.-Particles representing properties of the organism.-Naegeli's theory; the micellæ and their groupings; the two types of protoplasm; elementary characters.-Discussion of this system.De Vries' theory; the pangenes, their migration through the cells.

ARWIN'S theory was formulated in 1868, soon after Spencer's. It followed closely upon the scientific discoveries as to the cellular constitution of tissues.

According to Darwin, the various cells of the organism derive their properties from tiny j)articles which he designates as gemmules. These particles, of which there are as many varieties as there are categories of cells in the organism, are infinitely small, can move through the membranes and multiply by cleavage. The gemmules enter the various cells during the cells' embryonic development; they multiply within the cells until the cells have become definitively 
differentiated. The formation of new gemmules continues almost through the whole life of the cell and may begin again under certain circumstances after differentiation has become complete, for instance whenever the cell undergoes some physiological or pathological modification.

While the gemmules are multiplying within the cells, all the cells of the body send some of their gemmules to the sexual cells. This is done not only by the definitely fixed cells of the adult organism, but by all the ephemeral cells which appear during ontogenesis and then disappear. The same happens whenever the adult cells undergo a certain change. The sexual product contains therefore in the shape of gemmules all the anatomical and physiological character's of the cells which it represents.

Gemmules remain dormant in the ovum as long as it does not develop, but as soon as the cleavage begins, they distribute themselves among all the daughtercells at every stage of development and, owing to a certain force of attraction, they finally reach the very cells for which they are intended. They give life to them and, through them, they fecundate the whole organism. Hence the name of pangenesis. To each cell, the gemmules impart a character identical to that of the cell from which they issued at the very moment when the cell released them and dispatched them towards the sexual organs. 
Heredity is then easily accounted for, and is, in fact, one of the phenomena Darwin explains best. The transmission of acquired characters can be explained in the same way. Since at the very moment when the organism undergoes a modification, the modified cells send to the sexual organs modified gemmules, the gemmules penetrating the cells of the new organism must necessarily impart to it the modified characters of the parent.

If we grant these premises-the existence of gemmules and the properties Darwin ascribes to themthis theory gives a simple and satisfactory explanation of all the important biological phenomena, heredity, variation, regeneration, sexual generation, etc. This explanation appears so convincing that all modern theories have borrowed the idea of representative particles without adding to it any essential detail.

Can we, howerer, grant these premises? Unfortunately we cannot. Even if we should admit the existence of gemmules and of all their imaginary properties, we would be confronted by a difficult problem: the mode of transmission of the gemmules from one cell to another. How does the migration of gemmules take place, and what leads them, through innumerable series of cells in which they must not linger, from one end of the organism to the other? This can only be explained in two ways: The transmission can be effected by the blood flux or by the nervous cur- 
rent. But Darwin does not admit the first explanation and we know that the nervous current does not carry particles of matter.

There is another argument against it. Even supposing that there is some mode of circulation yet unknown to us, it remains to be shown how the gemmules are steered towards certain cells. Darwin supposes that before the arrival of the gemmules the cells are all alike. How then can they exert a varying power of attraction? On the other hand if the gemmules themselves are endowed with a power of selection, why should they select one cell in preference to another identical cell? We must then suppose that there exists between cells very subtle differences which make them favour certain gemmules. But how do we account for those differences? Not through the gemmules which have not reached them yet. And if any other factor can produce those differences, it may as well produce any other histological difference and we can dispense with the gemmules.

This is the weak point of the system and, in this respect, it is frankly inferior to some of the later theories. These theories do not deserve much credit for their superiority, as they only improved upon an idea which originated with Darwin. Many other theories which we will not mention here are based on the principle of cell-representation through special particles. All of them are but slight modifications of Darwin's 
theory of pangenesis. None of them, however, can rival it in importance.

In the opinion of other thinkers (Naegeli, Koelliker, De Vries, O. Hertwig, etc.), the particles do not represent organic cells but the very properties of the organism; in the opinion of others, like Weismann, they represent both the cells of the organism and its properties. Among the former, Naegeli and De Vries deserve special attention; Naegeli's theory is the most important and the most inclusive of all and De Vries' theory has introduced many new elements into the discussion and attracted much attention in the last few years owing to its new hypothesis as to the origin of species.

Naegeli's theory, formulated in 1884, preceded De Vries' theory by a few years.

The elementary particles which Naegeli designates as micellæ are, so to speak, organic crystals suspended in an aqueous liquid and separated from each other by thin envelopes of water, water being an integral part of the protoplasm, as in crystallisation it is an integral part of the crystal. Leaving aside all details of the micellæ's precipitation and multiplication, the essentials of the theory can be summed up as follows: The micellæ are at first without any special orientation. Owing to the action of their molecular forces, some of them group themselves with a parallel orientation, while the others remain unorientated. 
The former, clustered more closely, make up a more solid and less aqueous mass; the others constitute a more fluid protoplasm containing more water. The micella which have a definite orientation make up the idlioplasm or germ plasm, the others make up the nutritive plasm.

The difference between the two plasms is considered by Naegeli as supremely important; it has a!so become a fundamental principle of Weismann's theory. It is the idioplasm which, under different names, is, according to both theories, the origin of all vital phenomena, upon which depend all the characters of living things, and which is the basis of heredity.

According to Naegeli, the idioplasm appears in the primitive plasm in the shape of scattered particles. These particles multiply and unite so as to form filaments, then cords which gradually constitute a continuous network. That network spreads all through the organism of the animal or plant, from one cell to another, passing through the microscopic pores of the cell's envelope and invading the nucleus as well as the cytoplasm. 'The idioplasm reacting upon the various tissues and substances of the organism imparts to them their various characters, shape or colour. Here we encounter a first difficulty. As nothing indicates that the micellæ themselves have different characters, whence come the various characters they impart? In 
order to answer the question, Naegeli imagines molecular forces which have their origin, not in the isolated, powerless micellæ, but in clusters of micellæ grouped in a certain manner. Upon these groups of micellæ life is absolutely dependent.

Every group of micellæ forming a harmonised unit determines only one character of one living thing. There should be apparently as many groups of micellæ as there are characters; but the number of characters is so large that the idioplasm could not contain all the groups representing them; this new difficulty is solved through another clever hypothesis: The only necessary groups are those which determine the few characters designated as elementary characters; all other characters, that is the complex characters, are constituted by various combinations of the elementary ones and are therefore imparted to the living thing by the simultaneous action of the groups of micellae corresponding to their component elements.

How are the micellar groups disposed in the continuous idioplasmic network intersecting the whole organism? 'The answer Naegeli gives to the question is dictated by the necessity of accounting for the fact that one fragment of an animal or of a plant (eggcell, spermatozoon, spora, bud, twig) can reproduce by growth the entire individual with all its characters. This leads him to think that such a fragment contains all the micellar groups determining every character. 
Before being separated from the individual, the fragment was, like the rest of the individual, intersected by the network of micellar filaments. Those filaments must therefore be so constituted as to contain in every one of their parts micellar groups corresponding to every possible character. There is only one way of accounting for this. Those groups must be, so to speak, micellar files made up of identical micellæ joined end to end.

In order to determine an elementary character those files unite in the shape of strands; several strands are necessary in order to determine complex characters and the union of all those strands constitutes the continuous micellar cord. This structure of this cord is uniform all over its length and any one of its cross-sections would reveal all the strands or groups of strands corresponding to every character.

Such is the exact composition of the idioplasm according to Naegeli, who advances other secondary theories whenever new difficulties are encountered. For instance, the natural conclusion to be drawn from the foregoing is that the influence of the idioplasmic cord should always be uniform; it should not produce different characters at different points. Yet that is what it does. Naegeli explains that the various strands are not all equally active on all their length; active stretches are separated here and there by stretches in a passive state. According to the various 
cells they cross, certain strands or cords of strands become active to the exclusion of others and produce the characters which correspond to them.

The determining cause of activity or inactivity can be found in the greater or lesser excitability and tension of the various strands. Those in which the micellæ increase most quickly at the expense of the surrounding plasm grow longer and crowd out the others. Later, their development may cease and their micellæ may collapse; no new micellæ being added to them, they enter a state of inactivity and abandon the lead to other adjoining strands which, owing to a nore favourable location or a greater sensitiveness, are nore easily excited and manifest their activity by yrowing rapidly through the adjunction of new micellæ and by making their influence felt on the nutritive plasm surrounding them.

Nothing can be more easily accounted for in the light of this theory than hereditary resemblance. Since every particle of idioplasm contains strands representing all the characters, these characters must reappear in the organism which the cell containing them will create. When two sexual elements unite to produce a fertilised ovum, the orum contains the micellæ of both parents; the micellæ then unite in one single filament and whether newly formed micellæ assume an intermediary character or whether the original micellæ exert on one another a mutual influence, new 
characters are produced which strike an average between the characters of both parents.

In the fecundated ovum, the nature of the micellæ, their grouping, the periods of tension and relaxation, of activity and inactivity, which produce the various characters at a certain time and in a certain place, are all predetermined and can hardly ever be influenced by external conditions. External conditions, however, may modify the tension of the strands, which may be, for instance, strengthened by use, and therefore become more sensitive, or on the other hand weakened by disuse and reduced to a passive condition. Those modifications spreading through the tissues eventually reach the germ cells and are transmitted to the next generation.

Such is Naegeli's explanation of the transmission of characters; it is very indefinite and open to much criticism. He believes that characters are adaptive, but takes this view for purely finalist reasons. The necessary modifications are produced in the organism, he thinks, to fill certain wants created by certain influences exerting themselves on the organism. Explanations of this kind explain nothing.

Naegeli's entire conception of the evolution of beings is pervaded with the same spirit. The idioplasm of living things has possessed since the very beginning of life certain internal evolutive tendencies which have determined the ulterior phylogenetic develop- 
ment; the idioplasm of every species not only contains the micellar strands which characterise the species, but it contains also, potentially, the strands which characterise the one or several species which it will father. External conditions concur with internal tendencies in adapting organs and functions to life's needs, but cannot themselres initiate any erolution. Evolution results from an internal tendency toward progress and perfection. In the course of phylogenesis, new micellar filaments add themselves to the original ones, the structure acquires more complexity, characters and functions become differentiated, beings become more and more perfect. External conditions influence this progress in such a way as to insure its usefulness; they are the origin of adaptation but their influence can only exert itself upon what a progressive evolution has already created.

Naegeli's system, complex and inclusive, has contributed two new ideas which later theorists have taken up and developed: First, the idea of two kinds of protoplasm, of which one only contains the various characters of the organism, and secondly, the idea of elementary characters which, through their combinations, produce the greatest variety of properties. This last suggestion in particular has made the idea of representative particles more easily acceptable, for it remores the necessity of supposing that those particles are present in unlimited numbers. Were it not 
for the idea of elcmentary characters, the idea of representative particles would not have made as much headway as it has. When we come to Weismann's theories we will discuss in detail the notion of character representation. At present we will only discuss Naegeli's own and original hypothesis relative to the micellæ and their groupings.

Not only are the grouping of micellæ, their filaments and cords, and all the other details carefully and accurately described by Naegeli, arbitrary suppositions which find no confirmation in the existing organic structures, but this hypothesis is so fragile that the slightest change in one detail endangers the whole edifice. What is very difficult to understand is why the various cords should pass from an acive to a dormant state, the time at which this transition occurs being different for every point of every cord. As a micellar cord is uniform along its whole length, what influences cause sections thereof to pass from one state into another? We know that Naegeli does not recognise the influence of external factors; growth and tension must affect the whole cord and can not be purely local phenomena; varying degrees of excitability could account for it but they would also result from a variable structure of the cord at different points which is a contradiction of the fundamental hypothesis.

Naegeli's whole system is based upon the conception 
of micellar cords without which neither ontogenetic development, nor heredity, nor variation can be explained. The absurdity of that premise compromises the whole theory. It is not worth our while to examine in detail his theory of phylogenetic erolution; "internal evolutionary tendencies" explain nothing unless we are told in what well-known organic property they have their origin.

De Vries designates his theory as pangenesis and considers it as a direct derivation from Darwinism. While Darwin's gemmules, however, represent the various cells of the organism, De Vries "elementary units" or "pangenes" represent characters and are therefore more similar to Naegeli's micellar groups.

De Vries has contributed very little to the solution of the question at issue. Like the gemmules and micellar clusters, the pangenes are particles which determine the character of the cells, but unlike the gemmules, they do not distribute themselves through the organism and they differ from Naegeli's micellar groups in not being made up of smaller units. The pangenes are located in the nucleus; every nucleus contains a complete series of them representing all the potential or actual characters of the organism. Previous to the cleavage of a cell, the pangenes of the nucleus multiply also by cleavage so that every one of the daughter-cells may receive a complete series of them. If a cell becomes differentiated 
in a certain direction and acquires a determined character, it is because certain pangenes issue from the nucleus, multiply in the cytoplasm and impart to it a certain character. The nucleus always retains a complete series of pangenes, for they always multiply before migrating out of it. 'The pangenes only manifest their motor activity during their migration from the nucleus into the cytoplasm-what De Vries calls intracellular pangenesis.

Heredity is then easily explained. The nuclei of all germ cells contain the pangenes of every character of the parents; as the characters found in the offspring result from the clearage and migration of those pangenes, hereditary resemblance becomes inevitable. 'The inheritance of acquired characters remains unaccountable, and justly so, for De Vries denies it in toto.

Variation may be due to the multiplication of pangenes. One single pangene can represent a character but it cannot express it. In order to express a character pangenes must multiply and the larger their number the more deeply marked the corresponding character will be. As their multiplication may be quicker or slower it can become the source of many individual variations. Besides slight individual variations, there are more important and durable variations from which an entirely new species may spring up. These are the variations which De Vries desig- 
nates as "mutations" and upon which he bases his new theory. They result not merely from a quantitative but from a qualitative modification of the pangenes. It may happen that at a certain time a pangene is divided up into two slightly dissimilar halves or dissimilar daughter-pangenes which, when multiplying, will determine a new character.

We could raise against De V'ries' theory the very objection raised against the theories which preceded his and ask what determines the attraction certain cells exert on the Darwinian gemmules, what excites Naegeli's micellar strands, what drives De Vries' pangenes out of the nuclei? Thus far the question has not been satisfactorily answered. 


\section{CHAPTER IX \\ Weismann's Theory}

The two kinds of protoplasm; germ plasm.-Constitution of the nucleus; ids, idants, determinants, biophors.-Ontogenetic differentiation.-Disintegration of determinants; migration of biophors.-Continuity of the germ plasm.-Hereditary likeness.-Reserve determinants.

Wat has been called the Weismannian doc-
trine is an elaborate and inclusive set of related theories which constitute a well harmonised system and which offer a solution for every one of the main biological questions-heredity, variation, sexual reproduction, adaptation, phylogenetic evolution, regeneration, etc. The system was not created at one stroke. For twenty years it grew gradually in Weismann's mind, undergoing during that time many important modifications.

For the definitive form of Weismann's doctrine we must consult his "Evolution Theory" published in 1902 and which is, in his own words, a summary of all his previous scientific works. Weismann accepts Naegeli's postulate as to two diff erent kinds of protoplasm,morphoplasm (Naegeli's nutritive plasm) and idioplasm. The former plays a rather subordinate part; 
it can assimilate food, grow, multiply, but cannot undergo any qualitative change. It makes up the cytoplasm of the cell. The idioplasm, on the other hand, is the main component of the protoplasm; it is the "hereditary substance" and it determines all the properties which differentiate certain cells from other cells.

To this postulation, howerer, TVeismann adds one important detail which constitutes an adrance upon Naegeli's views. He endearours to make his hypothesis agree with the actual facts as to structures revealed by the microscope. This is why he locates his "hereditary substance" in the nucleus and more particularly in the chromatine, the substance which becomes visible at the time of cell clearage and collects then in the form of chromatic granules known as chromosomes, producing various karyokinetic figures. The hereditary substance exists in all the organic cells; in germ cells, it presents a special composition and is designated by the name of germ plasm.

The complex make-up of the cells' nucleus reveals an extremely complex hereditary constitution. 'The nucleus of a sexual cell consists of a certain number of particles which Weismann calls "ids." In many cases ids might be synonymous with chromosomes, at least in all the cases in which the chromosomes are simple, that is, are not composed of several similarly formed structures. In the salt water crustacean ( $\boldsymbol{A} r$ - 
temia Salina), there are 168 granular chromosomes, each of which must be regarded as an id. In the majority of living beings, however, the chromosomes are shaped like tiny rods which are composed of a series of granules. Each of these granules is to be regarded as an id, and the chromosomes constitute units of a higher order called "idants." Every id is composed of a particle of germ plasm containing everything which is necessary to make up a complete individual; the ids are therefore to a certain extent what Weismann calls primary constituents of individuals ( $\mathrm{Per}$ sonen-Anlagen) .

Here we must point out a similarity (recognised by Weismann) between the Weismannian theory of ids and the old evolutionary theory of germ encasement. It goes without saying that Weismann does not believe in any "homunculus" and that, while every id contains all that is necessary to make up a complete individual, there is absolutely no likeness between the embryonic shape of one of its parts and the fully developed part.

As an organism is composed of dissimilar parts, Weismann is led to conclude that this dissimilarity must already exist in the id wherein the parts originate. Therefore the id must be made up of even smaller units whose co-operation is necessary to form the individual and every one of which controls one of its organs. In other words, every part of the individ- 
ual which is to grow out of an id is determined in its life as well as in its nature by a corresponding particle of germ plasm. Those particles are therefore designated as "determinants" (Vererbungstiicke).

Here we encounter a difficulty. We might assume that there should be in the germ plasm as many determinants as there are cells to be determined in the adult individual at every stage of its development. This is not necessary; there must be as many of these as there are regions in the fully-formed organism capable of independent and transmissible variation, including all the stages of development. ${ }^{1}$

It is a well-known fact that the most dissimilar characters may vary independently. Every part of a butterfly's wing may vary independently from the adjoining parts, as is shown by variations in colouring; every part must therefore be represented in the germ plasm by an independent element, by a special determinant; at the same time, the id of a butterfly must also contain the determinants of all the variable regions of the caterpillar. As on the other hand all the red particles of the blood and all the hepatic cells of the liver "in all probability only vary en bloc" one single determinant suffices to represent them all.

The determinants have a concrete existence, for there must be in the plasm something which causes a certain structure or character to be present or lacking. 1 The Evolution Theory, p. 360. 
In this sense they are not hypothetical; they are as real as though they were visible to the eye. Speculation only begins when their shape is to be described. Even then certain affirmations are in order. It can be stated that they are not a miniature likeness of the individual (as the old evolutionist Bonnet imagined them to be); nor are they particles of lifeless matter, for unless they were live units, able to assimilate, grow and multiply, they could not endure through all the stages of development or resist certain material changes likely to annihilate them.

But how do the determinants impart to cells and tissues the special characters which they represent? Weismann accounts for this by suggesting that the determinants are not the ultimate division of living matter. They themselves are made up of biophors (life-bearers), which are the fundamental units, for they cannot resolve themselves into anything smaller than chemical molecules. These elementary units are endowed with all the attributes of life, nutrition, growth, multiplication and division; in their dimensions "they lie far below the limits of visibility"; the smallest protoplasmic granules revealed by the most powerful microscopes contain large numbers of them. They are larger, however, than the chemical molecules of which they are made up.

The higher units (ids and determinants), represent respectively the complete individual and its different 
parts, cells, parts of cells, groups of cells and other concrete structures. The biophors represent characters, and a germ cell contains as many biophors as the individual which this cell is to create will possess elementary indivisible characters, for complex characters result from various combinations of elementary characters. Every biophor may vary independently so as to produce a corresponding modification in the character it represents and determines; every biophor can assimilate, grow and multiply by division.

The germ plasm is not a mere loose aggregate of determinants; it possesses a structure, an architecture, in which the individual determinants have each their definite location. This location cannot be determined by chance but depends partly on their historical development from earlier ancestral determinants, and partly on internal forces called "vital affinities" to distinguish them from "chemical affinities."

What happens then when the ovum undergoes cleavage and development begins? As every determinant in the ovum stands in a certain relation to other determinants as to location, the process of development must be such that one determinant reaches through innumerable cellular divisions the very cell which it is to determine. This would be impossible unless there were qualitative differences in the first two sister-cells which appear after the cleavage of the ovum. One may contain, for instance, all the deter- 
minants of the left half of the organism, the other all the determinants of the right half; one may contain the determinants of the ectoderm and of all the organs which will develop out of it, the other the determinants of the endoderm with all its possible derivations.

At the next cleavage, the blastomere containing the determinants of all the ectodermic organs will be divided up into two or more daughter-cells, one of which will contain the determinants of all tegumina, the other the determinants of the nervous system and so forth. Ontogenesis is based upon the very fact that every cleavage results in dissimilar blastomeres and that these differences, becoming more and nore noticeable along the same line, produce in the end independent structures due to purely internal causes.

Releasing more and more of its determinants, as organs and tissues become differentiated, the ger'm plasm becomes less complex, more uniform and, when tissues are entirely differentiated, transforms itself into the idioplasm which is found in every cell and which only contains determinants of one cell and of parts thereof. Thereupon the determinants break up into biophors which cross the nuclear membrane and scatter themselves through the whole cytoplasm thus imparting to the cell its distinctive character. When the cell is not definitely differentiated but is destined in the course of its development to transform itself into another, some of its determinants are active (those 
which determine the cell's specific characters) and some other passive (those which, for the time being, exert no influence and will not exert any until a later time). The active ones only break up into biophors. Regarding the process by which biophors determine the various characters in the cells which they penetrate, Weismann states that it is not necessary for the biophors to be endowed, like De Vries' pangenes, with the very properties which impart to a cell for instance the character of a muscle cell or of a nerve cell. Through its action upon the elements of the cellular body, a specific biophor of the muscle substance creates this substance whenever it penetrates the appropriate cell-body, even though it may not be a contractile element itself. The biophors may transform the general character of an unspecialised embryonic cell into the specific cell of a certain tissue but they do not themselves possess any specific histological characters and cannot effect that transformation without the co-operation of the cell-body. In fact the biophor is not a character bearer, but a factor, in the algebraic sense of the word, the other factor being the cytoplasm of the cell.

It is evident that the determinants liberated in the course of the embryonic development cannot be recovered by the cell which released them. How can then the adult organism possess sexual products, every cell of which contains every category of determinant 
and can therefore reproduce the whole series? The problem is solved by the theory of the continuity of the germ plasm.

When the ovum undergoes cleavage, the sum total of its determinants is divided into two, then into four, then into eight unequal surns, but the totality of the germ plasm is not destroyed by the heterogeneous cleavage which produces the successive idioplasms; at every cleavage, a minute particle of germ plasm remains unaltered in one of the two blastomeres while the other blastomere and all its descendants will never contain any. This particle of unaltered germ plasm is transmitted from cell to cell until it reaches the cell destined to form the sexual elements. This mothercell then produces through homogeneous clearage the many sexual cells of the new individual and every one of the blastomeres receives a minute particle of the parental germ plasm thus transmitted through all segmentations.

In this way the organism is divided up into two independent parts: the differentiated tissues which constitute the soma and cannot rever't to the undifferentiated state of germ cells, and the sexual elements or germina which have received the parent's germ plasm in its original condition and are still able to initiate a new develepment.

'This process continues from generation to generation and the result is that every individual contains in 
its sexual cells some germ plasm, not only of its parents, but of its grandparents and of all its ancestors. Hence it consists of numberless ancestral plasms, represented by ids whose number corresponds to that of its ancestors.

Heredity as well as atavism are accounted for by the faithful transmission of those parental and ancestral plasms. Another conclusion to be drawn from these premises is that an individual can only inherit such characters as were innate in the parent, for the transmission only takes place from germ cell to germ cell, and only the elements existing in the ovum which produced the parent can exist in the ovum which produces the progeny. The differentiated tissues, or soma cells, are from the very beginning of ontogenesis, absolutely separated from the germen and no force which bears upon the former can exercise any influence on the latter. Consequently, characters acquired in the course of an individual's life cannot in any way be transmitted to its progeny. 'This is one of the most important conclusions reached by Weismann; it defines very clearly his attitude towards the Lamarckian doctrine and constitutes the main tenet of Neo-Darwinism of which he is the recognised exponent.

How then can a species evolve? As we said before, Weismann and his followers explain evolution by innate variations, preserved and fostered by natural 
selection. How can we, however, account for variations, when ancestral plasms are transmitted to the offspring without being ever affected by any outward influence? According to Weismann, variations result from sexual generation which combines the germ plasms of the parents and the ancestral plasms they contain in a way which varies for every product; it is upon this variety that natural selection exercises itself.

When two germ plasms, slightly different from each other, are united in one cell by fertilisation, their differences are preserved in the sexual cell thus produced. This cell, when mature, undergoes a process which changes the constitution of its plasm; it sends forth polar particles, liberating certain chromosomes and also a certain number of ids, while some other ids are allowed to remain in the cell. Here we have a first cause of variation. Then there arises a competition for food and space between the various ids, determinants and biophors, and as some of them emerge victoriously from the struggle, certain ancestral characters reappear to the exclusion of ccrtain others.

Let us suppose that character $A$ can assume four different aspects and that the four corresponding determinants are $a^{\prime}, a^{\prime \prime}, a^{\prime \prime \prime}, a^{\prime \prime \prime \prime}$; let us suppose also that for some reason which we will not discuss, the determinants of type $\mathrm{a}^{\prime}$ predominate in the germ plasm of the father, constituting $80 \%$ of the sum total of its determinants; the balance, or $20 \%$ being 
divided up as follows: $5 \% \mathrm{a}^{\prime \prime}, 10 \% \mathrm{a}^{\prime \prime \prime}$ and $5 \% \mathrm{a}^{\prime \prime \prime \prime}$; the resultant type will be designated as A". Let us suppose on the other hand that the same character is represented in the mother by $6 \%$ a'", $30 \%$ a", $5 \%$ a' and $5 \% \mathrm{a}^{\prime \prime \prime \prime}$; the type expressed by the mother can be designated as $\mathrm{A}^{\prime \prime \prime}$; in the product, after the liberation of polar particles, the determinants of type a" will be in the proportion of $1 / 2(80+30)$ or $55 \%$ while the determinants of the mother's $a^{\prime \prime \prime}$ will be in the proportion of $1 / 2(60+10)$ or $35 \%$. The child will therefore express the type $A^{\prime \prime}$ and resemble the father.

Still the determinants of other types may subsist in the child and cause it to resemble its grandfather. The following diagram vizualises the process which may bring about this resemblance. (Dark faced type indicates expressed characters, italics indicate idants containing repressed characters which are only potentially in existence, and bracketed letters indicate the idants eliminated through the liberation of polar particles.)

Grandfather Grandmother
a b c d $(e f g h)$
$\mathrm{m} \mathrm{n}$ o $\mathrm{p}(q r s t)$

$\underbrace{\begin{array}{c}\text { Son } \\ a b d(\mathrm{~m} \mathrm{no} \mathrm{p})\end{array} \quad \begin{array}{c}\text { Son's Wife } \\ v x y z(\alpha \beta \gamma \delta)\end{array}}_{\text {Grandson }}$

a b c d $(v x y z)$ 
The grandson would then resemble his grandfather without resembling his father. Such illustrations could be easily multiplied; but the point to be remembered is that variation results from purely internal causes, from the very fact of amphimixia.

Natural selection acts upon characters thus transmitted and we can now dispense with the hereditary transmission of characters, with environmental influence and other causes of rariation suggested by Lamarck. Natural selection is the only origin of those chance rariations, innate and individual, which are one of the postulates of Darwinism.

Every detail of the Weismannian doctrine is thus explained logically by another detail. Still Weismann did not succeed in preserving the integrity of his doctrine, and certain facts in contradiction to it necessitated additions, amendments, compromises and even the adjunction to his original system of a new theory, the theory of germinal selection.

Among those modifications and additions we will only mention those which concern the relations between soma plasm and germ plasm, a question germane to that of the hereditary transmission of acquired characters. According to the original theory, the cell of the adult individual contains only such determinants as correspond to its proper characters. This is contradicted, howerer, by facts of a-sexual reproduction. The end cell of a bud, for instance, must 
contain all the determinants of the plant, for it will produce branches bearing various organs, among others, flowers with sexual cells. A whole begonia will grow from a fragment of leaf planted in moist sand.

Similar phenomena can be observed in the animal world, such as cases of regeneration. Cut off one of the salamander's legs and a new member, normal in shape and in structure, will develop from the stump; segments of certain worms will grow a new head with all the organs appertaining to it. To account for these facts Weismann admits the presence, in the cells in question, of two or more categories of determinants, some of which are reserve determinants, inactive under ordinary conditions of life but waking up under the influence of a certain stimulus. Ovum and spermatozoon contain determinants of both sexes, those of one sex only becoming active.

This applies to secondary sexual characters as well. When a son inherits his maternal grandfather's black beard, the necessary determinants must have existed in the mother in a latent condition. Likewise, the varied forms observable in social insects must be due to the presence in the ovum of several kinds of determinants. A specific stimulus makes certain determinants active to the exclusion of the others. Each cell contains, like the initial germ cell, the whole complex of determinants, but at every stage of onto- 
genesis, that is in each of the developing cells, only the determinants which are to control the immediate successive cells are liberated through the specific stimulus.

This is extremely important, for if every cell is practically a germ cell, the distinction between germ plasm and soma plasm is no longer essential.

By insisting on this distinction, Weismann rejected absolutely the Lamarckian point of view, and his followers considered it as a refutation of the Lamarckian theory. The question of the inheritance of acquired characters was definitely disposed of. While Weismann denied the inheritance of acquired characters, he had to admit certain incontestable facts proving that modifications due to external influences reappeared in the next generation or generations. This is due, he thinks, to the fact that an influence may bear simultaneously on the soma and the germen; when cold, for instance, modifies the colouring of butterflies' wings, it acts simultaneously on the determinants of the pigment cells of the wings and on the corresponding determinants contained in the sexual cells. We may answer that this concerns only the process of transmission. As transmission remains a fact, it must be conceded that the Lamarckian idea was buried prematurely by Weismann. On the other hand, the influence of external factors, which the original Weismannian theory considered as nil, comes into its own 
once more, since Weismann recognises that it can stimulate certain determinants, and admits it as the cause of acquired modifications which reappear in the following generation. 


\section{CHAPTER $\mathrm{X}$}

\section{Germinal Selection. A Discussion of Weismann's Theory}

A theory created in support of natural selection.- Roux's struggle between the parts; the struggle between determinants.Advantages of the new hypothesis.-The idea of selection applied universally.-A discussion of germinal selection.A discussion of Weismann's system; the theory of the germ plasm, the representation of characters, the migration of biophors.

\section{THE most important addition made by Weismann}

1 to his system is the auxiliary theory of germinal selection which is closely related to the theory of natural selection and answers many of the objections which have been raised against the latter. The theory of germinal selection was not discussed in the chapters devoted to natural selection because it is based on the theory of determinants and is unintelligible unless the theory of determinants has been previously expounded.

The opponents of the theory of natural selection are right on many points, Weismann concedes; the fact that variations follow one another in a fixed sequence, the development of complex organs with 
many correlated parts, the appearance of useful variations at the proper time, the growth or atrophy of organs (even taking panmixia into account), are as many difficulties which natural selection is powerless to solve without the help of another factor. This factor is, according to Weismann, germinal selection. 'Thus Weismann avoids Lamarckian explanations, a thing he could not have done if this new theory had not supplemented the theory of natural selection.

The idea of germinal selection rests upon what Wilhelm Roux calls "the struggle between the parts of the organism." Weismann developed Roux's idea; not only is this struggle going on between organs, tissues, and cells, but also between invisible vital units, not only between soma cells, but between germ cells as well.

For example, when the determinants multiply by cleavage, the daughter-determinants thus produced are never alike in size or in faculty of assimilation, for there arise between them, as well as between cells, tissues and organs, differences due to the fluctuation of the food supply. Nutrition is, as we know, more than a passive act; a certain element not only assimilates food but deflects it toward itself the more powerfully as it is stronger and endowed with a greater faculty of assimilation. Consequently the strongest determinants of the germen will deflect more food and become still stronger; others, being 
weaker, will go without food, develop more slowly and produce less vigorous daughter-determinants. The result is that, in the second generation, certain parts of the organism, which were represented in the ovum by stronger determinants, will be more developed.

As, furthermore, the germ cell of the second generation receives the parent's germ plasm, with all its heterogeneous elements, the struggle will be resumed between the strongest determinants, and in the third generation certain characters will be even more strongly marked. This accounts for the accumulation of characters which was merely presupposed in the Darwinian system, and for the fact that modifications accumulate in certain directions to the exclusion of any others. These variations are not "predestined". in the sense Naegeli gave the word, but merely caused and directed by external conditions.

When certain organs or parts thereof are favoured by natural selection, the corresponding determinants are better nourished and their offspring is stronger. The degree of utility determines the line of variation and this explains why useful variations are always found present: their increase is, so to speak, automatic. The only obscure point, Weismann says, is the usefulness of variations in their incipient stages. According to Weismann, variations must be useful even in their incipient stages, or else natural selection would have nothing upon which to exercise itself, and 
the useful determinants would have no chance to predominate. As we are incompetent, however, to appreciate absolute usefulness, we are as well justified in admitting it as in denying it; we may therefore admit it, since it enables us to imagine the beginnings of adaptation. Weismann thus returns to his favourite idea of adaptation to the end, which, owing to the surrival of the best-adapted individuals, has ruled nature since the world began.

The struggle between determinants explains also, Weismann says, the complex adaptations of different parts which co-operate to the same end (nerves and muscles, eye and optic centers, protective colouration and corresponding instincts), adaptations which the Lamarckians considered as evidence against natural selection. Natural selection cannot account for them, but germinal selection explains (?) why the determinants on the upward grade correspond to all the parts which, in faroured individuals, contribute to assure the perfect activity of an organ.

The same applies to the degeneracy of useless organs; panmixia accounts for the beginning of that processus, as individuals in which useless organs are more developed survive as well as the others; but the later stages of the processus can only be explained through the influence of another factor, germinal selection. When a useless organ is less developed from birth in an individual, the determinants of its germ 
plasm will be much weaker. Being weaker they will secure less food, so that more food will go to the other determinants; in the following generations, they will become weaker and weaker, until the organ is completely obliterated. In other words, panmixia is an indispensable preliminary to this degeneracy; the struggle for food between determinants completes the process.

Germinal selection is at the very basis of natural selection and the conception of determinants is nceessary to explain the latter. The idea of selection must be made to include all living units without restriction. "If the principle of selection operates in nature at all, it must do so wherever living units struggle together for the same requirements of life, for space and food, and these units need not be persons, but may represent every category of vital units, from the smallest invisible units up to the largest. . . . It seems best to assume and distinguish between four main grades of selective processes corresponding to the most outstanding and significant categories of vital units, namely: germinal, histonal, personal, and cormal selection."

"Histonal selection includes all the processes of selection which take place between the elements of the body (soma), as distinguished from the germ plasm, of the Metazoa and Metaphyta, not only between the tissues in the stricter sense, but also between the 
parts of the tissues, that is, the lower vital units of which they are composed, and which Wilhelm Roux, when he published his Kampf der Teile (Struggle of Parts), called "molecules." . . . "In contrast to this is germinal selection, which depends upon the struggle of the parts of the germ plasm, and thus only occurs in organisms with differentiation of somatoplasm and germ plasm, especially in all Metazoa and Metaphyta, forming in these the basis of hereditary variations. . . ."

"Personal selection . . . decides whether the variation is to persist and to spread to many descendants so that it ultimately becomes the common property of the species.

"Cormal selection . . . is the process of selection which effects the adaptation of animal and plant stocks or corms, and which depends on the struggle of the colonies among themselves. 'This differs from personal selection only in that it decides, not the fitness of the individual person, but that of the stock as a whole." ${ }^{1}$

Such is the theory advanced by Weismann to remedy, as he says, the drawbacks of exclusive selectionism. It makes many concessions to Anti-Darwinian points of view and is, above all, a theory of orthogenesis, postulating a definite line of development. It is one of the most logical among orthogenetic the1 The Evolution Theory, Vol. II, pp. 376-3is. 
ories, for it accounts, at least hypothetically (the determinants being hypothetical), for definite variations. It is a causal and mechanical interpretation of orthogenesis.

The theory of germinal selection pretends to explain why useful variations are always observable; in reality it merely explains why they become more accentuated after they once make their appearance. It also explains, however, why any variation (unless it is harmful enough to kill the organism) may become more accentuated, and thus this theory defeats its very purpose.

External influences which were entirely ignored in Weismann's original theory, are considered as an important factor in germinal selection.

An increase or decrease of the food supply is bound to play a part in the competition between determinants; dearth, for instance, would kill the weakest determinants and allow only the strongest to survive. Weismann himself admits that the initial differences between determinants may depend upon an increased or decreased food supply. The mode of alimentation would also exert a deep influence upon the development of the future organism and what is more important, the modifications brought about by alimentation would of necessity be hereditary, for, according to the principle of the continuity of the germ plasm, the weaker determinants, defeated and killed 
off in the parent, could not reappear in the offspring, the complex of determinants being transmitted exactly as it happens to be found at the time of transmission. And thus the Lamarckian idea of the inheritance of acquired characters creeps into the Weismannian doctrine.

Moreover, Roux's idea of the struggle between parts is related to the idea of the development of an organ by use, as we will show when we examine Roux's theory of functional stimulation. By accepting this idea, Weismann to a certain extent countenances the Lamarckian point of view.

In other words, the theory of germinal selection is in name only a selection theory and it is simply Weismann's method of presenting the facts which reminds the reader of natural selection as understood by Darwin. A Lamarckian could well admit the struggle between determinants and describe it in terms which would hardly differ from those used by Weismann, barring the fact that he would not mention the initial differences. A Lamarckian might say, for instance: "Under favourable conditions of nutrition, determinants grow and multiply actively; the parts of the organism shaped by them become more highly developed and transmit their variations to the offspring."

Finally Weismann's statement as to the universal application of Malthus' principle is merely due to a 
habit of mind which makes him look at things from the selectionist view-point. In Lamarckian parlance we would speak of the universal influence of environment and mode of life on species, individuals and determinants.

Weismann has introduced into his biological system all the strong points of the earlier systems: Darwin's representative particles, Naegeli's separate plasms and elementary characters, De Vries' migration of the particles from the nucleus into the cytoplasm. By combining those ideas in a system of particles which are assigned different ranks in a definite hierarchy, he succeeded in creating a series of units accounting for phenomena which the properties of one single category of units could never explain. At the same time, he eliminated some improbable features of the earlier systems: Darwin's circulation of the gemmules and the uniform constitution of Naegeli's micellar strands. He also developed the idea of the germ plasm which had only been hinted at by Jaeger and Nussbaum and he added so much to it that it became a truly Weismannian idea.

The theory of the germ plasm preceded in Weismann's mind all his other theories. It is in fact a double theory: On one side we have a theoretical doctrine with all its hypotheses; on the other, a fact, a trivial fact, presented in such a way that it leads to definite conclusions. 
Weismann postulates a distinction between the soma plasm, which dies with the organism, and the germ plasm, which survives in the offspring and is therefore continuous and immortal. Weismann considers the latter as a special and independent substance and thus reaches the second part of his theory which is, not only open to severe criticism, but could lead, if it were strictly adhered to, to inadmissible consequences.

The fundamental postulate of the theory is that the somatic elements of the organism can exert no influence upon the germinal elements, as the two kinds are separated from the very first stage of ontogenesis. Consequently the germ plasm of the offspring is made up solely of the parents' germ plasm, barring, of course, modifications brought about by the liberation of polar particles and by fertilisation. These modifications, however, result merely from a reshaping of elements which existed previously in the ancestors; they cannot, therefore, add any new element to the make-up of the species. But whence come the variations, however slight they may be, which give rise to a new species? The evolution of higher animals grows to be unaccountable, and appears, in fact, impossible; for there-is no reason why our germ plasm should differ from the plasm of our Protozoan ancestors.

By admitting in his later writings the influence of 
external factors on the constitution of germ cells, Weismann opened a door of escape, but this very admission contradicts his theory for it is inconsistent with the idea of a rigorous predetermination.

If we now examine the factors of predetermination, we find more details to criticise. First of all, what are the biophors, bearers of hereditary characters? The notion of character is an abstract notion born of our mental habit of analysing the impressions made upon us by external objects. An object has as many characters as it produces distinct impressions on us which we are able to abstract. Those characters, on the other hand, have no actual existence of their own and cannot, therefore, be incarnated in any particle of matter. Besides, the fact of possessing characters is common to all the objects of the universe and is not the exclusive attribute of organised beings. Shall we then suppose that inanimate bodies also owe their properties to some kinds of biophors? And where would these biophors come from?

The very mode of action of the Weismannian biophors appears improbable. Every cell is supposed to be determined by biophors migrating from the nucleus into the cytoplasm. But whence come the biophors? From the ids in the nucleus. There is, however, more than one id in the nucleus; there is a large number of ids, since every one of them repre- 
sents one ancestor and the total number of ids represents the total number of the individual's ancestors. All those ancestors would then contribute their part to the constitution of the cell's characters. Moreover, there are in the cytoplasm of every cell biophors of every ancestral cell. If all those elements became superadded, the cells would, at the end of the ontogenesis, possess all those accumulated character's. This being the case, they could not be determined in any direction.

If there was to be any determination at all, if one character was to succeed another character instead of being simply superadded to it, the biophors of every mother-cell would have to die off; but IV eismann never mentions that biophors can be wiped out by death.

There is another difficulty. Why do biophors migrate from the nucleus? This question is as unanswerable as the question why Darwin's gemmules are attracted by certain cells. Weismann mentions a certain stage of maturity, but we fail to see how biophors could mature and why they should mature in one cell and not in another cell, in a soma cell and not in a germ cell.

This could only be accounted for by a difference in the conditions which influence them, but such an explanation would not be consistent with the postu- 
lates of the theory. To have recourse to this explanation would be to admit the uselessness of the hierarchy of representative particles which were supposed to predetermine everything and to leave nothing to be explained by the influence of the environment.

From our survey of the Weismannian theory, the most elaborate of the representation theories, it would appear that all similar systems are doomed to failure. The idea of character representation will never offer a satisfactory solution of the main biological problems. 


\section{CHAPTER XI}

\section{Wilhelm Roux's Theory}

The organicist view and its distinctive characters.-Importance of external factors.-Exponents of the theory: O. Hertwig, Herbst, J. Loeb, Driesch.-Tropisms and tactisms.W. Roux and biomechanics.-The theory of "the mosaic"; the struggle between parts of the organism; functional stimulation.-Evidence: the formation of spongy tissuc in bones; pseudarthrosis.-A discussion of Roux's theory; its merits. -Its relation to selectionism and Lamarckism.

THE theory which constitutes the subject-matter 1 of this chapter never dereloped into any system as elaborate and inclusive as the systems based upon the idea of representative particles. Wilhelm Roux ventures no such surmises and only considers the concrete organism, its tissues and cells. In his explanation of ontogenesis he attaches the utmost importance to external factors and to the activity of the various organs. In that respect, organicism is the perfect antithesis of Weismannism. While the latter theory is related to early evolutionism and to Neo-Darwinism, the former has many features in common with the old theory of epigenesis and Lamarckian transformism. 
Organicism is not so much a theory of heredity as a theory of ontogenesis. Roux and the other organicists lay special stress on the factors of individual evolution. To them the main question is the origin of ontogenetic, anatomic and histological differentiation. Weismann and his disciples considered the cells as potentially differentiated, at the time of the cleavage of the mother cell, by purely internal factors. The biologists of the organic school, among them O. Hertwig, Herbst, Loeb, Driesch (the last named in his earlier works only, as his vitalist studies led him later to draw different conclusions), locate the factors of differentiation outside of the cell.

Hertwig, for instance, considers the successive cleavage of the ovum as invariably homogeneous and makes the differentiation of a cell dependent upon its location relatively to the surrounding cells. "Differentiation," he says, "is due to location. In the gastrula it is not the endoderm which becomes invaginated; it is whatever becomes invaginated which constitutes the endoderm." In other words the mere fact that certain cells constitute the internal wall of the gastrula causes these cells to assume endodermic characters.

Others, Hartog, Roux and Kopsch, attribute differentiation to the influence of the various tropisms and tactisms, such as the mutual attraction of blastomeres and of cells, an attraction which Roux designates as 
cytotropism and Hartog as adelphotaxy and for which both have found a chemical explanation.

To demonstrate the existence of cytotropism Roux isolated in a neutral fluid the blastomeres of a segmentated ovum and noticed that whenever the space separating them did not exceed their diameter they moved towards one another and became clustered.

Herbst attributes the motions of the cells, beginning with the first blastomeres and continuing through all ontogenesis, to a certain chemical attraction he calls chimiotactism. This chemical action attracts certain cells toward the surface of the organism where they become epidermic cells and others toward the internal regions where they constitute the digestive apparatus. For instance, when a nerve is in formation, its axiscylinder first penetrates the surrounding tissue; the mesodermic cells, which later constitute Schwann's sheath, cluster around it, evidently attracted by a force originating from the chemical composition of the axiscylinder.

Likewise, perimysium forms around the muscles, the successive layers of the vascular walls grow around the endothelial sheath wherein the blood circulates, etc.; a conjunctive cell, at first undifferentiated, may become a neurilemma cell, or a perimysium cell or a periostis cell, according to the peculiar tactism which attracts it.

Besides this special tactism, whose physico-chemical 
nature las not been determined yet, and which is called biotactism, a certain morphogenic action is exerted by known factors, heat, light, electricity, gravity, fluids, pressure, etc. Numberless books and pamphlets have been published in the past twenty years demonstrating the importance of those factors in ontogenetic development. A special periodical founded by Roux, the Archiv für Entwickelungsmechanili, is devoted to this branch of biology which has been called the mechanics of development or, better still, biomechanics.

The various contributions to the study of the subject are not all inspired by a common theoretical thought, nor are all their authors exponents of the organicist theory. Herbst, for instance, endeavours to make his conclusions harmonise with Weismann's, a rather hopeless task, and Hertwig, the foremost exponent of the epigenetic school, has even formulated a theory of his own, his theory of idioblasts, particles which determine the elementary properties of the cells. This theory is an adventitious part of his system and adds very little to his explanation of ontogenesis.

Roux, whose theory attaches so much importance to the influence of activity upon the formation of organs, shows himself less uncompromising than Hertwig when it comes to the question of preformation and ontogenesis. According to Roux, the nucleus of the ovum is made up of materials, qualitatively different, 
disposed side by side, like fragments of stone in a mosaic, and destined afterwards to create the different parts of the organism. 'This conception, which is in contradiction to his main thesis, is not an integral part of the organicist system. 'This system comprises two theories which will be reviewed separately: the theory of the struggle between parts and the story of functional stimulation.

The protoplasm of the cell is composed of chemical molecules of various kinds which in the course of the assimilation and disassimilation of the cell undergo independent modifications. Nutritive fluids surrounding the cell favour the multiplication of certain categories of molecules, thus disrupting the equilibrium and allowing certain substances to predominate. Likewise certain physical and chemical factors exert their influence on substances which are not uniformly sensitive to stimulation, those which react more strongly undergoing more waste, and vice versa. Substances whose assimilation is faroured, derelop more than others, but as space is limited (for the capacity of the cell is limited), there arises between them a competitive struggle in the course of which some of them crowd the others out and, in the end, predominate. The preponderance of certain substances, which are different in every cell (for their initial conditions were different and the stimulation was also different according to the location of the cells 
in the organism) is the main cause of ontogenetic differentiation, chemical and functional.

A similar struggle is waged between cells, for cells also react differently when stimulated, and the space they can occupy in the organism is limited. The cells that are best fitted to multiply overpower the other cells. Differentiation then becomes more marked, for whenever cells of the same order are characterised by the presence of the same substance, those in which this substance exists in larger quantities multiply more rapidly.

The same struggle goes on between tissues and even between organs, with this difference, however, that organic necessity sets definite limits, and that the exaggerated development of certain organs could be harmful to the organism and cause it to be eliminated by natural selection. The struggle is not carried beyond the limits within which it contributes to the economical utilisation of food and space.

At the time when the cells become definitely differentiated there intervenes another factor of ontogenesis: functional stimulation. It is absolutely dependent, however, upon cellular differentiation; for after a certain stimulation has favoured in a cell the assimilation of a certain substance at the expense of others, and all other substances have been gradually eliminated, the cell is only sensitive to this particular kind of stimulation. The real function of the cell consists 
then in responding to that stimulation which becomes necessary to the cell's life. The activity of a cell, of a tissue or of an organ determines, therefore, the shape and degree of development of that cell, tissue or organ. 'This is universally admitted as far as the anatomical appearance of organs is concerned. It is true also, however, of their histological structure. Roux gave as evidence the structure of the spongy tissue of the long bones. It was noticed long ago that the lamellæ of this substance were so disposed as actually best to withstand the stresses brought to bear on the bones. Natural selection could not have brought about this disposition which is undoubtedly useful. If, at the very begimming, when the bone lamellæ were orientated in every possible direction, some of them had assumed a useful orientation, this slight variation would not have been sufficient to influence natural selection. If we suppose, on the other hand, that the variation affected at once a large number of lamellæ (and this could no longer be described as the usual fluctuating variation), this large number of lamellæ must have constituted the absolute majority in order to insure usefulness. In this case we cannot see why the transformation did not cease then and there instead of continuing until all the lamellw had been orientated similarly, which was supcrfluous. Natural selection could not favor the development of a useful structure beyond what is necessary; only 
functional stimulation can account for this phenomenon.

The functional stimulation of the bone is the mechanical action it bears while resisting the strains which, in the various motions, tend to destroy its rigidity. It is along this line of resistance that the stimulation is strongest; consequently it is in the lamellæ orientated in this direction that nutrition is most active. These lamellæ develop very actively while those orientated differently thrive poorly and become atrophied. The presence of cavities within certain bones is due to the fact that the parts located in the centre are not sufficiently affected by functional stimulation to survive.

Roux cites many observations in support of his view. In the case of fractures imperfectly set and in which the two ends of a broken bone do not dovetail properly, the lamellæ assume a peculiar direction which is along the line of greatest resistance. Another phenomenon more striking yet is observable in fractures when the bones have not become completely solidified. Owing to the mobility of the two segments a pseudarthrosis forms between them, that is, an articulation with cartilage and ligaments located in a place where heredity could not have predetermined such a formation.

Other cases have been instanced, after Roux, of cartilage disappearing where friction ceases and ap- 
pearing where it occurs. Bones submitted to a greater strain than they should normally sustain have been observed to assume, owing to functional stimulation, a much greater development. A seven-year-old boy had, on account of osteomyelitis, almost completely lost the shaft of his tibia, the only thing left being a spur a few inches long which was a continuation of the upper apophysis. Poirier tried to replace the tibia by the fibula by resetting the latter and uniting it to the lower apophysis of the missing tibia. Fifteen months later the fibula had trebled in size and had completely replaced the tibia. ${ }^{1} \quad$ In another case the welding of bones effected itself naturally in an adult individual. Owing to a disease which affected the patient in childhood the head of the tibia became separated from its diaphysis and became relded to the fibula. The latter bone grew and when the patient, then fiftyfive years old, was examined, both bones were of the same size. ${ }^{2}$

Cope cites two similar cases of luxated elbow joint, one in a man and the other in a horse. Friction eliminated the bony tissue at the point of contact and an articular surface appeared. ${ }^{3}$

1 Poirier. Rapport au Congrès de Chirurgie (1896) sur le remplacement d'une diaphyse tibiale détruite par l'osteomyélite par la diaphyse péronière.

2 Communicated by S. Ledvc to the editor-in-chief of l'Année biologique and reported in Vol. II of that publication.

3 Proceed. of the Amer. Philos. Soc., 1892, cited by Cope in Primary Factors of Organic Evolution, p. 277. 
Similar phenomena can be observed in every part of the organism: the shape and structure of passive organs are determined by the strain they have to bear; active organs, like muscles, develop in direct ratio of their activity.

Thus many structures, which certain theories attribute to heredity, are due, according to Roux, to functional stimulation. The activity of tissues and organs, he writes, begins long before birth; muscles form very early; bones, aponeuroses, ligaments, have at a very early stage to withstand various strains. Still mere activity in the course of one individual existence could not produce complex organs. To produce this result, it takes several generations in the course of which the effects of activity accumulate. This however would be impossible unless the modifications due to functional stimulation could be transmitted by inheritance. Roux, therefore, recognises the inheritance of acquired characters as a necessary factor, but he does not offer any physiological explanation for it, except as far as chemical modifications are concerned. These may result, he says, from a general condition of organic nutrition which affects the sexual cells. Roux thinks that to morphological characters chemical modifications probably correspond whose action is likely to extend to the reproductive elements.

Many criticisms can be formulated against almost 
every detail of Roux's theory. This theory, as we said before, is not a theory of heredity, for the struggle between parts and functional stimulation can only account for the appearance of general histological and anatomical characters which may be, and in fact are, common to all the individuals of one species, if not of one family or genus. They do not account, however, for any hereditary individual likeness. On the other hand, the inheritance of acquired characters is postulated by Roux as a logical necessity of his theory, but he does not explain its workings. Furthermore when Roux states that the competition among cells f,or space and food results in a more definite specialisation, he does not give any reasons for this phenomenon. What he says concerning the relative proportions of the various chemical substances in one cell is perfectly clear, for it is natural that the most favoured one should increase; but it is not certain that the same cause could produce a multiplication of the cells.

Other objections could be presented. Plate remarks, for instance, that, while activity sometimes develops an organ, it sometimes wears it out (as in the case of teeth) and that there are cases of uncompensated fatigue (in sensorial organs) or of spontaneous hypertrophy, etc.

In spite of all the defects of his theory and in spite of all the questions it leaves unanswered, Roux de- 
serves much credit for having drawn the attention of scientists to a factor as powerful as functional stimulation and for having proved that it accounts for many facts of prime importance. In this respect, Roux's theory differs widely from Weismann's. The latter leaves nothing unexplained or unprovided for; its details are above criticism but its basis is erroneous. Roux neglects the details, leaves many problems unsolved, but the main thesis is correct and likely to lear investigators along the right path.

The idea of functional stimulation is not new; it is derived from the Lamarckian principle of the creation of the organ by the function. By showing the practical application of that principle and by extending it even to passive organs and to the phenomena of cell life, Roux has gone a long step forward. The theory of functional stimulation with its corollary, the inheritance of modifications due to this factor, seems to us inspired by the Lamarckian point of view, in spite of the idea, however correct it may be, of the competition between parts of the organism which gives it a slight selectionist tinge.

The shortcomings of the theory of the struggle between determinants, in Weismann's system of germinal selection, make it evident that the theory of the struggle between parts cannot strengthen the position of the selectionists. On the other hand, a typical 
Neo-Lamarckian, Cope, very logically discovered in Roux's theories the embryological complement of his own phylogenetic theories and accepted them as the basis of his system. 


\section{CHAPTER XII}

\section{The Law of Galton and the Laws of Mendel}

Heredity considered from a new point of view.-Galton's statistical researches: the law of ancestral heredity.-Mendel's experiments.-The study of hybrids; the law of dominance and the law of segregation of characters.-Instances of the application of these laws.-Theoretical consequences of the Mendelian discoverics.

AL the theories of heredity we have thus far A reviewed, endeavoured to solve the following problem: by what physiological processus does an organism become, in the course of its development, similar to the organisms from which it is descended? This problem, however, can be formulated in a different way. We may set aside the phenomena arising in the fertilised ovum and in the various tissues, and, taking the resemblance which results from them as granted, let our observations bear upon this resemblance, its various stages and its variations in the course of several generations. This was the way in which Galton and Mendel approached the subject. The application of different methods, however, led these two scientists to draw different conclusions. 
The effects of heredity may be studied with the aid of statistics, general rules being deduced from the examination of a very large number of cases. Francis Galton was the first to apply this method to biological questions, with special reference to phenomena of variation. In his famous books on heredity, "Hereditary Genius," 1869, and "Natural Inheritance," 1889, le established the foundations of a new science, Biometrika. He was followed by many scientists, among them his immediate successor, K. Pearson, by Weldon, Bateson, Darbishire and others, whose observations have been recorded in a special magazine, Biometrika.

The first great generalisation Galton deduced from his vast statistical studies (he collected data relative to one hundred and fifty families, tabulating the most varied characters, physical or mental) is the following: when the variations of one character or one faculty are considered, there seems to be one constant average for every generation and every divergence from the average is compensated by another divergence. For instance, whether the father is above or below the average, the son will have a tendency to vary from the arerage in the opposite direction. It has been frequently observed that the sons of great men were rather poorly gifted and that the parents of remarkable men were inferior to the average. "The more bountifully the parent is gifted by Nature, the more rare will be his good fortune if he 
begets a son who is as richly endowed as himself, and still more if he has a son who is endowed yet more largely." 1 The hereditary transmission of talent or high qualities is therefore very doubtful, but so is, on the other hand, the transmission of individual blemishes.

A salient character, whatever it may be, is never transmitted in its entirety but is always attenuated in the following generation. This is the law of "regression" or reversion to the average, which is partly due to the fact that the average represents the most stable equilibrium and partly to the fact that we inherit not only our parents' but our grandparents' and our ancestors' characters. And thus we arrive at Galton's second great generalisation known as the law of ancestral inheritance.

Galton's theory of ancestral inheritance not only postulates the continuity of the germ plasm, but figures mathematically the amount contributed by each generation to the make-up of one given individual. A near ancestor bequeathes to the individual more elements than a remote ancestor. Galton determines as follows the respective contributions of an individual's ascendents: the parents determine onehalf of an inherited character (the father one-quarter and the mother one-quarter) ; the grandparents' share is one-quarter, that is one sixteenth for each, and so 1 Natural Inheritance, p. 106. 
on; the sum of all those fractions equals one, or the character of the individual in question.

According to the law of ancestral inheritance (either accepting the figures given by Galton or the law as formulated in a slightly different form by other biometrists), the effects of heredity become inevitably attenuated and rariations abandoned to their fate are doomed to disappear. Considered in this light, Galton's law constitutes a strong argument against the definitive constancy of accidental variations produced outside of the sphere of environmental influence. It has been used by the opponents of natural selection as a ready weapon. At the present day, however, a renewed interest in Mendel's discoveries has cast some doubts upon the accuracy of Galton's law, at least as a universal law, and the line has not been drawn properly as yet between the cases to which it seems to apply perfectly and the so-called Mendelian cases.

Generally speaking, Galton's law seems to apply more especially to reproduction within one race or variety, while Mendel's laws, based upon experiments in cross breeding, apply particularly to the characters of hybrids. Mendel's observations were made over' half a century ago. Gregor Mendel, a monk, devoted himself for many years to experiments on the crossing of plants in the garden of the Brünn monastery. In 1866 he published the results of his experiments in an obscure bulletin of the Natural History Society of 
Brïn where they remained buried until the botanists Correns, De Vries and Tschermak unearthed them in 1900.

By cross-breeding in different ways twenty-two varieties or sub-species of pea (Pisum sativum), Mendel observed certain character's such as the shape and colour of seed and pod, the size of the plant, etc., through successive generations, studying each time one single character to the exclusion of the others.

In order to study, for instance, the color of the seed, he crossed yellow seed peas with green seed peas; the offspring showed the character of one of the parents only, as yellow seed peas only resulted from the cross. Mendel designated as dominant the character which appeared in this first generation and as recessive the character which did not seem to be transmitted. Thus he came upon his first law, the law of dominance.

Mendel then made a cross between those hybrids which all resembled one of the parents (having yellow seed) and noticed that in the second generation of hybrids some peas gave yellow seed and some green seed in the proportion of three dominant hybrids to one recessive. The disappearance of the green seed character in the first generation of hybrids was only apparent, since this character reappeared in the second, to which each of the original varieties seemed to have transmitted separately its heritage. Mendel 
formulated then, his second law, the law of segregation of characters.

A study of the descendence of this second generation of hybrids reveals curious facts which enable one to make certain forecasts as to the number of individuals each category will contain: the recessives with green seed, on being crossed between themselves, produce recessives only, for an indefinite number of generations; the dominants give rise to a mixed off spring, one-third pure dominant (so called because they breed true for ever afterwards), and two-thirds impure dominants, which, in the following generations, breed dominants and recessives in the proportion of three to one.

Mendel's experiments were repeated and their results checked up by many botanists and zoölogists. Correns experimenting on peas and corn, Tschermak, De Vries, Bateson and his associates on various plants, Darbishire and Cuenot on mice, Hurst on rabbits, Toyama on silk worms, Davenport on fowls, all convinced themselves that Mendel's laws held good in the majority of cases. The result of certain crosses can sometimes be predicted with startling accuracy. Lang crossed two varieties of Helix hortensia or common snail, one with a bandless, the other with a banded shell. All the hybrids of the first generation had a bandless shell (dominant character); the following generation gave rise to a mixed offspring, bandless 
shells and banded shells being in the exact proportion of three to one. ${ }^{2}$

Correns crossed two varieties of nettles, Urtica pilulifera and Urtica dodartii, which differ only in the appearance of the leaf's blade, dentate in one case, entire in the other. Results from the cross confirmed Mendel's forecast.

Besides these simple cases, scientists have experimented with correlated characters, characters reacting upon one another, types presenting two dominant and two recessive characters allied, crosses between pure dominants and impure dominants, etc. Leaving aside such special and complicated cases, we will endeavour to estimate the theoretical importance of Mendel's laws.

The existence of independent characters which never blend with one another and may vary independently, the existence of character-units, is the conclusion Mendel himself drew from his experiments. The germ cells contain, he thinks, concrete representatives of those characters which, at the time of cross fertilisation, combine in such a way that the representatives of one character only become active. The presence of representatives of the other characters in the hybrids' germ cells reveals itself only in the offspring.

2A. LANG. Ueber die Mendelschen Gesetze, Art und Varietätenbildung, Mutation und Variation, insbesondere bei unsern Hain-und Gartenschnecken. (Verh. schweiz. Naturf. Ges. 1905, Luzern.) 
The hybrid gives rise to two categories of germ cells, equal in numbers and representing potentially the two contending characters, which accounts for the segregation of characters. Correns, rejecting Mendel's explanation, supposes that the segregation originates in the cleavage which occurs at the time of maturity.

Whatever the cause of segregation may be, the very fact of segregation harmonises with the modern theories of representative particles; it supplies new evidence in support of Weismann's theories of development and heredity.

The Mendelian discoveries have also an important bearing upon the question of natural selection, especially as one of the antiselectionist arguments is based upon the statement that the effects of selection disappear in the course of several generations, particularly in cases of cross-fertilisation. The observations made by Mendel and other scientists prove that characters can perpetuate themselves without suffering any attenuation, and therefore the argument based on Galton's law collapses entirely. The Neo-Darwinians draw from Mendel's observations the same conclusion as to the persistence of characters.

In the third place the fact that new characters appear per saltum, and not through the accumulation of what Darwin calls slight variations, constitutes an ar- 
gument in favor of discontinuous variation and of De Vries' mutation theory.

For the exponents of the Lamarckian tendencies, Mendel's laws present a special interest. In a book published recently, "La Crise du transformisme," Le Dantec, the most orthodox of French Lamarckians, examines in detail the theory of mutation and devotes a chapter to inheritance as presented by Mendel. His main contention is that the continuity of evolution is the central point of transformism. He opposes resolutely the idea of representative particles and the Weismannian hypotheses. The Mendelian experiments, however, point to discontinuous variations and to characters which act apparently like real entities. Le Dantec interprets these facts as follows: "There are in every individual, two kinds of characters: first, mechanical, essential, or adaptive characters, necessary to life which result from a slow evolution and do not in any way confirm Weismann's theories. The other category of characters comprises ornamental characters, peculiarities of form, which may be ruled by different laws. 'The latter are without any importance as regards the evolution of the species. It is to this category that all the Mendelian characters belong and Mendelian cases are not universal but exceptional.

"In these exceptional cases, characters are really represented by some concrete element and there is a real discontinuity. But this discontinuity is due to 
some symbiotic microbe which determines characters corresponding to certain diatheses." 3 The representative particles are simply independent organisms, microbes, which are lacking in ordinary cases of mechanical characters but are superadded to the orum in other cases, and whose presence produces ornamental or descriptive characters. To interpret the process in this way is simply to substitute Pasteur's terminology for Weismann's without altering any of the facts, for as far as their definition and the properties attributed to them are concerned, representative particles and microbes are identical. The only difference between them is that, instead of being parasitic like microbes, representative particles are symbiotic, that is, live the life of the organism. The characters determined by them, however, serve no purpose in the formation of species.

Le Dantec interprets the Mendelian theory of heredity as follows: Two individuals of the same species but of different varieties are crossed; one of them is characterised by diathesis $a$, the other by diathesis $b$. The ovum from which the hybrid will issue is made up of the egg proper to the species under observation and of two microbes, one of which determines diathesis $a$, the other diathesis $b$. The individual born from that ovum will belong to the same species as its parents but will be endowed with a

¿La Crise du transformisme, p. 211. 
double diathesis; it will be a diathetic hybrid, a Mendelian hybrid. In certain cases the diatheses will exist simultaneously; in other cases (those especially observed by Mendelians) only one of them will manifest itself, as happens in cases of microbian antagonism.

The discontinuity of erolution is always due, therefore, to the presence or absence of a symbiotic microbe which determines one diathesis-character or another. "Mutation," Le Dantec writes, "can be accounted for in the following way: A sudden morphological change reveals a diathesis caused by symbiotic microbes introduced accidentally into the organism. When those microbes exist in regions where mutating plants grow, and especially when they are external parasites on these plants, it is easily conceived that traumatism or fecundation by a pollinic tube which crossed a polluted stigma, may inoculate into the bud or the ovum the new active factor." " 4 Let us remark that Le Dantec does not give this hypothesis as a final explanation of mutation whose causes he seeks elsewhere; he only offers it as an illustration.

No special interpretation is necessary, however, before conclusions can be drawn. The facts of Mendelian heredity are incontestable and there is no evidence that they are produced by some symbiotic element or are in any way abnormal. Mendel's laws hold good in a large number of cases; a larger number ${ }_{4}$ La Crise du transformisme, p. 212. 
of other cases are not ruled by these laws or are ruled by entirely different laws. Mendelian cases, like those observed by De Vries in the course of his experiments demonstrate, however, the existence of discontinuous variation. We may discuss the extent of this phenomenon, the part it plays in the evolution of species, but we cannot deny its existence. Besides, we fail to see how it could imperil the transformist view which does not prejudge the mode of variation (gradual or sudden) through which the transformation of species is brought about. 'This is why we cannot whare Le Dantec's fears nor consider Mendel's laws and the theory of mutation as dangerous heresies.

Mendel's observations also show that in spite of Galton's statements to the contrary, there are cases (Mendelian cases) when certain characters do not disappear. This, however, does not apply to all cases nor to all characters. Characters which are hardly perceptible at first and only become accentuated in the long run (the most interesting characters from the Darwinian point of view), do not lend themselves very well to experiments of cross-breeding which require deeply marked characters. Consequently it is useless to discuss the possibility of a universal application of the Mendelian deductions.

For reasons given elsewhere, we cannot accept the principle of representative particles. The very thought of concrete particles representing abstract 
notions is illogical. 'This is why the authors of representative theories have never offered any evidence based on experiments or observation, nor are they likely ever to offer any. We must therefore look elsewhere for an explanation of the independent appearance of characters and of all the other facts of heredity for which the representative particles seem, at first glance, to account so easily. 


\section{CHAPTER XIII}

\section{Transmission of Acquired Characters: Theoretical Controversies}

Importance of the question:- Evidence from daily observation.-

Darwin on the transmission of acquired characters.-Modern controversies.-Definition of acquired characters by Montgomery, Le Dantec, Weismann.--What the Weismannians reject.-An arduous problem.-Spencer versus Weismann; the papillæ of the tongue; the sense of touch; the degeneration of the fifth toe; seasonal dimorphism of butterflies; neuter ants and bees.

THE most important fact in biology, adaptation, 1 is accounted for at present either by natural selection of innate variations, or by the inheritance of acquired characters. Between the two theories there is an impassable chasm, and each of them places an absolutely different construction upon a multitude of other questions, such as the process of ontogenesis, regeneration, heredity, etc. We may add that upon the solution of the problem, depends the solution not merely of many biological questions but of many moral and social questions as well.

The inheritance of acquired characters has become 
the burning question in transformism, and for very good reasons. If the modifications undergone by the organism under the influence of its mode of life are transmitted to the offspring, the evolution of species is easily explained without the help of elaborate systems, of auxiliary hypotheses or of logical subterfuges.

This is the first explanation suggested by all the facts known about the influence of the use or disuse of organs and about the action of the environment on the structure of individuals. We observe every day that the parts of the body which are particularly active become more developed and that, on the other hand, the organs which are seldom used become atrophied. The strong muscles of a blacksmith's arm, the "horny hands" of a workingman, the small hands of individuals whose ancestors never did any manual labour, the development of certain faculties by constant use, the stamp which certain professions put upon a man's physical appearance, are familiar to everybody, and though there is no absolute evidence that such characteristics can be transmitted hereditarily, there has existed in all times a universal belief in their heritability. In the animal kingdom, the long legs of wading birds, the neck of the giraffe, the degeneration caused by disuse in cases of parasitism, the blindness of animals living in darkness, the atrophy of the whale's forelimbs, are so many examples prov- 
ing apparently that peculiarities determined by life conditions are hereditary.

This idea is the basis of Lamarckian transformism and Darwin has recourse to it whenever natural selection does not seem to furnish him with an adequate explanation for certain facts. For we must not forget that Darwin accepts explicitly the heredity of acquired characters and the name of Darwinian assumed by scientists who deny it is a misnomer. Many quotations from "The Origin of Species" support our statement:

"Changed habits produce an inherited effect as in the period of the flowering of plants when transported from one climate to another. With animals the increased use or disuse of parts has had a more marked influence; thus I find in the domestic duck that the bones of the wing weigh less and the bones of the leg more, in proportion to the whole skeleton, than do the same bones in the wild duck; and this change may be safely attributed to the domestic duck flying much less, and walking more, than its wild parents. The great and inherited development of the udders in cows and goats in countries where they are habitually milked, in comparison with these organs in other countries, is probably another instance of the effects of use. Not one of our domestic animals can be named which has not, in some country, drooping ears; and the view which has been suggested that the drooping is 
due to disuse of the muscles of the ear, from the animals being seldom much alarmed, seems probable." 1

The heredity of acquired characters, taking this term in its broadest sense, was almitted by all naturalists until the relatively recent time when Weismann reopened the question. Since then naturalists have taken sides either with the Neo-Darwinians or with the Neo-Lamarckians. At the present day, the majority seems to be in favour of non-heredity, especially as De Vries' new theory of mutation (see Chapter XX) furnishes a new explanation that is perfectly acceptable to those whom Darwin's theory of slight variations does not absolutely satisfy. Many naturalists, however, have implicit faith in the heredity of acquired characters.

The question at issue is really a double question: I-Are the facts cited by the Neo-Lamarckians to prove that acquired modifications are inherited, real facts and have they been interpreted properly? 2-Can there be any hereditary transmission, in other words, is there a processus by which an organic modification due to the influence of the environment or to a reaction against the environment can be transmitted to the germ cells and reappear under the same form in the sexual product?

It was very necessary to formulate an accurate definition of the terms "innate characters" and "acquired

1 Danwis. The Origin of Species, Chap. I, p. 10. 
characters" and to draw a sharp line between cases of transmission. Weismann deserves much credit for having, by his criticisms, compelled scientists to make a more searching analysis of the question and more precise observations of the facts.

By "acquired character" is meant such character as, in an individual when compared to its parents, is not only new (for all innate variations would answer to this description) but does not originate in the ovum nor in the spermatozoon. The word is used in a broader sense by Montgomery, and in a more restricted sense by Weismann.

According to Montgomery, the problem is not well formulated. We should not ask whether acquired character's are transmissible; we should ask what acquired characters are transmissible. In every fact of the transformation of species, at every stage of the changes undergone by species in the course of their existence, we find incontestable evidence that characters acquired during the life span of the race have been transmitted hereditarily. Every step forward in the transformation of species is a new acquired character. Either we must suppose that the entire development of beings was determined from the beginning by the nature of the ancestral germ plasm, so that phylogenesis were merely the carrying out of the original plan (and then we must admit that variations appear anatomically in the germ plasm); or we must sup- 
pose that variations are only a manifestation of the energy of the germ plasm combined with the influence of the environment. ${ }^{2}$ 'The latter hypothesis seems to be the rational one, for the germ plasm is not independent anatomically nor physiologically from the rest of the organism, and besides, to admit the appearance of variations without cause would be as absurd as to admit the possibility of spontaneous generation.

All variations are therefore acquired, and we are not justified in designating exclusively as acquired those which appear at a later period of the individual's life and whose appearance we can personally observe.

Le Dantec, a Neo-Lamarckian, gives a definition of acquired characters which makes the discussion of their hereditary transmission apparently useless.

"By acquired characters we must only designate definitive variations which do not disappear with the cause that produces them. It is only in the case of such truly acquired characters that it is worth while finding out whether they can be transmitted by inheritance."

'These truly acquired characters never remain purely local phenomena for "the organism cannot be affected except by general modifications" and every local influence necessarily generates a certain disturbance in the general equilibrium, which spreads as far as the repro-

2 Tr. H. Moxtgomery. The Analysis of Racial Descent in Animals, Chap. V: Variations and Mutations. 
ductive elements and consequently affects the future progeny. An acquired modification is, so to speak, "included in the patrimony" and consequently transmitted to the next generation.

How can we, however, account for the fact that some acquired modifications, purely local, such as mutilations, are not transmissible? Le Dantec overcomes the difficulty in the following way: "Let us suppose that a man has lost one arm. As no acquired character could be purely local, what determines the new form assumed by the organism after the ablation of the arm, is not the ablation itself, but the form assumed by the skeleton. This form is permanent. If being one-armed is a local character, it is not an acquired character according to our definition. We call acquired character a character determined by the direct influence of a cause located outside of the individual, and which persists after the cause has ceased to exert its influence. In the case of the maimed individual the cause of his mutilation endures; it is the ablation of the arm bones. We cannot say therefore that when he lost one arm the man acquired a local character. In other words we cannot admit that a character has been really acquired unless it is included in the patrimony, unless it is transmissible." 3

Le Dantec's view of the matter differs widely from the accepted view. To the majority of people, the ${ }^{3} \mathrm{LE}$ DaNTEc. L'unité dans l'être vivant, 1902, pp. 57-64. 
cause that made the man one-armed was the knife thrust which severed the lower segment of the arm, and the effect is the absence of that lower segment. This constitutes therefore a character which persists after its cause has disappeared (an acquired character according to Le Dantec's definition), which, however, remains purely local and is not transmissible.

Le Dantec argues his way out of the difficulty by saying that the cause of the mutilation is the absence of the bone of the amputated segment and that the effect is the conformation assumed by the fleshy parts of the stump. The cause is therefore as permanent as the effect and the one-armed character is not an acquired character since it does not outlast its cause. It follows logically that it is not transmissible.

This is a very artificial way of solving the difficulty. The question as to what is the real cause of the infirmity, the temporary act of amputating the arm or the permanent absence of the arm is purely academic, and besides, this attempt at demonstrating through logical subtilities the heredity of acquired characters does not bring us nearer the solution of the problem. Let us suppose that Le Dantec's definition is accurate and that no character should be called an acquired character unless it constituted a modification transmissible hereditarily. We are not further advanced thereby and besides, we are now in need of a new term to designate all the characters, inherited or not in- 
herited, which wehavethusfar called "acquired characters."

Montgomery's definition goes nearer the root of the matter. He questions whether the difference between modifications produced during the development of germ cells and later modifications is so very essential. Weismann himself, when he introduced germinal selection as a factor of development had to admit that the victory of determinants in their struggle for life was directly influenced by the supply of certain substances and by nutrition, a view somewhat similar to Montgomery's.

If the term "acquired characters" assumes in Montgomery's almost Lamarckian conception a very broad meaning (in accordance with his interpretation of the process by which those characters are transmitted hereditarily), the definition given by Weismann and his followers, which presupposes the independence of the germ plasm from the rest of the body, is too narrow and too exclusive. The only characters which Weismann considers as really acquired are those which, appearing at first in one part of the body and due to the action of some external condition, afterwards influence the germ cells. He thus excludes all cases in which an action is exerted simultaneously on the soma and on the germ cells, and he challenges the Lamarckians to prove that this condition obtains in the cases they instance. Let us give an example: 
"Paul Bert tried to acclimatise some Daphnæ to salt water by gradually adding salt to the aquarium. At the end of forty-five days, when the water contained $1.5 \%$ of salt, all the adults had died, but the eggs in their brood chambers survived, and the new generation arising from these flourished well in the salt medium." 4 Packard, a Lamarckian, who cites this case from Cuenot, sees in it evidence of the heritability of a modification, but Thomson, a Weismannian, regards it merely as an instance of the direct modification of the germ cells or of the embryos.

The line is very hard to draw in the majority of cases and the evidence demanded from the Lamarckians is difficult to produce, for the two actions are not easily dissociated in real life. And even if this could be done, it would only have a theoretical bearing upon Weismann's theory of the germ plasm; it would have no bearing at all upon the question of the heredity of acquired characters as a factor in the evolution of species.

This distinction only assumes a certain importance in the case of characters resulting from the use or disuse of organs and generally localised. These characters are considered as very important by the Lamarckians who have not been able thus far to account for them. As far as all other cases are concerned, it matters very little whether a modification is produced 4 J. A. Thomson. Heredity, p. 189. 
directly and simultaneously in the germ and the soma cells or in the soma cells first and in the germ cells afterwards.

"Another distinction, not less subtle and quite as useless, for the explanation of evolution, is that made by certain Weismannians, between the possible inheritance of a particular modification and the possible inheritance of indirect results of that modification, or of changes correlated with it. 'Thus for example, the occupation of parents can exert an influence on their children, but inasmuch as the children's structural modifications are not similar to their parents' we will not speak of the inheritance of acquired characters." 5

The Weismannians also contend that an acquired character must be transmitted in its totality from parent to offspring. If the offspring presents a certain feature which is not absolutely identical with that observed in the parent, although it may affect the same tissue or the same organ, the Weismannians class it with correlative characters and consider its transmission as quite unimportant.

This limits the debatable points more and more, although in an artificial and arbitrary way. These restrictions do not throw any light on the subject but they add almost insuperable difficulties to every experiment which might prove conclusive. How can we 5 J. A. Thomson. Heredity, p. 190. (Thomsox admits to a certain extent the heritability of these characters.) 
create conditions such that the character under observation will answer all the requirements and, above all, how can we interpret phenomena over which we have no control, which we can merely observe when they appear, and which originate under conditions of which we are totally ignorant?

Weismann and the other systematic opponents of the Lamarckian theory challenge all the cases of transmission observed in unicellular organisms, such as microbian cultures modified by certain external influences (whose virulence, for instance, has been attenuated), and which transmit their new character to numberless generations. Those experiments, they say, mean nothing, for in unicellular organisms, germ plasm and soma plasm are not yet differentiated. This difference, however, is not very important and we must not establish a comparison between the reproduction of protozoa and that of metazoa, but between the cleavage of a unicellular organism and that of the ovum of a multicellular organism.

From one generation to another the ovum undergoes a large number of cell cleavages, while the unicellular organism undergoes only one, and it is quite possible that in the course of ontogenesis a modification can be transmitted by the ovum to many generations of cells, but disappear before reaching the end of its development. In other words, a modification may be hereditary and be transmitted as is the case 
with bacteria, although we find no trace of it in the adult organisms.

Such restrictions and reservations can only obscure and complicate the discussion of the cases cited in support of the transmission theory. Every time the transmission of an acquired character has been demonstrated, the systematic opponents of the transmission theory have declared that this character was not truly an acquired character. The only cases they accept as evidence are those in which the transmission of a character cannot be proved and in which the character might be considered as innate. And it is probably the difficulty encountered in finding cases which fulfil all the requirements, which is responsible for the strange fact that instead of presenting numberless examples, as we should expect if their contention were true, the Lamarckians present very few of them in support of their thesis, and always the same ones at that.

Both the Neo-Darwinians and the Neo-Lamarckians instance cases which can be accounted for by their respective theories. What complicates the discussion, however, and makes proof hard to furnish, is that each party demands that the other bring negative proof: the Neo-Lamarckians must prove that a certain modification cannot be due to natural selection; the NeoDarwinians must prove on the contrary that it cannot be due to the hereditary transmission of acquired char- 
acters. The gathering of negative evidence is no easy matter.

Spencer, who always held that the heredity of acquired characters was as incontestable as the hereditary transmission of any other racial or familial character, explains in one of his earliest works, his "Principles of Biology" (1864), that owing, not to the nature of the discussion but to the nature of the phenomena themselves, scanty evidence can be furnished of hereditary transmission.

"Changes produced in the sizes of parts by changes in their amount of action, are mostly unobtrusive. A muscle which has increased in bulk, unless the alteration is extreme, passes without remark. Such nervous developments as are possible in the course of a single life, cannot be seen externally. And if the changes of structure worked in individuals by changes in their habits are thus difficult to trace, still more difficult to trace must be the transmission of them: further hidden, as this is, by the influences of other individuals who are often otherwise modified by other habits, or may be due to natural or artificial selection." ${ }^{6}$ The heredity of acquired characters is to Spencer what the contrary thesis is to Weismann-a theoretical and logical postulate.

These two remarkable men entered into a very 6 Principles of Biology, Vol. I, p. $30 \%$. 
searching and inclusive controversy. ${ }^{7} \quad$ Spencer started it by criticising Weismann's statement that natural selection was the all-sufficient factor in the evolution of species. We reviewed elsewhere his most important arguments. We will only mention here the counterpart of the argumentation, that is, the discussion touching the heredity of acquired characters, a factor which Spencer, while he does not deny the effects of natural selection, believes to be as important as selection. "Natural selection or survival of the fittest is almost exclusively operative throughout the regetal world and throughout the lower animal world, characterised by relative passivity. But with the ascent to higher types of animals, its effects are in increasing degrees involved with those produced by inheritance of acquired characters; until, in animals of complex structures, inheritance of acquired characters becomes an important, if not the chief cause of evolution." 8

The heredity of acquired characters is always a factor either alone or in combination with natural selec-

7 H. Spexcer. Inadequacy of Natural Selection (Contemporary Review, Feb., March and May, 1893); A Rejoinder to Prof. Weismann (Ibid., Dec., 1893); Weismannism Once More (Ibid., Oct., 1891). WersMAxr: The All-sufficiency of Natural Selection (Ibid., Sept., 1893); The Effect of External Influence upon Development (The Romanes Lecture, 1894); Teue Gedanken zur Vererbungsfrage. Eine Antwort an Herbert spencer (1895).

8 Principles of Biology. Appendix B. Inadequacy of Natural Selection, p. 632 . 
tion; but for the transmission of characters, evolution would be incomprehensible; either acquired characters can be transmitted hereditarily or there is no evolution.

The question may be asked: what are the facts which prove the heredity of acquired characters? Since many organic modifications are hereditary we may logically answer that any modification may become hereditary. Those who contend that only certain modifications are hereditary are then welcome to bring proof. It is true that not every acquired character is inherited, but this is due to the fact that the farther back a character goes, the more deeply rooted it is, and that the more recently it has been acquired, the more easily it may disappear. This is why a character which has persisted for many generations is more likely to be inherited, while a character of recent origin disappears more quickly.

Spencer cites many cases which cannot be explained by natural selection nor by panmixia and in which the heredity of acquired characters must be the only factor. Take for instance the origin of the lingual papillæ. They have multiplied not because they are useful or necessary to life but because the tongue, during the process of speech or mastication, constantly comes in contact with various points of the oral cavity. The distribution of tactile discriminativeness on the surface of the body shows that tactile corpuscles are 
not more numerous in places where they would be most useful ' for they should be more numerous on the dorsal surface, where they could warn the individual of danger, than on the abdominal surface) but in places where the body comes most frequently in contact with external objects. Every one knows to what extent the sense of touch becomes developed in the blind or in compositors, etc. The degeneration of the little toe in man is an acquired character which has become hereditary. It is due to bipedal walking which, in order to balance the body, develops almost exclusively the inner side of the foot.

Weismann's answer to the foregoing is to the effect that, while the discriminativeness of the tongue is of little use to modern man, it may have been very useful to his ancestors and, therefore, has been affected by natural selection. Spencer answered that this was a case in which panmixia, otherwise so active, should have intervened and allowed this discriminativeness to. dwindle away. As far as the degeneration of the little toe is concerned, Weismann opposes to Spencer's hypothesis another hypothesis: this degeneration is an innate, not an acquired variation,

The reaction of organisms against their environment is, according to Weismann, predetermined long in advance, for in the struggle between determinants, germinal selection allows those determinants to survive which present the greatest sensitiveness to their spe- 
cific stimulus, and it is this sensitiveness which determines the ulterior reactions of the organism.

It is not a somatic change brought about by the activity of a certain function which constitutes the primary fact. On the contrary, a change in the soma plasm is always preceded by a change in the germ plasm. 'The modified form resulting from the struggle between parts, determines and precedes the modified function; this is the absolute antithesis of the Lamarckian maxim that "the function creates the organ."

The influence of the environment can be only indirect. When certain animals assume a different colouring in a changed environment, when for instance a butterfly, the $V$ anessa, presents a different pigmentation in different seasons, or when certain arctic animals turn white in winter, this dimorphism is not due to the immediate action of external conditions but to a more complex process by which natural selection supplemented by germinal selection produces a protective variation.

A more accurate explanation could be given of these facts. Certain insects breed twice a year, once in summer and once in the fall and their caterpillars take on a different colouration in each season. For instance, the summer caterpillars of the Lycana pseudargiolus living on the white blossoms of Cimicifuga racemosa are white, while the fall caterpillars living 
on the yellow blossoms of Actinomeris squamosa are green or greenish yellow. Weismann attributes this phenomenon to reserve determinants which he creates for the express purpose of explaining seasonal or sexual dimorphism.

"The germ," he said, "must thus contain all the primary constituents (Anlagen) of these different forms; and a stimulus produced by the kind of food, by light, by warmth, or by some other external influence, serves sooner or later to start the development of one kind or another, as well as to decide which kind it shall be." 9

What enables those stimuli to exert their action, is the previous existence of individual differences between primary constituents, of a preformed adaptation, due to natural selection. The determination of the sex in bees and ants is considered by Weismann as good evidence for it. The sexless character of the workers is not directly due, as the Lamarckians think, to the larvæ's insufficient supply of food, but to the presence in the ovum (as a consequence of selection) of two kinds of determinants, one corresponding to a rudimentary, the other to a perfect ovary, the former developing when the young larvæ receive insufficient food. Nutrition certainly plays an important part but only in an indirect way. Scarcity of food is the stimulus which causes certain determinants to emerge o Weismans, The Romanes Lectures, 1894, pp. 52, 53. 
from their dormant state and which provoles the development of rudimentary ovaries and of all the other secondary sexual characters which distinguish the workers from the queen.

We hardly need to point out how arbitrary Weismann's hypotheses become (for instance his statement that insufficient nutrition acts as a stimulus for the determinants of barren ovaries) when he endeavours to make his theory fit the real facts.

Sexual dimorphism in ants and bees and the characters of the workers constituted one of the capital points in the controversy between Weismann and Spencer. Weismann contended that the degeneration of the ovary and the various characters depending upon it could not result from disuse, since the workers do not breed and therefore cannot transmit those characters to any off spring. Spencer answered that the workers were only females with arrested development. This is proved by the fact that the bee or ant communities can in an emergency breed queens by overfeeding larvæ, which under ordinary conditions would have developed into workers. The gradual growth of social life among insects leads one to suppose that all their other characters and also their instincts were acquired before those insects became specialised, when they lived an isolated life or belonged to homogeneous communities.

Many other cases were brought forth in the course 
of the Spencer-Weismann controversy, which we have outlined very superficially. Neither Weismann nor Spencer scored a decisive victory; worse yet, Weismann by resorting too often to forms of speech such as "Why could we not suppose?" imparted to this debate the character of a meaningless word tournament. 


\section{CHAPTER XIV}

\section{Transmission of Acquired Characters. Observations and Experiments}

Experiments instituted to ascertain the hereditary transmission of acquired characters.-Wutilations and disease.-BrownSequard's guinea pigs.-The adaptation of living beings to external conditions.- -Variations produced in butterflies by temperature and food: experiments made by Kellogg and Bell, Pictet, Fisher.-Influences producing local modifications: facts instanced by Cunningham, Hyatt, Cattaneo.Transmission of psychical characters such as a talent for music.-How acquired characters may possibly be transmitted.-A chemical theory; the theories of A. Gautier, Le Dantec and Montgomery.-The proper method to follow.

W ANY experiments have been instituted for the 1 purpose of demonstrating the heredity of acquired characters and much evidence has been presented in support of the heredity theory. This evidence is not of uniform value and is more or less open to criticism; very little of it is convincing, probably on account of the difficulties we pointed out in the preceding chapter, difficulties of experimentation and, above all, of interpretation. We will review the vari- 
ous cases offered as evidence, beginning with the most doubtful ones.

One of the simplest and easiest experiments consists in performing a mutilation and observing its hereditary effects. The results of such experiments have supplied the opponents of the transmission theory with their most powerful arguments, as mutilations even though performed on several generations are never inherited by the off spring.

It is the custom in many countries to dock the tails of cats and dogs, but these animals never bring forth any tailless progeny. Weismann tried the same experiment on several generations of rats without any result. Every one knows that amputations, accidental injuries, like fractures or scars, are not transmitted; neither are the mutilations customary among certain races, such as circumcision among Hebrews and Moslems, the deformation of the feet in Chinese women, the piercing of nose or ears in sarage tribes, etc., which have not become hereditary in spite of having been practised for numberless generations.

It might not be possible to draw such definitive conclusions in the case of mutilations or lesions affecting the whole organism, especially the nervous system, but it can be said that, judging from the experiments made thus far, mutilations are not hereditary. On this score the Anti-Lamarckians triumph easily. The theory of the transmissibility of acquired characters, 
however, does not claim that all characters are transmissible; its exponents are satisfied if some characters are prored to be transmissible.

Strange as it may seen, diseases, non-congenital but acquired, cannot furnish evidence for or against the idea of transmission, for the cases cited admit of too many different interpretations.

Not only is it very difficult to determine whether a disease is congenital or acquired, but in the case of bacterial diseases the pathogenic microbe can be transmitted directly in the germ, and this does not constitute a case of hereditary transmission. Many diseases whose causes are unknown may some day be traced to a microbian infection. In other cases when the appearance of the disease synchronises with the production of a certain toxin or is determined by a certain chemical phenomenon, the relerant substance may pass directly from the organism of the parent into that of the off spring. Sanson ${ }^{1}$ cites the case of a flock of sheep which, after staying in a damp location, contracted an articular disease. Although the fiock was later transferred to a dry location, several generations of the sheep suffered from that disease until all the affected individuals were replaced by other individuals of the same race which had not been exposed to the same influences. This was a case of ${ }_{1}$ SANsov. L'Hérédité normale et pathologique (1893). 
hereditary transmission of an acquired character, but as the disease may have had a chemical or microbian origin, this case is open to the objections we mentioned before.

A classical example cited and discussed in all the literature on the subject is the case of Brown-Sequard's guinea-pigs. For a number of years, from 1869 to 1891, he experimented on thousands of these animals and determined in them a certain form of epilepsy through certain operations on the nerves, cross hemisection of the spinal cord or section of the sciatic nerve. In certain cases the young were affected with the same form of epilepsy. The results of these experiments have since been confirmed by other scientists and brought into dispute by others.

Weismann makes the suggestion "that, during or after the operation, some kind of pathogenic microorganism might easily reach the wounded parts, and there excite inflammation which may extend centripetally to the brain. ${ }^{2}$ There is no evidence that such a supposition is well founded but other objections have been presented. Guinea-pigs are strongly predisposed to epilepsy and therefore the results of Brown-Sequard's experiments might be a pure coincidence or they might be due to the transmission of a chemical substance. This last suggestion was made

2A. Weismaxn. The Evolution Theory, Vol. II, p. 67. 
by Voisin and Péron, ${ }^{3}$ who explain that in epilepsy a toxin is produced which affects the sexual cells.

In other words no definite conclusion can be drawn from these experiments as to the transmissibility of acquired characters. Certain modifications, incontestably due to some exterior influence, are observed to reappear in the offspring. Plants, for instance, can adapt themselves to a different climate. Those plants sometimes present modifications which their ancestors acquired progressively in the course of many generations; cherry trees acclimatised in Ceylon acquire perennial foliage (case cited by Detmar). But in all similar cases, the causal factor is still exerting its influence, and it is impossible to determine the part played by heredity in making new characters constant.

There are other cases, however, in which modified plants taken back to the regions where they originated retained for several generations the character acquired under the influence of the previous change of climate.

In the animal world there is the case of hereditary transmission observed among Daphnæ and which we mention elsewhere. Here is another case: in the course of experiments to determine the influence of salt in rarious quantities on certain aquatic animals, Ferronière transferred a Tubifex from fresh water

3 Archives de Neurologie, 1892-93, and Vorsin: L'Epilepsie (Paris, 1897, p. 125-133), quoted by J. A. Thomson: Ileredity, p. 235.

4 Etudes biologiques sur la forme supralittorale de la Loire-Inférieure, 1901. 
into sea water. The animal became acclimatised and presented certain modifications (loss of hair, etc.) which became more deeply marked in the following generations. The most important fact, however, was that after several generations the Tubifex had become absolutely unable to live in its original environment. In this case the influence of the environment seemed to continue after the environment had changed.

More systematic and convincing experiments have been made with a view to determining the variations produced in the caterpillars of some butterflies by different kinds of environment. Butterflies are especially easy to study; therefore many scientists have placed caterpillars under different conditions of temperature, light, food, etc., and observed the influence of those various factors on the adult and its progeny.

Kellogg and Bell fed the larva of Bombyx mori, or silkworm, varying quantities of nulberry leaves or replaced mulberry leaves by lettuce leaves. ${ }^{5} \quad$ A scanty allowance of food produced a decrease in the size of the imago and that decrease was apparent even in the third generation, although the larvæ of the first and second generations had received a normal quantity of food. After two or three successive generations were kept on a low diet there arose a dwarf breed of silk

5 Variations induced in larval, pupal and imaginal stages of Bombyx mori by controlled varying food supply. (Science, XVIII, 1903, pp. 741748.) 
worms whose butterflies only attained the size of microlepidopters. Scanty nutrition or change to a less favourable kind of food also retarded the various physiological processes, such as the metamorphosis, and lowered the reproductive powers. Those characters were transmitted to three generations after which the observations were interrupted by the death of all. the butterflies.

A hereditary influence is apparent in this case which, however, could be rejected as evidence, for the modifications transmitted are too general and amount really to a weakening of the organism. It is not so much that characters due to the influence of the environment have been transmitted but that weak parents have bred weak offspring whose weakness could not manifest itself except through those very characters.

While Pictet's experiments are similar, more accurate conclusions can be drawn from them. They do not bear merely upon a general condition of health but upon one single physiological character. The larvæ of every species of butterfly feed on certain leaves exclusively and cannot easily accustom themselves to any others. To some larvæ which feed usually on oak leaves, Pictet gave lettuce or walnut leaves; they adapted themselves to the new food with difficulty, but after the adaptation had become perfect, they produced butterflies whose larvæ-progeny accepted the new food without repugnance. There occurred evi- 
dently some modifications, probably a chemical modification, which was transmitted to the butterflies and, through their eggs, to the new generation of larvæ.

The larva of Ocneria dispar feed habitually on oak or birch leaves. Pictet fed them walnut leaves to which they finally became accustomed although with difficulty. The butterflies produced by those larvæ presented changes in the colouration and pattern of the wings which became accentuated when several generations of larvæ were kept on the same diet. In the normal state the male is ash grey or brownish, with four zigzag lines across the upper wings; the female is lighter coloured, being greyish white or yellow, with a less distinct pattern. By feeding the larvæ walnut leaves, one produces in the first generation smaller individuals of lighter hue, with fainter pattern; the females become almost colourless. If the diet remains unchanged these characters reappear in the second generation.

In another experiment (Pictet's sixth experiment), the hereditary influence persisted in spite of a return to the normal diet. The first generation was fed on walnut leaves and presented the characters described above; the second and third were fed on oak leaves but the characters due to feeding on walnut leaves persisted. In the third generation the female showed some signs of reversion to type such as slightly plainer markings. 
Pictet observed certain cases in which the insects had become so completely accustomed to walnut leaves that they finally reverted to their original type. This would indicate that a defective organic condition prevailed, resulting from an imperfect adaptation, and that the characters observed were mere symptoms of that weakened condition. The fact that walnut leaves produce a lighter colouring and obliterate the pattern of the wings seems to point to the same conclusion. Other experiments, however, show that a change in diet does not always produce that result, and may on the contrary deepen the colouring and make the markings more distinct. This occurred when Pictet fed his larvæ esparcet and dandelion. He also combined the various abnormal diets by first feeding the larvæ walnut leaves and then keeping the next two generations on esparcet. The characters due to walnut leaves persisted in spite of the change to esparcet.

We can therefore suppose that there was in this case a mere weakening of the organism. While there is no positive proof of this, a doubt can be entertained as to whether Pictet's experiments prove the transmissibility of acquired characters.

Fisher's experiments, also on butterflies, are less open to criticism. He concentrated his attention upon the influence of temperature. Pupæ of Arctia caja were exposed to a very low temperature, $8^{\circ}$ centigrade; the butterflies showed certain abnormal modi- 
fications in pattern and colouring and even in the shape of wings and legs. Fisher cross-bred them, raising the pupæ of the second generation in a normal temperature. Still, many of the hybrids presented some of the characters produced by a low temperature.

In this case distinct characters were transmitted to the offspring, for a modified wing is not merely a symptom of a defective condition. Here we have a bona fide example of hereditary transmission of a character acquired under the influence of the environment.

And yet, uncompromising Anti-Lamarckians would reject this evidence, for there is no proof that the action of a low temperature did not exert itself simultaneously on the soma cells and on the germ cells. We have already stated that this objection did not seem to us to carry any weight as far as the determination of the factors of evolution went, but as it has a certain importance from the point of view of the theories of heredity, and as it is always brought forward in controversies of this kind, we must find other examples which are not open to this criticism.

One of the most accurate and most remarkable experiments was made by Cunningham on flat fishes, flounders and soles. Those fishes are asymmetrical, one side of their body being coloured, the other uncoloured, and both eyes being on the same side. This curious conformation is due to the fishes' mode of life. Symmetrical and bilateral when young, they later on 
fall to the bottom and remain on one side the rest of their lives. The side on which they rest being deprived of light remains uncoloured. At the same time the eye on the lower side passes gradually around or through the forehead to join its fellow on the upper side. Cunningham took young fish two-thirds of an inch or so in length, but having begun to undergo their metamorphosis, that is, already accustomed to lying on one side. The pigment was already abundant on the upper side while the lower side remained uncoloured. He put those fish into an aquarium lighted from below by means of mirrors and covered with an opaque lid, shutting off all light from above. Several other fish taken from the same school were kept under normal conditions for comparison.

A month and a half after Cunningham examined the two lots and found very little difference between them; in the one as in the other the lower side was greyish white. Pigment did not appear in the fish under observation, although they were placed under conditions which should have caused it to appear. A certain distribution of pigment cells determined in the ancestral series by external conditions was maintained by heredity.

Later on, however, actual conditions seemed to assert their influence. Two months afterward, when the death of the fish put an end to the observations, Cunningham noticed in a number of individuals a few 
black and yellow pigment cells at the base of the dorsal fin and on the lower side, and two longitudinal stripes extending as far as the head. The normal fish did not present any pigmentation on the lower side of the body.

This experiment appears conclusive. In this case one cannot speak of a general condition, nor of transmission of a chemical substance, nor even of a simultaneous action on the germ and soma cells. How could the germ cells be affected by the absence of light? A character incontestably acquired and exclusively somatic has consequently been transmitted hereditarily. And yet we must state, not because the arguments presented have any value, but in order to show how far prejudice may go, that the Anti-Lamarckians find reasons for rejecting this evidence. Th. H. Morgan addresses to Cunningham the following criticism: "It is not shown that if the loss of colour on the lower side had been the result of the inheritance of an acquired character, the results seen in Cunningham's experiment would follow as a consequence." " To give some weight to his criticism Morgan should tell us how things should have turned out in this case. Since he failed to do so, we can but accept Cunningham's conclusion, for no other interpretation of his observations seems plausible. Morgan also offers another explanation of the phenomena

- Evolution and Adaptation, p. 258. 
observed by Cunningham: "If, on the other hand, we suppose the difference in colour of the two sides to have been the result of a germ-variation, we need only suppose that this was of such a kind that the colour of the under side is only in a latent condition, and if an external factor can cause a reaction to take place on the light side, it is not surprising that this should call forth the latent colour patterns. The result can be given at least a formal explanation on the theory that the original change was a germ-variation." 7 It is very difficult however to conceive how a germ-variation, which is not controlled by the direct influence of the environment, should have coincided precisely with the absence of light, a factor which generally produces discolouration, and how, furthermore, that accidental variation could have affected the whole lot of fishes. Why seek such a complex explanation when the facts suggest naturally a much simpler one?

One of the best examples of transmission of an acquired character is supplied by $\mathbf{A}$. Hyatt, one of the foremost exponents of Neo-Lamarckism, who has made a special study of certain cephalopods of which only one species, the Nautilus, has survived.

Since their first appearance in primary strata, the shells have successively assumed many different shapes: the straight beehive shape (orthoceran shells), then a curved shape (cyrtoceran), which becomes more

7 Evolution and Adaptation, p. 259. 
and more accentuated until it forms a spiral, whose whorls are at first very loose (gyroceran shell) and then coiled closely (nautilian shell). Later, those shells undergo the opposite evolution. Owing to a kind of degeneration, the whorls uncoil, and when the snails are on the point of becoming extinct, the shells revert to the curved or even to the straight shape. During the upward evolution, however, as the whorls become tighter and tighter, each whorl imprints itself upon the next and smaller whorl, producing a characteristic furrow or "impressed zone." Hyatt demon- . strated through a series of experiments that the impressed zone had a purely mechanical origin. This impressed zone, which in the adult is due to mechanical causes, is also apparent in the larval shell at a stage of growth in which no effective pressure has yet been exerted, and the earlier the geological strata are, the earlier the impressed zone appears in the larvæ. ${ }^{8}$ This is a perfect example of a purely local influence affecting the offspring, an example which the many and accurate observations taken by Hyatt made indubitable.

Le Dantec, who takes Hyatt's experiments as evidence of the heredity of acquired characters, states that the impressed zone produced by the pressure of whorl upon whorl persists in the degenerated and

8 A. Hyatr. Phylogeny of an Acquired Characteristic. (Proceed. Amer. Philos. Soc., Vol. XXXII, 1893, pp. 349-616.) 
straightened-out shells. Le Dantec is certainly mistaken, for Hyatt in his description of the degenerated shells says that they become deformed, smaller and smoother, that their coils assume a more cylindrical shape and that their impressed zone disappears. ${ }^{9}$ Hyatt mentions somewhere the absolute similarity between the degenerate adult shells and the original straight shells, which excludes the existence of an impressed zone in the former.

Our last example will illustrate the effects of use and disuse of organs. Cattaneo made a study of animals which for countless ages have been domesticated, horses and camels, and he suggested, after Buffon, that the camel's humps and the callouses on their knees were due to the loads that are placed on their backs and to the kneeling attitude they are made to assume while being loaded. He mentions that the famous traveller Prjevalsky killed in Central Asia two wild camels or rather two camels having reverted to the wild state, which had no callouses and whose humps were twice as small as the normal ones. Humps and callouses are, as we know, hereditary in camels and are not acquired by every new generation.

Another author, Ritter, described upon the authority of a Turkish geographer of the seventeenth century, camels having run wild and whose humps were hardly noticeable. Certain drawings from Nineveh and ๑ A. Hrate, loc. cit., p. 337. 
Babylon also represent camels with humps smaller than those of the modern animals. An observation of the same order, cited by Cattaneo, was reported by Fogliata. A female ass, which had long been used as a pack animal, presented on her back a large adipose protuberance corresponding to the area covered by a pack saddle and due to the pressure of the saddle. That female mated with a normal male and bore a young which presented exactly the same peculiarity. ${ }^{10}$ However striking these isolated cases may be, they are not as convincing as the observations of a more general character we cited above, for they may have been due to a mere coincidence.

Many of those cases are proof against the usual objections raised by the strict Anti-Lamarckians. They cannot be explained by direct infection through the germ, nor by possible transmission of a chemical substance from parent to offspring, nor by simultaneous action of an external factor on germ and soma. The characters involved are purely somatic, strictly localised, and due to influences which cannot bear upon the organs of reproduction. Examples of this kind prove that certain acquired characters can be transmitted.

Among other characters acquired through use, we $10 \mathrm{G}$. Cattaneo. Le gobbe e le callositá dei cammelli in rapporto colla quostionè dell'ereditarieta dei carratteri acquisiti. (Rend. Ist. Lombardo, XXIX, 1896.) 
may mention psychical characters, instincts, etc., which occupy a very particular place and seem to be more evidently hereditary than some others. This is what Spencer has to say upon the heredity of musical aptitudes: "It is very questionable whether, taking the musical career as a whole, it has any advantage over other careers in the struggle for existence and multiplication. Still more if we look back to those early stages through which the faculty must have passed before definite perception of melody was arrived at, we fail to see how those possessing the rudimentary faculty in a somewhat greater degree than the rest would thereby be enabled the better to maintain themselves and their children. There is no explanation but that the habitual association of certain cadences of speech with certain emotions, has slowly established in the race an organised and inherited connection between such cadences and such emotions; that the combination of cadences, more or less idealised, which constitutes melody, has all along had a meaning in the average mind, only because of the meaning which cadences had acquired in the average mind; and that by the continual hearing and practice of melody there has been gained and transmitted an increasing musical sensibility. Confirmation of this view may be drawn from individual cases. Grant that among a people endowed with musical faculty to a certain degree, spontaneous variation will occasionally produce 
men possessing it in a higher degree; it cannot be granted that spontaneous rariation accounts for the frequent production, by such highly endowed men, of men still more highly endowed. On the average, the children of marriages with others not similarly endowed, will be less distinguished rather than more distinguished. The most that can be expected is that this unusual amount of faculty shall reappear in the next generation undiminished. How then shall we explain cases like those of Bach, Mozart, and Beethoven, all of them sons of men having unusual musical powers who were constantly exercising those powers and who greatly excelled their fathers in their musical powers?" 11

Refuting Spencer on this special point, Weismann recognises that natural selection could not develop musical aptitudes, but he denies the progressive evolution of musical genius, thereby avoiding to admit that this is a case of heredity of acquired characters.

He admits that musical aptitudes are as developed in the best gifted sarages as in our modern composers, the only difference being that musical art has progressed more in civilised peoples and that certain individuals possess a keener sensitiveness.

To the facts advanced in favour of the Lamarckian thesis, Weismann and his followers oppose neither a different interpretation, nor criticisms upon the ob11 Principles of Biology, Vol. I, pp. 311-312. 
servations and experiments, but their general postulate, the theoretical impossibility of the transmission of such characters. We have explained elsewhere how their thesis of the distinction between soma and germ plasm precluded all idea of transmission.

Our present knowledge of the mechanism of heredity does not enable us to refute Weismann's assertions positively. For instance, we do not know exactly how the growth of the camel's callouses, due to friction, can influence the germ cell so as to produce in the offspring a similar modification.

It may be that the chemical composition of the protoplasm, very little known yet, will some day give a solution of the problem. For the present we must confine ourselves to very general and perhaps vague considerations; the most important thing, however, is to point out a method to follow. We will therefore present once more a thesis developed in another work of ours ${ }^{12}$ and suggested to the author by Sachs' theory of "formative substances." What distinguishes the ovum from the other cells of the organism, is the fact that in the course of embryogenetic development, the cells to which it gives rise, all alike at first, become gradually differentiated and specialised and lose when specialised the faculty of creating an entire organism, while the germ cells retain that faculty. This difference seems to preclude the possibility for the ovum 12 Yves Delage. L'Hérédité, etc., pp. 899-843, 1903. 
of being influenced by any modification produced in specialised parts of the organism and also the hereditary transmission of acquired characters. If we analyse it closely, however, we shall see that it is neither as deep nor as important as we might think.

Ontogenetic differentiation results from the predominance of certain substances in the various cells. Some of those substances arise de novo in those cells, others come from the ovum in which they originate. The ovum, like every other cell, possesses a certain contractility, a certain excitability, which, whenever a muscle or nerve cell becomes differentiated, develops considerably in those cells at the expense of other properties. If we admit that contractility and excitability are due to a certain substance or to a special structural disposition, it follows that this substance or this disposition must also exist in the ovum which possesses such properties in a lesser degree.

The same may be true of some other less salient characters, although we cannot say that it is true of all characters, for we would then return to the absurd idea of representative particles with all its complications and its improbability.

Those substances, however, do not represent the various functions of the organism, nor do they remain in the ovum in prevision of an ulterior development; they are merely substances necessary to the existence and the proper functioning of the ovum. 
Let us now suppose that a chemical substance is introduced into the organism or that the organism's mode of nutrition is modified. The resistance of the organism to modifications due to such causes is very great; still they may in the long run alter to a certain extent the composition of the blood. This is well illustrated by the action of poisonous and medicinal matters and in a lesser degree by the effects of ordinary and normal alimentation.

The substances which, after being introduced into the blood, modify in a specific way every category of organic cells, must also exert a certain influence on the sexual cells, for why should sexual cells constitute one sole exception to the general rule? If the ovum contains, as we suppose, the same substances which are found in other cells of the organisn, it will be susceptible to the influence of the same factors. Factors that have a stimulative action and favour the development of certain organs by determining in them the formation of a certain substance in larger quantities, will also increase the supply of that substance in the ovum and consequently in the organism which will originate in this ovum, and in which, therefore, the relevant organ will be more developed. The opposite phenomenon occurs when a substance causes decrease or degeneration of an organ or tissue.

This general thesis or interpretation of observed facts admits of the transmission of acquired char- 
acters and, at the same time, accounts for the great variety of cases revealed by observation or experimentation. Certain characters can be transmitted, those, namely, which correspond to a substance present, not only in the organ under consideration, but in the ovum as well. They are not necessarily characters of prime importance, very noticeable or indispensable to the life of the developed organism. They are characters common to the organism and to the ovum.

Other characters, equally important perhaps, but determined by substances which do not exist in the ovum and only develop in the course of ontogenesis, are not transmitted. The same holds true of modifications which, while very noticeable, bring about no qualitative change in the composition of the blood. This explains the contradictory results of the various experiments bearing upon different somatic modifications.

It is most natural that certain mutilations, such as docked tails or amputated limbs, performed on organs made up of tissues found everywhere in the organism, should not be hereditary, as this occasions no qualitative change in the blood. Things may be different, however, when the organ resected contains the totality of a certain kind of tissue. The organism is then deprived of the substance characteristic of that tissue and the sexual product, at the time of its formation, 
will be deprived of the source from which it received that substance. This substance will not be found in the sexual product or only in very small quantities. When the ovum develops, the organs characterised by that special substance will only appear in a degenerated condition.

The same holds true of modifications resulting from use or disuse of organs or from hereditary aftereffects of diseases which affect the cell plasm for a greater or smaller length of time. This is the way immunity, for instance, can be transmitted to the offspring. Vaccines affect certain chemical elements of the organic cells and the related substances in the ovum which will impart to the future organism the same character of immunity.

Certain characters are acquired under the influence of life conditions, nutrition being one of the foremost factors. Our explanation of the mechanism of transmission can be easily applied to nutrition, for the influence of diet on the composition of the blood is incontestable. Through the medium of the blood, food stuffs act upon the sexual cells and upon the substances they contain and which will, afterwards, reappear in the cells of the future organism. This accounts, if not for the influence of soma cells upon germ cells, at least for the simultaneous and correlative influence of certain external factors upon soma and germ cells. 
The theories which emphasise the part played by modifications of chemical origin and attribute to species a chemical basis, are supported by many facts of observation and by all the experiments made recently with toxins and serums. From his observations on the colouration of wines and on the various hydrocarbonated essences, A. Gautier draws the conclusion that the elements of the living plasm differ from a chemical point of view in every species or even in every race, and that chemical variations are the origin of morphological variations. Albumina belonging to the same chemical group are different in every animal species; the hæmoglobin of every species is different as shown by the morphology of hæmin crystals; finally the action of the various serums in the process of immunisation reveals capital differences between them. ${ }^{13}$

The chemical definition of species upon which Le Dantec's entire system is based, leads him to admit, as we do, that while the orum possesses neither muscle nor nerve, it possesses to a more or less marked degree certain peculiarities which, developing along different lines, impart to every differentiated tissue its proper characters. ${ }^{14}$

13 Armand Gautier. Les mécanismes molécularies de la variation des races et des espèces. (Revue de viticulture, 1901.)

14 Eléments de philosophie biologique, p. 121.

YOTE OF THE TRANSLATOR.

LE DAxTEC holds that life is a chemical phenomenon and that specific 
Another author with a leaning toward Lamarckism, Th. Montgomery, lays much stress upon the close relations between the germ cell and the other elements of the body which constitute its environment. The germ cell, he thinks, cannot live or act normally if it is protected against the influence of other cell substances. Its food, water and oxygen come from outside, and everything which constitutes its immediate environment has already felt the influence of the soma plasm. The germ plasm is therefore absolutely dependent upon the rest of the organism and, through the medium of the organism, upon the external environment.

Observations and experiments show that the germ plasm is not a divine entity able to exist regardless of all external influences; on the contrary, it is intimately bound with the latter. There could not be any deep difference between germ cells and soma cells, for every differentiated cell originates in a germ cell and retains a certain quantity of germ plasm; owing to this similarity in constitution, both necessarily present the same general reactions.

Thus we observe among modern biologists a tendency to find in organic chemistry an explanation for the facts of heredity. While those explanations are differences are only chemical differences. While a chemical species can take no primary account of form, chemical similarity usually implies morphological similarity and therefore the individuals constituting a chemical species are similar in form. 
less precise and less attractive than those offered by the Weismannians, they point at least in the right direction. The application of this method will probably lead to the solution of the mooted question of the heredity of acquired characters. It is to be hoped that by studying in the light of the observations on heredity the various physiological, histological, and physico-chemical phenomena which accompany ontogenesis, we may some day discover the mechanism of character transmission. At any rate, our present ignorance concerning that mechanism does not justify us in rejecting the theory postulating that transmission. 


\section{CHAPTER XV}

\section{The Lamarckian Theory}

The main thesis in Lamarckism.---Lamarck's "Philosophie Zoologique."-Mode of life and habits of animals.-Lamarck's two great laws.-Modern Lamarckism; its essential characteristics; the Lamarckian attitude to the main biological issues.-The growth of Lamarckism.

T AMARCKISM, as a system, is not easy to define. Lamarck's writings embody only the essential features of modern Lamarckism and so many details have been added to the original system, that Lamarck's works can not be regarded as presenting in its entirety the so-called Lamarckian creed.

Seldom has a new idea been developed fully by the man in whose mind it originated. The ideas of the life-struggle, of natural selection, of the evolution of species were, in spite of the many cases cited in support of them, formulated but vaguely by Darwin. Likewise the possibilities of Lamarck's conceptions are but roughly indicated in his masterwork, "Philosophie Zoologique." ${ }^{1}$ To Darwin's and Lamarck's suc-

1 Note of the translator. In translating the quotations from LAMARck's Philosophie Zoologique we have availed ourselves, whenever possible, of the extracts quoted in English by Thomas Hext Mongax in his Evolution and Adaptation. 
cessors fell the task of discussing, supplementing, and developing the master's' theories.

Lamarck's main thesis is the influence exercised on living things by their environment and their mode of life. "In animâls and in plants," Lamarck writes, "whenever the condition of habitat, exposure, climate, nutrition, mode of life, etc., are modified, the characters of size, shape, relations between parts, colouration, consistency and, in animals, agility and industry are modified proportionately." 2

The new races and varieties created artificially by breeders are a striking illustration of this statement. The environment, however, does not exert its influence on plants and animals in an identical manner. 'The immediate action of external factors is more noticeable in plants, among which it creates remarkable differences between individuals of the same species. "As long as the Ranunculus aquatilis is immersed in water, its leaves are all finely divided and their divisions are capillaceous; whenever the stems reach above the surface the leaves which develop in the air are longer and simply lobed. Individuals growing in marshy soil, where they are not covered by water, have short stems and none of the leares are divided into capillaceous segments. This gives rise to $R a$ nunculus heredaceus which botanists regard as a distinct species." 3

2 Philosophie Zoologique, Vol. I, p. 227.

s Vol. I, p. 231. 
Generally speaking, modifications in plants are due to changes in nutrition, while modifications in animals are produced in a more indirect way by what Lamarck calls "habits." "Important changes in conditions bring about important changes in the animals' needs and changes in their needs bring about changes in their actions. If the new needs become constant or durable, the animals acquire new habits which are as durable as the needs which created them. Whenever new conditions, becoming constant, impart new habits to a race of animals, that is, induce them to perform new actions which become habitual, these habitual actions lead to the use of a certain part in preference to another, or to the total disuse of a part which is now useless." 4

This, in turn, leads to a modification in shape and structure. "The lack of use of an organ, made constant by acquired habits, weakens it gradually until it degenerates or even disappears entirely. The vertebrates whose general plan of organisation is almost identical, although they present a great variety of details, are supposed to have their jaws armed with teeth; in those, however, which, owing to special circumstances, acquired the habit of swallowing their food without first masticating it, teeth have not attained any development. Either the teeth have re4 Vol. I, pp. 223-224. 
mained concealed in the jaw bones or they have disappeared without leaving any traces."

Lamarck cites as illustrations the ant-eater, whose teeth have disappeared, owing to its habit of swallowing food without masticating it, and the baleen whale, which was, for a long time, considered as absolutely toothless, but in whose foetus teeth have been observed to exist.

"It is an essential part of the plan of organisation of the vertebrates and of many other animals that they should have eyes in the head. The mole, however, which on account of its habits hardly needs to see plainly, has small, almost invisible eyes, because it hardly ever uses those organs. The Aspalax which, like the mole, lives underground and is probably even less exposed to the light, has totally lost the power of sight; consequently, it has only the rudiments of the organs wherein it resides; and moreover, those rudiments are absolutely concealed under the skin and other parts which cover them, allowing no light to reach them." The Proteus, which inhabits deep and dark caves, presents the same peculiarities. "It is part of the plan of organisation of reptiles as well as of other vertebrates, that they have four legs attached to their skeleton . . . but snakes acquired the habit of gliding over the ground and concealing themselves in the grass; owing to their repeated efforts to elon- 
gate themselves, in order to pass through narrow spaces, their bodies have acquired a considerable length not commensurate with their width. Under the circumstances, legs would serve no purpose and, consequently, would not be used; long legs would interfere with the snakes' desire for gliding and short ones could not move their body, for they can only have four of them. Continued lack of use of the legs in snakes caused them to disappear, although they were really included in the plan of organisation of those animals."

'This is observable, not only in the phylogenetic evolution of the various animal orders, but in one given individual in the course of its existence. "It is well known that heavy drinkers, in an habitual condition of inebriety, partake of very little solid food, and hardly eat anything, for the liquids they absorb abundantly and frequently suffice to nourish them. As liquid foods, however, do not remain long in the stomach or the intestine, the stomach and the intestinal track of drunkards and of sedentary persons, who apply themselves continually to intellectual work and are accustomed to partake of very small quantities of food, lose the habit of being distended. The stomach gradually contracts itself and the intestine shrinks." 5

On the contrary "the frequent use of an organ, made constant by habit, increases the faculties of that 5 Vol. I, pp. 240-247. 
organ, develops it and causes it to acquire a size and strength it does not possess in animals which exercise it less. A bird driven through want to the water to find the prey on which it feeds, will separate its toes whenever it strikes the water or wishes to displace itself on its surface. The skin uniting the bases of the toes acquires, through the repeated separating of the toes, the habit of stretching; and in this way the broad membrane between the toes of ducks and geese has acquired the appearance we observe to-day. Similar efforts to swim, that is to repell the water and move in it, have stretched the membranes between the toes of frogs, sea-turtles, otters, beavers, etc. . . . Likewise, . . the shore birds which do not care to swim, but must approach the water in order to obtain food, are continually in danger of sinking into the mud; but wishing to act so that their body shall not fall into the liquid, they try their best to extend and lengthen their feet. Owing to the habit those birds acquire, of extending and lengthening their feet, they find themselves raised as upon stilts, having gradually grown long legs, bare of feathers up to their thighs or even higher." c

I amarck mentions other examples such as the tongue of the ant-eater, the eyes of fishes which are bilateral in the majority of species and asymmetrical in those that swim on one side and receive a greater 6 Vol. I, p. 248. 
amount of light on the opposite side, the eyes of snakes which enable those animals to see everything above them while they glide on the ground, the broadening of the body in herbivorous mammals, due to their attitudes, the claws, retractile and otherwise, of birds of prey, the special conformation of the ostrich and of the kangaroo. He also gives the classical example of the giraffe. "The long neck and the form of the giraffe offer a curious case. We know that the giraffe is the tallest of all animals. It inhabits the centre of Africa, living in those localities where the earth is nearly always dry and without herbage. It is obliged to browse on the foliage of trees, and this leads to its stretching its neck continually upwards. As a result of this habit, carried on for a long time, in all the individuals of the race, the anterior limbs have become longer than the posterior, and the neck has also lengthened, so that the giraffe without rising on its hind legs stretches up its neck and can reach to the height of six metres." ?

From all those examples Lamarck deducts his first law: "In every animal, that has not passed beyond the term of its development, the frequent and sustained use of any organ strengthens it, develops it, increases its size, and gives it strength proportionate to the length of time of its employment. On the 7 Vol. I, pp. 254-255. 
other hand, the continued lack of use of the same organ sensibly weakens it; it deteriorates, and its faculties diminish progressively until at last it disappears."

Those modifications, however, would not have any importance as far as the future of the species is concerned unless they were transmitted to the following generations. Their hereditary character is affirmed by Lamarck's second law: "Nature preserves everything that she has caused the individual to acquire or lose by the influence of the circumstances to which the race has been for a long time exposed, and consequently by the influence of the predominant use of certain organs (or in consequence of its continued disuse). She does this by the generation of new individuals which are produced with the newly acquired organs. This occurs, provided that the acquired changes were common to the two sexes, or to the individuals that produced the new forms." 8

The physiological information at hand in Lamarck's days did not enable him in the least to explain how the phenomena mentioned in these two laws can be brought about, how organs develop by use and how acquired characters are transmitted hereditarily. And very naturally, he gives us explanations which were considered as such in his time. This defect is particularly noticeable in the second volume of "Philo8 Vol. I, pp. 235-236. 
sophie Zoologique" which treats of nervous phenomena, feelings, sensibility, psychology, and holds for us a historical interest only.

His two great laws, howerer, deducted from observation, or rather foreseen intuitively, are all that has survived from his works and been bequeathed to science, forming the basis of all the so-called Lamarckian theories.

The truth is that Lamarckism never was a real system. Its main tenets have never been systematised by any theorician nor combined into a definite creed. Lamarckism is far more difficult to define than Darwinism or Neo-Darwinism. Darwinism emphasises the part played by innate variations, modifications predetermined in the germ and due to chance, and it regards the struggle for life between individuals and between species, and the resultant natural selection, as the main factors of evolution.

Neo-Darwinism, which has found its most complete expression in Weismann's writings, constitutes a wellharmonised system of conceptions relative to the structure of living matter, ontogenesis, heredity, evolution of species, etc. $r$ Lamarckism on the other hand is not so much a system as a point of view, an attitude towards the main biological questions.

Whatever theory emphasises the influence of the environment and the direct adaptation of individuals to their environment, whatever theory gives to actual 
factors the precedence over predetermination can be designated as Lamarckian.

While the Lamarckians (Spencer for example) do not deny the reality of natural selection, they endeavour to restrict its field of action, and to place on a par with it, if not above it, other factors, known as Lamarckian factors.

In the questions relative to ontogenesis and heredity, the Lamarckians reject the idea of exclusive predetermination, that is, the idea that the fertilised ovum contains all the characters of the future individual.

Lamarckism rallies all the scientists who consider predetermination as only of secondary importance and seek the explanation of ontogenesis and heredity in the internal and external conditions which affect the ovum in the course of its derelopment. Lamarckism stands for epigenesis as against preformation. All the observations and experiments made to demonstrate the heredity of acquired charącters (a capital question in Lamarckism) and all the theoretical considerations which explain the mechanism of heredity are inspired by the Lamarckian spirit. We may say that all the research work of experimental zoology, more and more frequently undertaken in our days, the studies in biomechanics, inaugurated by Roux, in experimental parthenogenesis, in experimental teratogenesis, the various experiments on the influence of temperature and light on the organism, are Lamarckian in spirit. All 
those researches which, after all, aim at finding a mechanical explanation for life's phenomena, have brought us near the solution of the problem of the process by which the organism reacts against the influence of its environment. Still this research work is not exclusively done by Lamarckians nor from a purely Lamarckian point of view. Weismann himself had recourse to a Lamarckian explanation when he discovered that $V$ anessa levana and Vanessa prorsa, which had always been regarded as two distinct varieties of butterflies presented only a case of seasonal dimorphism due to differences in temperature. NeoDarwinians have accomplished as much in that direction as Neo-Lamarckians, but the path was blazed by the Neo-Lamarckians.

It is difficult to state which of the two theories is the more popular at the present day. We shall not be far from the truth when we say that the biologists who call themselves Lamarckians are less numerous than those who proclaim their allegiance to Darwin. But Lamarckism is making great strides and is influencing even its professed opponents. An official census of the scientific world would reveal more Darwinians than Lamarchians, but many of the scientists who follow the Darwinian flag are in reality Lamarckians who lack the courage of their convictions. 


\section{CHAPTER XVI}

\section{Representative Lamarckians of To-day}

Cope's theory.-Physiogenesis and kinetogenesis; the mechanical origin of certain structures: muscular tissue, the columella of gastropods, the astragalus, the vertebral column.-Ontogenetic differentiation; bathmism.-The energetic point of view.-Le Dantec's theories.-Functional assimilation; organic beings as units; hereditary transmission.-Lamarckians of the vitalist school.-A parallel between Darwinism and Lamarckism.

THE absence of dogmatism which characterises 1 the Lamarckian tendency and also the large number of books containing fragmentary details of the Lamarckian creed makes it rather difficult for the historian to list all the modern exponents of Lamarckism.

One of the first naturalists to approach the problem of evolution from the Lamarckian view-point was Herbert Spencer, who, from the very beginning, attributed much importance to the influence of the environment and placed the hereditary transmission of environmental effects on a par with, if not above 
the eff ects of natural selection. He owns in his Autobiography to having been influenced by Lamarckian ideas through Lyell's writings; for Lyell makes frequent reference to Lamarck in his "Principles of Greology" and in his correspondence.

Haeckel, although a determined partisan of the selection theory, paid Lamarck a high tribute in his "History of Creation," the first edition of which appeared in 1868. "To him will always belong the immortal glory of having for the first time worked out the theory of descent, as an independent scientific theory of the first order, and as the philosophical foundation of the whole science of biology. . . . This admirable work, 'Philosophie Zoologique,' is the first connected exposition of the theory of descent carried out strictly into all its consequences. By its purely mechanical method of viewing organic nature, and the strictly philosophical proofs brought forward in it, Lama ck's work is raised far above the prevailing dualistic views of his time; and with the exception of Darwin's work, which appeared just half a century later, there is none which we could in this respect place by the side of the "Philosophie Zoologique." " 1

What contributed more to the propagation of Lamarckism were controversies which threw much light on the exaggeration of the selectionists. It must be noted that in the course of controversy Darwin showed

1 Haeckel. History of Creation, Vol, I, p. 114. 
much more fairness than the Neo-Darwinians ever did. In the sixth edition of "The Origin of Species," which he considered as the final edition, Darwin estimated as follows the part played by Lamarck in the development of the transformist idea: "He first did the eminent service of arousing attention to the probability of all change in the organic, as well as the inorganic world, being the result of law, and not of miraculous interposition." 2

In the next paragraph, Darwin presented Lamarck's views relative to the various factors of transformation. In the same edition of "The Origin of Species," he acknowledged that environment and life conditions have more importance than he had attributed to them previously. Furthermore, in a letter addressed to Moritz Wagner in 1876 and reproduced in Wagner's book on "Species-forming Through Isolation," Darwin confessed that the greatest mistake he had ever made was to minimize the importance of the direct action of the environment (food, climate, etc.), independently of natural selection.

When he wrote "The Origin of Species" there were few proofs at hand of the direct action of the environment. There were many, he added, at the time he wrote the letter to Wagner.

On the other hand, we observe, even in the earlier American naturalists, a Lamarckian turn of mind, 2 Origin of Species, Historical Sketch, p. vi. 
although those scientists were not very familiar with Lamarck's works. One of the first exponents of that tendency, the very man who coined the word NeoLamarckian, Packard, gives us a historical sketch of Neo-Lamarckism in his book on Lamarck, which Marcel Landrieu took as the basis of his book on the same subject.

Natural selection did not seem to the Neo-Lamarckians an adequate explanation of evolution, as it does not account for the origin of the variations which it fosters. They preferred to attribute the origin of those variations to the direct action of the environment. A large number of books on comparative anatomy and on paleontology were written from this point of view. As early as 1866, A. Hyatt published a monograph on fossil cephalopods in which he ascribed their successive transformations to the action of the primary factors of evolution, fixed by the transmission of acquired characters. The same year appeared Cope's book on the "Origin of Genera" written from the same view-point. A few years later, in 18\%1, Cope confirmed his allegiance to Lamarckism, by recognising, besides the action of the environment, the action of use and disuse of organs. It is in his masterwork, "The Primary Factors of Evolution," published in 1896, however, that we find a complete exposé of his system, to which we devote a part of this chapter.

In 1870, Packard was led by his observations on 
arthropods, to adopt the Lamarckian views of which he has been an exponent ever since.

"Neo-Lamarckism," he writes, "gathers up and makes use of the factors both of the St. Hilaire and Lamarckian schools, as containing the more fundamental causes of variation, and adds those of geographical isolation or segregation (Wagner and Gulick), the effects of gravity, the effects of currents of air and of water, of fixed or sedentary habits as opposed to active modes of life, the results of strains and impacts (Ryder, Cope and Osborn), the principle of change of function as inducing the formation of new structures (Dohrn), the effects of parasitism, commensalism, and of symbiosis, in short, the biological environment; together with geological extinction, natural and sexual selection and hybridity." 3

Neo-Lamarckians, Packard affirms, do not minimise the rôle of natural selection; they consider it as a factor of prime importance whose action made itself felt as soon as living things began to people the earth; but they endeavour to limit its sphere of influence.

It is in the United States that Lamarckism has won the greatest number of partisans, especially among paleontologists. It is there only that Lamarckians form what can be designated as a school. Everywhere else, Lamarckism has only scattered representatives, considering as such those who really call

3 Packard. Lamarck, The Founder of Evolution, p. 398. 
themselves Lamarckians, to the exclusion of the many naturalists who are inspired by the Lamarckian views.

In France, A. Giard, who began his transformist propaganda very early, contributed a great deal to the advance of Lamarckism. While he is not an uncompromising Lamarckian, he has always in the course of his scientific career laid much stress upon the influence of the environment and the primary factors of evolution. He first made his view public in the opening lecture of his course on the Evolution of Beings in 1888. ${ }^{4}$

In order to illustrate the different interpretations of which the Lamarckian view admits, we will review in detail the theories of two typical Lamarckians, Cope, an American, and Le Dantec, a Frenchman.

Cope's system includes a theory which originated with him, the theory of archæstetism, an exposé of which will be found in the chapter on orthogenesis (Chapter XIX). His views on evolution are expressed as follows:

"I propose to cite examples of the direct modifying effect of external influences on the characters of individual animals and plants. These influences fall naturally into two classes, viz., the physico-chenical (molecular), and the mechanical (molar). The modifications so presented are supposed to be the result of the action of the causes in question, continued

4 Published in Revue Scientifique, 1889, no. 21, pp. 641-649. 
throughout geologic time. To the two types of influence which thus express themselves in evolution, I have given the names Physiogenesis and Kinetogenesis. . .

"It has been observed that both in natural conditions and in confinement, shells of fresh-water Mollusca grow to a larger size in larger bodies of water, and become reduced in size as the bulk of water in which they live is reduced." . . . "Taking Artemia salina, which lives in brine of moderate strength, Vladimir Schmankewitsch gradually diluted the water, and obtained as a result a form which is known as Branchinecta schaefferii." . . . "The yellow colour of canaries can be altered to an orange red by mixing cayenne pepper with their food." . . . "By exposing the pupæ of butterflies to low temperatures material changes in the colouration of the mature insects can be produced."

Cope designates the foregoing phenomena as cases of physiogenesis.

"In the regetable kingdom it is quite evident that evolution is more usually physiogenetic than kinetogenetic. In the animal kingdom we may reasonably suppose that kinetogenesis is more potent as an efficient cause of evolution than physiogenesis." ${ }_{5}$

The second category of modifications is by far the most important in animal life; some are due to the

${ }_{5}^{5}$ The Primary Factors of Evolution, pp. 225-230. 
use or disuse of organs and some to the motions animals perform in response to external stimuli. This is what Cope calls kinetogenesis.

Kinetogenesis claims Cope's special attention and this is in perfect accord with the Lamarckian viewpoint. Cope deserves much credit for not confining himself to a theoretical discussion but bringing forth much evidence in support of his thesis. His evidence was derived partly from the observation of the lower animals such as muscular tissue which he regards as having developed in higher Protozoa at the expense of the protoplasmic filaments which are observable in the lower Protozoa; plication of the columella in gastropods, resulting from the insertion and activity of the muscles, etc. But it is in the vertebrates, and especially the vertebrate skeleton, that Cope, thanks to his marvellous knowledge of paleontology, finds most of his evidence.

"In the first place, I will select an illustration of the effects of use on the articulations of the limbs and feet of the Mammalia. I take first the ankle and wrist-joints. In the ruminating animals (ox, deer, camel, etc.) and in the horse, among other living species, the ankle-joint is a very strong one, and yet admits of an extensive bending of the foot on the leg. It is a treble tongue-and-groove joint; that is, two keels of the first bone of the foot, the astragalus, fit into two grooves of the lower bone of the leg, the tibia, 
while between these grooves a keel of the tibia descends to fill a corresponding groove of the astragalus. Such a joint as this can be broken by force, but it cannot be dislocated. Now, in all bones, the external walls are composed of dense material, while the centres are spongy and comparatively soft. The first bone of the foot (astragalus) is narrower, from side to side, than the tibia which rests upon it. Hence the edges of the dense side-walls of the astragalus fall within the edges of the dense side-walls of the tibia, and they have pressed into the more yielding material that forms the end of the bone, and causing bone absorption, pushed it upward, thus allowing the sidewalls of the tibia to embrace the side-walls of the astragalus. Now, this is exactly what would happen if two pieces of plastic dead material, similarly placed, should be subjected to a continual pounding in the direction of their length. And in view of the facts already cited we cannot ascribe any other immediate origin to it in the living material.

"The same active cause that produced the two grooves of the lower end of the leg produced the groove of the middle of the upper end of the astragalus. Here we have the yielding lower end of the tibia resting on the equally spongy material of the middle of the astragalus. There is here no question of the hard material cutting into soft, but simply the result of continuous concussion. The consequence of con- 
cussion would be to cause the yielding faces of the bones to bend downward in the direction of gravity, or to remain in their primitive position while the edges of the astragalus were pushed into the tibia. If they were flat at first they would begin to hollow downward, and a tongue above and groove below would be the result. And this is exactly what has happened. This inclusion of the astragalus in the tibia does not occur in the reptiles, but appears first in the Mammalia, which descended from them."

"I have shown that without exception, every line of Mammalia commenced with types with an astragalus which is flat in the transverse direction, or without median groove (Periptychus rhabdodon of New Mexico)." . . " From early Tertiary times to the present day, we can trace the gradual development of this groove in all the lines which have acquired it. The upper surface became first a little concave (Pabrotherium labiatum of Colorado), the concavity gradually became deeper, and finally formed a well-marked groove (Prothippus sejunctus of Colorado). The history of the wrist-joint is similar."

"There is another striking instance of the same kind in the feet of Mammalia; that is, in the development of the keels and grooves which appear at the articulation of the first set of bones of the toes (metapodials) with the bones of the second set (phalanges). A 
third and similar example is furnished by the elbowjoint of the Quadrumana and Diplarthra."

Cope also mentions the evolution of the foot in digitigrades and plantigrades and the variations in the number of toes: "The types with reduced digits are dwellers on dry land, and those that have more numerous digits are inhabitants of swamps and mud, or are more or less aquatic." . . . ${ }^{6}$

He also points out the correspondence between the various dental types and the mode of mastication, etc. Finally we come to Cope's hypothesis as to the formation of the vertebral column: "If we now imagine that either the integuments, or an axial rod of a worm-like animal has become the seat of a calcareous or chitinous deposit, it is evident that the movements of the animal in swimming or creeping must have interrupted the deposit at definite points of its length. At the lines of interruption, joints would be formed, and if the movements were habitually symmetrical, these interruptions would be equidistant. Thus the segmentation of the osseous sheath of the chorda dorsalis in both primitive fishes and batrachians has been accomplished in wedge-shaped tracts precisely as may be observed in the folding of a tolerably stiff sleeve of a coat which ensheathes the arm, under the influence of lateral flexures. The wedge-shaped tracts are superior and inferior, the apices directed towards each

- The Primary Factors of Evolution, pp. 289-309. 
other. Seen from the side they form two wedges with their apices together, and their bases one up and the other down.

"Now, if a person who wears a coat of rather thick material will examine the folds of his sleeve as they are produced on the inner side of his arm, he will see a figure nearly like that of the segments of the rertebral column described. The folds will correspond to the sutures, and the interspaces to the bony segments. $\mathrm{He}$ will find that the spaces are lens-shaped, or, when viewed in profile, wedge-shaped, with the apices together. This arrangement results from the necessary mechanics of flexure to one side. In flexure of a cylinder like the sleeve, or like a vertebral column, the shortest curve is along the line of the greatest cenvexity of the cylinder. Here is the closest folding of the sheath, and here, consequently, the lines of fold in soft material, or interruption in hard material, will converge and come together. That is just what they do in both the sleeve and the rhachitomous vertebral column. The only difference being that in the animal it is exhibited on both sides, and on the sleeve on only one side. This difference is, of course, due to the fact that the animal can bend himself in both directions, while the arm only bends in one direction."

"From the rhachitomous column two divergent lines have arisen. The inferior segment has been retained in the fish-batrachian line, whence $I$ have termed their 
vertebræ 'intercentral,' while these bodies have disappeared or become rudimental in the higher Vertebrata. The pleurocentra have, on the other hand, developed downwards, and, meeting below, have formed the effective centrum of the vertebra.

"'The Reptilia display a greater variety of vertebral articulation than any of the classes of Vertebrata. After the primitive biconcare (amphicolous) type was abandoned, the two principal types assumed are the ball and socket (Procolous and opisthocœlous) and the plane (amphiplatyan). In those families in which the body is more or less in contact with the ground, owing to the absence, shortness, or position of the limbs (Lacertilia, Ophidia), the rertebral bodies exhibit the ball-and-socket articulation, while in types with longer limbs which supported the body in progression, so that the latter never reached the ground (Dinosauria), the articulations are plane. The balland-socket articulation may be inferred to have been produced by vermiform movements which utilise points of resistance on the earth as aids to progression, while the plane articulation has probably resulted from the persistence of the fixed relation which is appropriate to a body which should be relieved by the legs of all share in movements necessary to progression. That this position is correct is sustained by the fact that the cervical vertebræ of various reptiles and mammals which have plane dorsal vertebræ have the 
ball-and-socket structure. This is probably due to the constant flexures to which that part of the column has been subjected, as compared with the fixity of the dorsal region." $\tau$

We need not cite any more of the cases which Cope presents as evidence in support of his theoretical views. His chapter on kinetogenesis is one of the most successful efforts made to account for the various structures in the light of the Lamarckian principles. From that point of view Cope's work is very original; it shows how a comparative physiological anatomy could be based upon organic functions, a comparative dynamic anatomy as it were.

The idea of energy is the leading thought of Cope's system which on the whole is rather complex and intricate. In ontogenesis, it is a mode of movement of the protoplasmic molecules, growth-energy, which determines all differentiation; this energy which Cope designates as bathmism (from bathmos, degree) results, when it becomes diversely localised, in plications, invaginations, etc. "The most rational conception of the hereditary transmission of innate as well as of acquired characters (for the former were once acquired characters), is, he writes, the transmission of a mode of motion from the soma to the germ cells." This energy combines itself with inherited energy and produces the energy of evolution, growth energy, bath7 The Primary Factors of Evolution, pp. 368-373. 
mic energy. A certain mode of motion is probably transmitted through the nervous system which stores up the impressions received by the parents. This is Hering's heredity-memory, an idea revived recently by. Semon.

Our exposition of Cope's riews on ontogenesis and heredity and especially on bathmism, may appear somewhat vague to the reader; unfortunately, Cope's own explanations are equally rague. The important point in Cope's system is the substitution of the energetic point of view for the material point of view in the conception of heredity.

The dynamic riew-point is not peculiar to Cope. It is accepted by almost every Lamarckian and it is based upon Lamarck's statement that the function creates the organ, a statement to which the "energetic" philosophy of to-day has imparted a good deal of timeliness. It may be but a mere figure of speech, a mere way of describing things, but this figure of speech has suggested a new line of thought and given a new aim to research work.

Le Dantec, the leading French Lamarckian, follows an entirely different method of reasoning, a method which we might characterise as speculative. To Le Dantec, Darwinism and Lamarckism are not two opposite points of view but rather two ways of approaching the same question: "Darwinism," he writes, "proceeds after the manner of physical sciences which 
formulate an approximative law. Its method consists in taking living individuals in the condition of assimilation pure and simple, that is individuals which are not varying but simply maintaining themselves through assimilation in the same condition. Then the various disturbances this condition may undergo (variations) are observed, regardless of their origin, and the result attained is judged afterwards, when the various individuals have passed through the sieve of natural selection.

"Lamarckism on the other hand does not consider variation apart from life itself, that is apart from assimilation. It pays no special attention to assimilation pure and simple (for there is no such thing in reality), but to assimilation as the result of organic activity or the functioning of organs."

Thus Le Dantec comes to the idea around which his whole system revolves, the idea of "functional assimilation." All physiologists since Claude Bernard have held that organic matter suffers loss in periods of activity and recuperates in periods of rest. "This is considered," Le Dantec writes, "as an evident truth, and is never seriously questioned by physiologists; and still it is merely a preconceived idea derived from a certain dualistic prejudice from which even Claude Bernard could not free himself. He thought that the type of activity we can observe in laboratories could not be the essential of life and that 
the real building up of living matter must occur mysteriously in periods of rest. In reality, however, what is spent during the functioning of organs is not living matter but reserve substances, dead matter. If an active muscle becomes thinner, it is because it consumes adipose reserve matter; but its real substance, muscle substance, is developed by activity." $s$

Functional assimilation is regarded by Le Dantec as the solution of the question pending between Darwinians and Lamarckians. Lamarck had this phenomenon in mind when he formulated his first law, and adaptation is merely the direct and immediate result of functional assimilation.

In order to prove that Darwinism and Lamarckism are but two different methods of approaching a subject, Le Dantec relates a pathological case, the infection of sheep by anthrax bacillus, using first the Darwinian and then the Lamarckian vocabulary. This is the Darwinian account of the case: "Let us take any bacterial culture in which variations whose cause is unknown to us have taken place along several lines. We inoculate a sheep with this culture. (This is a truly Darwinian case, for the conditions in which the bacilli have varied in the previous dead environments are not directly related to their fitness to live in sheep, and the rariations they have under-

${ }^{8}$ La Crise du Transformisme, p. $26 \mathrm{1}$ and following; Eléments de Philosophie Biologique, pp. 66-69. 
gone are absolutely fortuitous as far as the environment goes.)

"The sheep will in this case play the part of a sieve. Those of the bacilli which, after the variations have taken place, happen to be virulent for sheep, that is fit to survive in sheep, will develop in the animal's internal environment. On the other hand those which, after the variations have taken place, do not happen to be virulent for sheep, will die off in the animal's interior environment, for according to the definition of non-virulence, they are not fit to multiply in this internal environment. In the end the virulent bacilli will kill the sheep and will remain alone in its blood; thus the fittest will survive as a consequence of the selection operated by the body of the sheep."

Let us see now how these bacteria go through a process of adaptive evolution. A well-known experiment instituted by Pasteur, Chamberland and Roux has demonstrated that if anthrax bacillus not virulent enough to kill a sheep is inoculated in a mouse one day old it will kill it and then become virulent enough to kill a mouse one week old; it can then kill successively an adult mouse, then a guinea-pig and finally a sheep. A Darwinian would relate the experiment as follows:

"The bacillus passing through the newly-born, the older and the adult mouse, encounters continuously, at ${ }^{9}$ Eléments de Philosophie Biologique, pp. 136-137. 
every inoculation, the sieve 'mouse' whose meshes become finer as the mouse grows older. Under such conditions the bacilli multiply and undergo chance variations in every direction. Among the bacilli thus multiplied, however, those which have fortuitously varied in the direction of decreased virulence are caught in the meshes of the sieve 'mouse' which destroys them, while those which have fortuitously varied in the direction of increased virulence, pass through the meshes and survive. The virulence increases with each new generation of bacilli passing through mice, that is, through the same sieve, which performs ceaselessly the same selection."

The same facts are now retold in the Lamarckian vocabulary: "A' sheep is inoculated with a bacillus. This protean organism, like all living cells which continue to live, directs all its activity against the external condition of its environment. When it finds itself in the interior of a sheep it directs its struggle against the sheep."

In every living being a large number of activities may take place and it is the sum total of prevailing external conditions which foster the development of some activities in preference to some others. Here it is the activity of struggle or to use Le Dantec's expression, "the organ of struggle against sheep" which will develop to greater extent, and consequently the virulence of the bacilli will increase. They could 
now kill a second sheep more easily than the first. When a bacillus insufficiently virulent for sheep acquires the necessary virulence by passing successively through several animals, the increase is due to the gradual development of that organ through its functioning.

We may describe the facts in any way we desire; the result will be the same-increase in virulence, that is, adaptation.

It is now perfectly clear that what Le Dantec criticises mostly is the Darwinian method. As far as the basic thought of Darwinism is concerned, Le Dantec recognises all the importance of natural selection, although he objects to the fortuitous characters of the variations on which it bears. "Those variations," he writes, "are directly determined by the environment and are adaptative."

Roux's theory of the struggle between parts has exerted a certain influence on Le Dantec; we find traces of it in his monograph on plastidia, or elementary living units. "They compete," he writes, "for better conditions of assimilation, as the environment does not act upon them uniformly and only the fittest survive."

This natural selection bears upon the primary constituents of the organism and results in the direct adaptation of the organism to its environment. The Darwinian idea applied to internal tissues leads ultimately to Lamarckian conclusions. 
In certain respects Le Dantec shows himself an orthodox Darwinian, namely, in regard to slow variations, the only ones he recognises. We have seen elsewhere his attitude towards the theories which countenance the idea of discontinuous variations.

While Le Dantec gladly reconciles the two points of view, he is frankly hostile to the Neo-Darwinians, not only on account of Weismann's theory of representative particles, but also owing to the Neo-Darwinian attitude to the question of the transmission of acquired characters.

Taking exception to the usual views on the subject, Le Dantec considers the inheritance of acquired characters as a fact much more common than the inheritance of innate characters. "The transmission by parents to offspring of the unmodified hereditary patrimony," he writes, "is only one special and isolated example of a truly universal phenomenon, the inheritance of acquired characters." 10

Nearly all characters are acquired, but they do not become fixed unless the influence which determines their appearance is of sufficient duration and reaches the very chemical constitution of the organism. Then only can this influence make itself felt in the offspring.

Le Dantec regards character as a corollary of the idea of organic unity, for no modification of the or10 Eléments de Philosophie Biologique, p. 2:11. 
ganism can be a purely local one. His theory of character transmission endeavours to explain not only. the influence of an external factor on the reproductive elements, but also the reappearance in the offspring of modifications identical with those observed in the parent.

"Natural phenomena group themselves," he says, "in parallel series of different scales of magnitude." For instance, we can distinguish within one series among sound vibrations, light vibrations and another type of motion observed in a very different formthe periodicity of planetary revolutions. In another order of phenomena which present a direct interest in the study of life we can also distinguish several structural series. There are first of all the atoms, the seat of chemical phenomena, "which are therefore of the scale of magnitude of the atoms or at least of the distance which separates the atoms within the molecules or the molecules themselves." Then comes the colloidal structure which offers a special interest for biologists as the living substance presents that very strucıure; colloidal particles are much larger than chemical molecules of which they contain a large number; "chemistry deals with atomic dimensions; the colloidal state on the contrary is the seat of activities whose scale of magnitude is larger than that of molecular reactions." Biological phenomena, which involve chemical phenomena "take place along two different 
scales of magnitude simultaneously." Our information as to colloids, scanty as it is at present, proves that the chemical reactions taking place in them are able to influence the colloidal state, and that reciprocally "if direct action influences the colloidal state, chemical variations may result from it, that is, molecular reactions between the particles in suspension and the solvent."

If we proceed further, we now observe "after phenomena taking place along the colloidal scale of mairnitude, those phenomena which take place along the anatomical scale" (phenomena generally visible in animal life, such as motions).

Phenomena taking place in those three scales can react upon one another. For instance, "colloidal activity can be indirectly influenced by external phenomena, which, according to their scale of magnitude would, if acting directly, only influence the chemical activities; colloidal variations, howerer, influence chemical activities, and reciprocally, external phenomena acting directly upon chemical phenomena, can indirectly influence colloidal activities."

On the other hand "animal activities can, through the colloidal mechanism of protoplasms, modify the chemical equilibrium of their constitutive elements." 11

In other words, a modification produced in an animal by its use of a certain organ, could influence its 11 Eléments do Philosophie Biologique, pp. 29-30. 
whole chemical constitution, not excluding its reproductive cells. Furthermore, owing to the reciprocal interaction or "reversibility" of colloidal phenomena and chemical phenomena, the new chemical condition of the germ cells will affect the colloidal structure of the organism to which the germ cells will give rise. 'The logical consequences of this are evident-acquired characters can be transmitted hereditarily. ${ }^{12}$

This is subtile and interesting but the author fails to account for one essential detail - the interaction of the various phenomena. We may admit the possibility of this interaction but as long as its process is not revealed to us the problem remains unsolved.

We cannot help being fascinated by Le Dantec's broad generalisations, by his bold conceptions and the novel vistas he opens, but after reading his books we feel that we have not advanced a single step. This is mere intellectual gymnastics, academic juggling with difficult problems. The question is approached from an unexpected side, in a very impressive way, but we are as far as ever from the solution sought for.

The fault lies less with the author's conceptions than with the method he follows. By introducing mathematical reasoning into biology he gives the impression of absolute accuracy and of unimpeachable rigour of conclusions in matters where everything is, in real12 Eléments de Philosophie Biologique, Chs. III, IV et V. 
ity, complex and variable and where every proposition implies many necessary restrictions.

From our survey of the various Lamarckian theories it appears that Lamarckism is a strictly mechanical system of biology. The fact that it lays such stress upon the influence of the environment lends a logical aspect to the mechanical view of life adopted by the majority of Neo-Lamarckians. There is, however, a peculiar form of Lamarckism (mostly professed by German scientists) which accepts literally Lamarck's statements as to the efforts made by the living individual to adapt itself to its needs, and regards the efforts as conscious and resulting from a mental process or "judgment."

This element of consciousness manifests itself (according to representatives of that school, among others, Pauly) not only in the adaptation of organs to the various new needs (e. g. the transformation of a crustacean's limbs), but in the modification of histological characters, consciousness being an attribute, not only of the organism but of its elements. Pauly ascribes this attitude even to inorganic bodies, thus endeavouring to bridge the gap between living and lifeless matter.

This is vitalist and teleological Lamarckism, a type of Lamarckism which lends itself very easily to violent attacks. Nothing could be farther removed from the Lamarckian spirit with its mechanical con- 
ception of evolution and its strictly positivist method. Ridiculous statements have been attributed to Lamarck, for instance, the statement that if the giraffe possesses a long neck it is because it strove for it diligently. Lamarck never expressed such a thought, although we must confess that the state of psychological knowledge in his days enabled him to word his explanations relative to the intervention of the animal's will in the activity of certain parts of its body in a way which the more searching psychology of today would no longer countenance. It seems strange therefore to hear scientists mention the "judgments" passed by elements of the tissues.

We need not dwell any longer upon this peculiar variety of Lamarckism. It has only retained the perishable part of Lamarck's theories-their form and the few details which modern science rejects.

Should Lamarckism be regarded as the antithesis of Darwinism, especially of Darwinism as formulated in Darwin's books? We do not think that such a view is justified. Not only did Darwin countenance in his writings many of the so-called "Lamarckian conceptions," but even leaving aside the transformist basis common to both systems, we may state that Lamarckian and Darwinian factors are in no wise irreconcilable. Darwin does not occupy himself with the origin of variations; Lamarck concentrates his attention on 
that very question and he attributes the origin of variations to factors whose influence Darwin does not deny. Darwin's leading theory, the theory of natural selection, does not conflict with any of Lamarck's ideas; none of the modern Lamarckians reject that theory, and all of them ascribe to natural selection a rôle which is not exclusive but very important.

Lamarckism and Darwinism are alike in another respect. Neither system has succeeded in solving all biological problems. No heredity theory has yet found a complete explanation for the transmission of acquired characters; neither has the physiological process by which an organ increases through its activity ever been elucidated. Spencer, for instance, states that "a considerable waste giving considerable power" of assimilation, is more favourable to accumulation of tissue than is quiescence with its comparatively feeble assimilation." ${ }^{13}$ Le Dantec on the other hand denies that any waste results from the functioning of organs and asserts that organic activity results in assimilation of nutritive reserves.

Certain objections formulated against the theory of natural selection hold good against Lamarckism. Neither system can account for the appearance of especially complex organs such as the eye of vertebrates, neither do they account for the existence of 1i Principles of Biology, Vol. I, p. 228. 
certain determined lines of development (orthogenesis), not for certain passive but complex cases of adaptation (mimicry).

As far as these and many other puzzling problems are concerned, we can only follow the path opened by the discoveries of modern scientists. Certain complex questions, such as mimicry, seem a little less obscure when studied in the light of the Lamarckian theories. For instance, the protective white colouring of animals inhabiting the polar regions, which had long been attributed to the action of natural selection, results merely, according to Metchnikoff's observations, from the direct infuence of cold, which in the course of experiments caused hair and feathers to turn white. It appears probable, in view of the increasing frequency of such experiments, that many other problems will be solved in similar manner. 


\section{CHAPTER XVII}

\section{Organic Selection}

A compromise between Darwinism and Lamarckism.-Acquired variations coincide with germinal variations.-Parallel adaptation, complex instincts.-The theories of Baldwin and Osborn.-Advantages and defects of the theory.

R ESIDES Neo-Darwinism, or pure selectionism, and Lamarckism, there are certain theories, not as comprehensive as those two fundamental and typical systems, which do not play as important a part in the discussion of the main biological problems and which cannot be defined as either Darwinian or Lamarckian. Some of them diverge more or less from both systems; some endeavour to combine them.

Among the latter we can mention the theory of organic selection which was formulated almost simultaneously, although with slight differences of detail, by Baldwin and Osborn in America, and by Lloyd Morgan in England. It postulates both natural selection (which it regards as the main factor of evolution), and the heredity of acquired characters, and it endeavours to dispose of the grave objections raised against the theory of natural selection by supplementing it with direct individual adaptation. 
This theory is also known as the theory of ontogenetic selection, of orthoplasis, of coincident selection or of coincident variations. The last designation is certainly the most fitting, as it describes very accurately its characteristic features.

This theory is what we might call a compromise between Darwinism and Lamarckism. One of the principal objections made to the selection theory is that slight variations or fluctuations are too insignificant at first to form a basis for natural selection. The selection theory also fails to explain why those first stages of variation are preserved and transmitted hereditarily. We know that, in the course of its life, every living thing adapts itself continually to its environment and acquires thereby some useful structure. This constitutes the so-called ontogenetic adaptation, taking the word ontogenetic in its broader sense, and applying it not only to embryonic life but to the entire span of individual existence.

If the variation faroured by the environment coincides with an innate variation of similar nature, the effects of both variations are more likely to make themselves felt than the effects of either of them separately. It may happen that a slight innate variation, too insignificant to serve any useful purpose, is somehow amplified by an acquired variation of similar nature which adds itself to it, and the two varia- 
tions, in combination, form a proper basis for natural selection.

Natural selection, then, preserves individuals thus favoured to the exclusion of the others and the innate variation is in turn preserved and transmitted, owing to the usefulness of the acquired variation. Afterwards, the combined variations accumulate in the same way in which, according to Darwin, useful innate variations accumulate, that is, by gradual addition, and the character in question becomes more and more developed. Darwin himself instanced certain characters which, while serving no useful purpose, may owe their survival to the usefulness of some other correlated character. Both characters were innate in the cases cited by Darwin; in the theory we are dealing with, one of the characters, which plays toward the other the part of a protector, is an acquired character.

This would solve the arduous problem of the incipient stages of useful variations and another no less distressing problem-that of the heredity of acquired characters. Heredity would therefore be a matter of illusion, for what is inherited is not the visible somatic variation, but the invisible innate variation coincident with the former.

In the series of generations this coincidence becomes more and more perfect, for it is beneficial, and natural 
selection gradually eliminates the individuals in which an adaptive variation does not coincide with the correspondent innate variation. Germinal variations are really the ones which are transmitted hereditarily but as they facilitate the unavoidable ontogenetic adaptations it is the latter which seem to be directly transmitted.

The theory of coincident variations also disposes of another objection to natural selection, an objection based upon parallel adaptations, neither of which taken separately, would serve any purpose; for instance, antlers would be useless to a deer, unless the muscles of neck and shoulders were developed in proportion. This argument was used by Spencer in the controversy with Weismann in order to demonstrate the heredity of acquired characters. Here, again, however, heredity is only apparent; it is, in reality, an innate variation which causes the antlers to develop in some individuals more fully than in others; ontogenetic adaptation brings about, afterwards, the corresponding enlargement of the neck and shoulder muscles which renders the modification of the antlers useful. On the other hand, it may happen in one of the following generations that an innate variation strengthens the muscles. This additional strength would be useless and disappear if the previous development of the antlers (an innate variation preserved thanks to an acquired variation), had not assigned it 
a function in the mechanism of the body. Natural selection favours this strengthening and the two variations continue to develop in parallel directions.

In the case of complex instincts a simultaneous and accurate adaptation cannot very well be accounted for by natural selection alone; for ontogenetic adaptation develops many special instincts which, taken separately, would serve no useful purpose.

There is also another factor which gives acquired instincts the appearance of being hereditary : the training of the young by the parents. Whaterer one generation acquires through ontogenetic adaptation is transmitted to the next generation which progresses and develops within the limits and following the example set by the first generation. Thus the results of organic selection create the illusion of a direct hereditary transmission. Baldwin designates this type of heredity as "social heredity."

The theory of organic selection explains why variations may succeed each other in a determined direction. 'The determining factor, according to Baldwin, is not the germinal variations but the action exerted on them by acquired modifications. In this respect Baldwin's theory bears a certain likeness to the orthogenetic theories based on germinal rariations (like Osborn's theory of organic selection), and in order to avoid confusion, Baldwin designates this determined evolution by the name of orthoplasis. 
The theory of organic selection endeavours, like Weismann's theory of germinal selection, to dispose of grave objections made by the anti-selectionists, by compromising with them on several points, and to a certain extent, it attains its purpose. All the theories based solely on innate variations or on acquired modifications are weakened by their exclusiveness. The theory of organic selection, which recognises the influence of those two factors, is more inclusive and nearer the truth. It gives at least an explanation of the fact of common observation that, when a group of individuals is submitted to the influence of a new environment, they do not all respond in the same degree to the new stimulus. For example, if the fur of several black animals transported to the polar regions turns white, the degree of discolouration will not be the same in every animal; the peculiar sensitiveness to a change in climate evinced by some of them is certainly due to a germinal peculiarity.

Unfortunately, this theory does not solve the problem in a satisfactory way; like all the theories which postulate the cumulation of innate variations, it fails to supply a physiological explanation of that cumulation. Furthermore, eren if we accept the "illusory" heredity of acquired characters as a satisfactory explanation of useful adaptations, we cannot very well understand the transmission of peculiarities which lack usefulness, such as the colouration of butterflies, 
the absence of pigment cells in tissues deprived of light, or the furrow due to the pressure of a shell whorl. In fact, the clearest examples of character transmission belong to this very class of useless characters, and most naturally so, for in the case of useful adaptations, it is often difficult to draw the line between what is due to the influence of the environment or to the mode of life and what has been fostered by natural selection.

Finally, if innate variations are too insignificant at first to present any adrantage and if ontogenetic adaptation is the main factor in the definitive constitution of individuals, ontogenetic adaptation must be operative in all individuals whether they do or do not present innate variations. It is very doubtful whether the supplementary action exercised by germinal selection would suffice to insure the survival of some individuals in preference to others, for otherwise no further factor would be necessary.

The theory of organic selection reveals an interesting intellectual tendency. It modernises the idea of selection by recognising the important part played by environmental action. No effort, however, to reconcile Darwinism and Lamarckism will avail unless it leads to an entirely new conclusion or brings in an entirely new factor. 


\section{CHAPTER XVIII}

\section{Isolation}

Geographical isolation and physiological isolation.-Moritz Wagner's theory.-Wallace on the distribution of American butterflies and island fauna.-Gulick and Romanes.--Two modes of isolation.-D. S. Jordan.-Physiological selection. -Vernon's theory of reproductive divergence.-Discussion.

A MONG the so-called auxiliary systems, which A accept either the Lamarckian or the Darwinian premises, but modify those fundamental conceptions by laying special stress on some special factor, we must mention in the first place the theories of isolation, which were the first in date, as they simultaneously appeared with the formulation of the Darwinian doctrine.

Their basic idea is that fortuitous variations can not give rise to a distinct species, unless some obstacle prevents the individuals affected by those variations from mating with constant individuals, unless, in other words, the varied individuals are isolated from the constant.

Isolation may be due to several causes: migration may lead a part of the species into a different region; a geographical barrier may divide the region inhab282 
ited by a species into two sections which no longer intercommunicate (geographical isolation); finally a variation may arise which creates a physiological hindrance to reproduction (physiological isolation). Most authors consider the influence of geographical distribution and of physiological variation simultaneously.

Moritz Wagner, a famous German explorer and naturalist, was the first to formulate the theory of geographical isolation. His travels and observations in America, Asia and Africa, led him to the conclusion that, while natural selection might modify species, it could never differentiate species, that is, produce new species. Geographical isolation alone can produce new forms which become constant. A continuous isolation of this kind never fails to bring about a differentiation, for the modifications due to a change in habitat are necessarily perpetuated through exclusive interbreeding of individuals having varied along the same line.

Changes in habitat are of very common occurrence, for overcrowding and scarcity of food create in animal species a necessary tendency to migrate, to spread out more and more over the face of the globe.

Wagner's first enunciation of his theory was made in 1868 in a paper entitled: Die Darwinsche Theorie und das Migrationsgesetz der Organismen, and until his death in $\mathbf{1 8 8 7}$ he steadily fought for his views as 
against the theory of natural selection. And yet there is no direct antagonism between Wagner's and Darwin's theories, although the Neo-Darwinians are far from agreeing with Wagner. It is true that Darwin does not regard the distribution of organic beings as an indispensable factor in species-forming and only mentions geographical distinctions and the affinity of the various faunæ as arguments subsidiary to his main thesis - the common origin of all species. He recognises, however, the importance of natural barriers and he gives many illustrations of interfaunal differences which are in proportion to the difficulty witl which intervening barriers can be crossed. ${ }^{1}$

On the other hand, Wallace, a Darwinian, emphasised in a paper read before the Congress of the British Association in 1876, the importance of local conditions. He mentioned the case of South American moths, several subfamilies of which, Danaince, Acraenice and Heliconince, present differences in pattern and colouration according to the regions where they are found. Thus the South-Andean species (Peru and Bolivia) are orange and black; in the North-Andean species, the orange colour is replaced by yellow. There could be no question of mimicry in those cases, for the three species are equally well protected against insectivorous birds by an objectionable secretion. In tropical Africa two groups of but${ }_{1}$ The Origin of Species, Chap. XIII. 
terflies belonging to two different families present a greenish-blue colouration which has not been observed in any other butterflies, and yet, neither of those groups possesses any means of self-protection.

The same can be said of the differences in colouration between island and mainland butterflies. Island species are generally less pigmented and sometimes larger sized. In the Andaman archipelago, lighter hues prevail not only in butterflies, but in birds as well. Certain colour's seem to be localised in certain regions. For instance, there are no red parrots anywhere except in the Molucca Islands and in New Guinea. Such specific differences are incontestably due to geographical distribution. Wallace remarks, however, that they are not due merely to the bare fact of isolation but to new conditions which modify the mode of action of natural selection.

This question was given much attention by two scientists who reached their conclusions simultaneously though independently-Romanes, ${ }^{2}$ a famous Darwinian, one of Darwin's direct disciples, and Gulick, ${ }^{3}$ a missionary who for fifteen years observed the land and fresh water molluscs of the Sandwich Islands. While Gulick devoted himself exclusively

2 J. T. Romanes. Physiological Selections (1885) and Darwin and After Darwin (London, 1892-1897).

3 J. T. Gulick. Divergent Evolution through Cumulative Segregation (J. Linn, Soc., XX, 189-274), and Intensive Segregation. (Ibid., XXIII, pp. 312-380.) 
to studying the various modes of isolation, geological and biological, Romanes concentrated his attention on physiological selection, a new scientific notion which originated with him.

In his book on "Darwin and After Darwin," Romanes adopted many of Gulick's ideas and the two theories are identical as far as the influence of geographical isolation is concerned.

Isolation, whatever its nature may be, is, according to the exponents of the isolation theory, a universal factor, more general than even natural selection, a factor ranking in importance with heredity and variation, the other two factors of organic evolution. In virtue of this principle, the transformation of a type cannot occur unless interbreeding becomes impossible between a part of a species and the rest of that species. When no obstacles whaterer hinder interbreeding over the whole area inhabited by a species, changes in conditions, however radical they may be, cannot result in the appearance of any new forms. Natural selection unaided will be incapable of producing a divergence of characters, Darwin's statement to the contrary notwithstanding. On the other hand, whenever a geographical barrier arises, new types will appear, the more dissimilar as the isolation lasts longer, as the distance is greater and life conditions are more different. Among the gastropods of the Sandwich Islands, there is an immense number of varieties, every variety 
being restricted, not merely to the same island but actually to the same valley. Moreorer, the differences between varieties in the various valleys increase in proportion to the distance which separates the valleys. Thus it was possible for Gulick to estimate roughly the amount of divergence between the occupants of any two given valleys by measuring the number of miles between them. 'To Wallace's remark that this fact might be due to the direct influence of life conditions, Gulick answers that no actual difference was observable between valleys and that life con- ditions could not account for the regular progression of variations.

In this case, the action of isolation seems to have been perfectly fortuitous. A certain number of individuals similar to the others, were separated from the rest of their species by a geographical barrier, and from the mere fact of isolation, new characters appeared in them; and this undoubtedly occurred without the help of any environmental influence, for whenever any number of individuals are divided up at haphazard into two groups, the average extent of individual divergence is never the same in both groups. This is the starting point of variation. Whenever the influence of the environment is superadded, divergences grow more and more noticeable.

Besides this first form of isolation, or geographical isolation, which segregates a heterogeneous group of 
individuals, and what Romanes designates as "apogamy" there is another form, designated as "homogamy," which fosters more directly the development of a new type. In homogamy, all of the individuals making up the isolated groups possess one certain character which distinguishes them from the others; they may have adopted a new mode of life or consume different food or they may present physiological or psychological divergences. Natural selection and artificial selection are but two of the forms of isolation among heterogeneous individuals; they isolate the fit from the unfit, those that present a desirable character from those that lack it; thus these two general factors are only manifestations of a more general factor, i. e., isolation.

One of the most ardent upholders of the speciesforming potency of geographical isolation at the present day is David Starr Jordan, the foremost American student of the distribution and classification of fishes. "Nowadays," he writes, "much of our discussion turns on the question of whether or not minute favourable variations would enable their possessors little by little to gain on the parent stock, so that a new species would be established side by side with the old, or on whether a wide fluctuation or mutation would give rise to a new species which would hold its own in competition with its parent. In theory, either of these conditions might exist. In fact, both of 
them are virtually unknown. In nature a closely related distinct species is not often quite side by side with the old. It is simply next to it, geographically or geologically speaking, and the degree of distinction almost always bears a relation to the importance or the permanence of the barrier separating the supposed new stock from the parent stock."

"A flood of light may be thrown on the theoretical problem of the origin of species by the study of the probable actual origin of species with which we may be familiar, or of which the actual history or the actual ramifications may in some degree be traced."

"In regions broken by a few barriers, migration and interbreeding being allowed, we find widely distributed species, homogeneous in their character, the members showing individual fluctuation and climatic effects, but remaining uniform in most regards, all representatives slowly changing together in the process of adaptation by natural selection. In regions broken by barriers which isolate groups of individuals we find a great number of related species, though in most cases the same region contains a smaller number of genera or families."

"In these and in all similar cases," he adds in conclusion, "we may confidently affirm: the adaptive characters a species may present are due to natural selection or are developed in connection with the demands of competition. The characters, non-adaptive, 
which chiefly distinguish species, do not result from natural selection, but from some form of geographical isolation and the segregation of individuals resulting from it." 4

We must add that, in order to test the accuracy of his own deductions, Dr. Jordan sent to a number of American ornithologists a question blank asking them among other important questions whether two or more subspecies had ever been observed to inhabit exactly the same region. The answers were unanimously negative, thus upholding Dr. Jordan's contention.

Another form of isolation is physiological isolation, or physiological selection, as it has been termed by Romanes, who gives it much credit for species-forming. One can observe, he thinks, at a given time within a given species, variations which make intergenerating among all the individuals impossible and restrict it to a certain category only, variations in the structure of the genitalia, differences in the epochs of maturation of the genital product, modifications in the sexual instinct, etc. Romanes cites in support of his theory the data collected by Gulick and the observations made by the botanist $\mathrm{A}$. Jordan on plant varieties which, while presenting only insignificant morphological differences, give generally negative re-

${ }^{4}$ The Origin of Species through Isolation. (Science, Nor. 3, 1905, p. 557.) 
sults when interbred." Here is a typical case cited by Kellogg. "We know of numerous species of butterflies which appear in different seasons of the year in different colour-pattern. This is not a colour change in individuals but results from an earlier or later hatching of eggs laid in the autumn or summer before. These eggs may, indeed, be all of one batch or lot, laid by a single female. Some of these eggs hatch in the spring; the butterflies that come from these spring larvæ are of one colour-pattern; some of the eggs, however, delay hatching until summer; from these larva come butterflies of another colour-pattern; some of the eggs even go over until fall before hatching; these latest butterfly individuals may be of a third colour-pattern. The colour-pattern here must have some fixed relation to the time or season of hatching the egrgs; it is not a result of isolation. But the condition well illustrates the actual existence of a biological isolation within a species: the spring butterflies must mate among themselves, the summer individuals among themselves, and the fall butterflies among themselves. Within the one species are three biologically isolated groups of individuals restrained from interbreeding." 8

It may also happen in the plant world (this example is quoted by Romanes from Darwin), that pollen from

5 Darwin and After Darwin, Yol. III.

- Darwinism To-day, pp. 213-244. 
two different varieties falls on the same pistil; this pistil exercises, so to speak, its power of selection; a certain exclusive crossfertilisation occurs which finally results in a new type. Many other cases could be instanced of sexual antipathy between varieties of one species and of slight modifications in the structure or activity of organs, etc.

Vernon has formulated a theory which he calls the theory of reproductive divergence in the following words: "Supposing that among the members of any species those individuals more alike in respect to any. different characteristic, such as colour, form or size, are slightly more fertile inter se than less similar individuals, it necessarily follows that in the course of succeeding generations the members of this species will diverge more and more in respect to the characteristic in question, whereby the original species may be ultimately split up into two or more fresh species." As a concrete example, Vernon supposes that in the Lepidopterous Ithania Urolina, a certain insect found in the Amazon Valley, small individuals were slightly. more fertile when mated with other small individuals than when mated with large individuals, while these were also more fertile inter se. "Then it would follow that fewer individuals of intermediate size would be produced, and in the course of time the species would be split up into a small and large variety." 7

${ }^{7}$ H. M. Vernow. Reproductive Divergence: An Additional Factor in Evolution. (Nat. Sc., 1897, p. 181.) 
Vernon's theory rests upon an arbitrary supposition: the greater fertility of similar mates. Since Darwin's time, however, the superiority of crossbreeds upon the interbreeding of identical individuals has been a fact universally recognised and one which the few examples cited by Vernon in support of his view are insufficient to invalidate. His theory also includes a mathematical demonstration the conclusions of which are similar to those embodied in Delboeuf's law and are open to the same criticism.

Romanes' theory of physiological selection has not won many supporters among naturalists. It presupposes too many coincidences. For instance, variations in genitalia must necessarily occur in both sexes at the same time; also variations of this order would be insufficient to create a new race of beings, for it is not clear why the progeny of individuals, varied in that respect only, should differ from the rest in many other respects. Finally, sexual variations could not accumulate without the assistance of natural selection, whose intervention would remove precisely that cause of sterility within a species.

It is most likely that if sexual variation affects a restricted number of indiriduals, if, in other words, it remains, as Darwin thought, an individual variation, those individuals are more apt to die off without learing any progeny than to constitute the nucleus of a new species. If the variation is more general, it may 
give rise to polymorphism, as observed by Kellog: in butterflies, but it is hard to see how that divergence could grow to the point of constituting a specific difference.

The last mentioned objection can be formulated against any isolation theory, whether the isolation be geographical or physiological. Whenever a species is split up into two groups by the arising of a natural barrier, there are certain differences which existed previously and which on account of this barrier are not likely to be wiped out by interbreeding; they will therefore endure, but why should they become accentuated in the following generation?

Their ulterior fate may depend, according to their environment, upon characters which have nothing in common with them. This must be true, in particular in all cases of apogamy. On the other hand, if the division results from some character of specific importance, we must account in some way for the origin of the new character and whatever factor accounts for it will also account for the formation of the new species regardless of the intermediary fact of isolation.

The same holds true when the accentuation of differences between organic beings on both sides of the barrier is due to a difference in conditions. Here again the important factor is the conditions and not the incident which submitted the individual to the influence of these conditions. 
Isolation, geographical and physiological, undoubtedly plays an important part in species differentiation, but it is not an independent factor; much less can it be regarded as the exclusive factor. From a theoretical point of view it will ever remain an auxiliary factor, furnishing a new basis for natural selection or introducing a noticeable change into environmental conditions. 


\section{CHAPTER XIX}

\section{Orthogenesis}

Variations occurring in determined sequence.-Exaggerated development of certain structures; giant reptiles; the tusks of the mammoth and of the Babirussa, the antlers of the Irish stag, the protective colouring of the Kallima.-Eimer's orthogenesis and his laws of organic growth.-Cope's archæsthetism; the rôle of consciousness.-Naegeli's views.

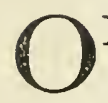

NE of the gravest objections formulated against the theory of natural selection as the main factor in evolution, was based upon the nature of initial variations. Those variations are supposed to be of many kinds, purely accidental, and tending towards all possible directions; they do not serve any purpose until natural selection acts upon them and fosters the most useful ones.

On the other hand, a number of facts seem to indicate that the development of certain organs and of certain structures follows a well-defined line, regardless of whatever usefulness they may present. In certain cases, we even observe that an organ, useful at a certain stage of its evolution, may, by developing continuously in the same direction, become positively harmful and cause a species to die out instead of pro296 
moting its welfare. This idea was suggested to paleontologists by the study of fossil organisms. Koken, a geologist and paleontologist, made frequent use of this argument. The point is well illustrated by the gigantic reptiles found in cretaceous strata, whose very size, weight and lack of agility became incompatible with their survival; likewise the exaggerated dimensions of the Irish stag's antlers and the overdeveloped and curved tusks of the mammoth led to the extinction of these two races of animals.

Overdevelopment of certain structures beyond the limit of usefulness is observable, not only in extinct species, but in modern animals as well. We mentioned elsewhere the orerperfect protective colouration of the Kallima and the overdeveloped tusks of the Babirussa. We could also mention, among other examples, the eyes of certain crustaceans, located at the end of exaggerated eyestalks. It seems as though in these cases, development having once begun, had continued through inertia in one given direction without being able to stop after reaching the stage when natural selection should have not only ceased to foster it, but prevented it.

The same may be true of characters which differ from the point of view of usefulness, such as the dimensions and proportions of certain inactive structures, details of colouring, etc., which do not appear accidentally, but show a tendency to develop in definite 
directions. The study of the pattern and colouring of insects' wings furnishes a good many illustrations of this tendency.

We also observe that rariations are not endless in number nor indeterminate, but only occur in a limited number of directions. "Through the very fact," Plate writes, "that an animal belongs to a group, the possibilities of variation are distinctly delimited and in many special cases these possibilities may indeed be very narrow." 1 Many cases are offered in evidence. It is impossible, according to the exponents of this theory, to produce blue lily of the valley, grass with divided leaves, dogs with leopards' eye spots, blue or green chickens, or blue or red canaries.

Certain biologists have been led to the conclusion that evolution is going on in several definite directions. This is what is called the orthogenetic view. Theories of orthogenesis differ from one another according to the factor to which scientists attribute the direction followed by orthogenetic variations.

The most representative theory of orthogenesis was formulated by Th. Eimer. Radically opposed to the Weismannian tendencies, he attributes to natural selection a very unimportant rôle. According to him, it cannot exercise itself until characters have reached an advanced degree of development. Natural selec-

1 PLATE. Über die Bedeutung des Darwinschen Selectionsprincips. Quoted by Kelloga: Darwinism To-day, p. 281. 
tion does not create new species but preserves those already in existence. The main factor in the transformation of species is a definite evolutionary direction which disregards usefulness completely.

This direction is not determined by any mysterious or metaphysical cause, such as Naegeli's "principle of perfection." "I find," Eimer writes, "the actual causes of orthogenesis to lie in the effects of external influences, such as climate or nutrition, on the constitution of a given organism." 2

The organism, however, does not remain passive; it reacts in its own and individual way; and therein resides the internal cause of evolution. "Development is possible only along a few lines, for the constitution and material composition of the body necessarily determine those lines and prevent modifications from following any others." The complex of all those external and internal causes acts on the individual or phylogenetic growth of organisms, a process which Eimer designates as organophysis or morphophysis.

Eimer believes in the inheritance of acquired characters, but he disagrees with the Lamarckian view (which he interprets in too narrow fashion) as the characters he considers are not acquired adaptive characters, due to use or disuse of organs (Cope's Kinetogenesis),

2 On Orthogenesis and the Powerlessness of Natural Selection in Species-forming, p. 22. 
but indifferent characters, produced by external conditions regardless of their usefulness (physiogenesis). Such is the colouring of butterflies' wings or molluses' shells, etc., a character no more useful to butterflies or molluses, Eimer thinks, than a yellow glimmer is to gold or iridescence is to a soap bubble. Those characters which had their origin in almost imperceptible variations are developed by evolution, not, as selectionists thought, along various lines, oscillating around a median or modal point, but along one straight line of advance or retrogression.

The origin of species depends essentially on the standing still of certain forms at definite stages in the developmental line, while others, more sensitive to various external influences that are active at the time, continue the onward march. A break occurs then between forms in the continuous organic chain. This phenomenon which Eimer designates as Genepistase, is considered by him as the main factor in species separation which is effected without the assistance of geographical isolation. The divergence between species is also increased by the fact that the degree of development is not uniform in the different organs (Heteropistase).

Geographical isolation, physiological isolation (Kyesamechanics), that is, hindrance in reproduction due to some modification of the genitalia, and finally the appearance by saltation of sudden variations due 
to environmental action-such are the supplementary factors in species-forming.

Besides this general theory of phylogenesis, Eimer drew from the results of his personal observations certain conclusions which he calls "laws of organic growth." Those laws, of varying importance and value, are intended to supplement his theory of orthogenesis and to determine the line followed by the evolution of living things. He states among other things, that development may come to a standstill or retrogress; that the same characters may develop identically in individuals not otherwise related; that colouration in the most different animals, molluses, birds, reptiles, mammals, and certain insects, appears first in longitudinal bands; those bands afterwards break up in spots, which blend in cross bands, and finally, by spreading more and more, produce a uniform colour, etc., etc.

Many of the statements made by Eimer are apparently founded on facts, but his theory is not convincing. His laws are mere statements of facts the cause of which is not determined. The reasons why characters in their development follow an upward or downward direction without deviating from a definite line, remains very obscure. Eimer declares that he does not attribute to the organism any mysterious property in order to explain its tendency to develop along one definite line, and that environment is the 
main factor of organic development. Environmental conditions, however, are very variable. Eimer fails to determine which of them plays the principal part and, in spite of his declaration of principles, he seeks in the organism the factor of orthogenetic development. As Eimer does not throw any light upon this factor and does not relate it to any histological or physiological conditions, this factor remains mysterious, not to say metaphysical.

Another exponent of the orthogenetic view is E. D. Cope, who, while accepting the Lamarckian theory, formulated an orthogenetic theory known as archæsthetism. Cope endeavours to explain what Darwinism failed to account for, the beginning of variations. They originate, he thinks, in the movements made by the individual in order to satisfy its needs. "Sensation (consciousness) has preceded in time and history, the evolution of the greater part of plants and animals both unicellular and multicellular." " 3 In no other way can we account for the various motions of the protozoa. Those movements, resulting from sensibility, may be regarded as conscious. (Cope very often uses the expression "consciousness or" sensation" without drawing a line between the two.) Consciousness, he says, coincides with the dawn of life. "The automatic involuntary movements of the heart, intes-

3 The Primary Factors of Organic Evolution, Ch. X. The Function of Consciousness. 
tines, reproductive system, etc., were organised in successive states of consciousness; it is not inconceivable that circulation may have been established by the suffering produced by an overloaded stomach demanding distribution of its contents; thus might have originated the contractile vesicle of some protozoa." In the long run and through constant use, these manifestations of consciousness become automatic. Conscious acts are not, as generally believed, the result of reflexes; on the contrary, reflexes are the result of conscious acts. "We can affirm," says Cope, "that not only has life preceded organisation, but that consciousness was coincident with the dawn of life."

The process of evolution consists then in the successive passage of conscious acts into the unconscious, automatic stage, a retrogressive process which Cope calls catagenesis. Such a retrogression, however, is not characteristic of evolution in general; on the contrary, individuals progress and develop intellectually and the most intelligent of them triumph.

As soon as the previous acquisitions have gradually passed into the unconscious stage, new conscious and voluntary acquisitions are made, which in turn become automatic and serve as a starting point for future acquisitions.

Such is the process of evolution which assumes a determined direction in obedience to special laws. 
"The structural relations of organisms may be expressed in the following canons:

"1. Homology.-This means that organic beings are composed of corresponding parts; that the variations of an original and fixed number of elements constitute their only differences. A part large in one animal may be small in another, or vice versa; or complex in one and simple in another. . . .

"2. Successional Relation.-This expresses the fact that species naturally arrange themselves into series in consequence of an order of excess and deficiency in some feature or features." (Thus a species with three toes would rank in every other respect between species with one and four toes.)

"3. Parallelism.-This states that all organisms in their embryonic and later growth pass through stages which recapitulate the successive permanent conditions of their ancestry. . . ."

"4. Teleology.-This is the law of fitness of structures for their special uses, and it expresses broadly the general adaptations of an animal to its home and habits." 4

Eimer's and Cope's theories are frankly Lamarckian in tendency; both also have recourse to facts revealed by observation and experiment, the action of the environment or the conscious reaction against it, to account for the definite direction followed by evolution.

4 Primary Factors of Organic Evolution, pp. 19-20. 
The idea of a conscious reaction is not associated in Cope's mind with any mysterious conception of a vital force; it is merely a psychological generalisation.

Other orthogenetic theories stray from the domain of science and admit metaphysical entities as factors of orthogenesis. Such is Naegeli's system which seeks the main factor of evolution and the origin of orthogenesis in an internal organic tendency towards perfection, in a principle of progressive development. Others have followed the same path and created similar metaphysical entities to which they have given various names. We shall not even mention them as they have not contributed anything to science. 


\section{CHAPTER XX}

\section{Mutation}

Continuous variation and discontinuous variation.-Examples of discontinuous variation.-Theories based upon it.-Korshinsky's heterogenesis.-De Vries' experiments; the theory of mutation. Its theoretical importance according to De Vries. - Formation of new varieties and species.-The mutations of Enothera.-The laws of mutation.-Individual selection and interspecific selection.-The origin of mutations.Partisans and opponents of the mutation theory.-Its practical importance.

THE orthodox Darwinian theory of natural se1 lection is based upon individual variations of fluctuations which affect all the individuals, so that, as far as one given character is concerned, mere differences of degree, sometimes insignificant, separate one individual from another. If the degree of development of that character in every individual of a generation were represented by various levels on the scale, the line joining all those levels would describe a curve without any sudden saltation.

This mode of variation is designated as slow or continuous variation, slow because of the long accumulation of hardly noticeable characters necessary to con306 
stitute a new race or a new variety, continuous because of those insignificant gradations, of those numberless transitions between individuals. It is also called Darwinian variation, because the characters created by this variation determine, according to Darwin, the individual's survival or disappearance in the struggle for life.

Those variations are almost universally observable. They are taken into account by breeders and horticulturists who select individuals presenting the most desirable characteristics in the highest degree and allow them to breed to the exclusion of all others. One can also list among slow variations those due to climate, mode of life and nutrition. They are therefore the basis of the Lamarckian theories as well as of all the Darwinian theories.

Besides this mode of variation there is another mode designated as sudden or discontinuous mode. It comprises the modifications which appear suddenly and are noticeable enough to be regarded as anomalous. The new character they impart to individuals is not necessarily salient: the difference between the individual thus varied and the normal may not be any greater than that which separates the two extremes in fluctuating variations. What distinguishes this mode of variation, however, is the absence of transitional forms. The result is that the characters of one species or of one variety may be suddenly modi- 
fied without any accumulation of infinitesimal variations.

The phenomenon of discontinuous variation had been observed for many years; many instances of it were cited and designated as "sports" or frealis." Darwin mentions many cases of discontinuous variation: black-shouldered peacocks distinguished not only by their colouration but by their size, strength and fecundity; dachshunds; ancon sheep presenting the same peculiarities as dachshunds; Meauchamp sheep; hornless Paraguayan cattle, etc.

Since Darwin's days, many other examples of discontinuous variation made constant by heredity have been noted, both in the animal and the vegetable kingdom: Niata cattle, known also as bulldog cattle or flatnosed cattle, characterised by foreshortened nasal and superior maxillary bones, the nose and upper lip receding considerably; single-hoofed pigs; albino axolotls. In the vegetable kingdom there are plants with striped, variegated or double flowers, and other characters which, having once appeared, become through transmission the starting point of new varieties (striped larkspur, cinquefoil clover, etc.). Those varieties which originate accidentally are especially frequent in cultivated species, as artificial selection, operated by man, maintains the heredity of the new character by preventing cross-breeding which might obliterate it. 
While Darwin was well acquainted with those discontinuous variations, he disregarded them entirely in formulating his theory; he considered them as an insignificant factor in comparison with continuous individual variations which are so frequent and so general. From Darwin's time, however, to the present day, nany naturalists have endeavoured to make discontinuous variation the basis of evolution theories. In 1864 Köllicker, in 1877 Dall, and more recently, in 1901, Korshinsky held the belief that these saltations, these variations without transitional forms (a phenomenon designated as heterogenesis) were responsible, to the exclusion of infinitesimal individual fluctuations, for every transformation of species.

This theory, supported by a large number of experiments, was developed into a real system by the Dutch botanist De Vries, who designated it as the Theory of Mutation. It is winning recognition from a constantly increasing number of biologists. Among De Vries' predecessors we can only name one whose views are worth while recording. It was Korshinsky according to whom the evolution of species is due to the sudden appearance of certain modifications which are transmitted to the off spring, especially in cases of reproduction by nodes, layers, etc. These modifications originate in the germinal cells, and as far as the individual is concerned, they are independent of the external environment; the latter, however, is an 
important factor in determining their ultimate destiny.

Korshinsky's theory is not based upon any very large amount of personal experimentation and observation and it is probably for this reason that it has failed to attract as much attention as De Vries' theory, very similar, but based on solid facts and more systematically developed.

De Vries' system is the result of many years' experimenting on transplanted wild plants and on various cultivated plants in the botanical gardens of the University of Amsterdam. It was in 1886 that De Vries began his experiments and he waited until 1901 before making his conclusions known to the public. De Vries considers that the experimental method is much more important in biology than accidental observation. "Observation usually begins," he writes, "when the mutation has made its appearance; but all conditions previous to mutation are of far higher importance than all those subsequent to it. The parents, grandparents and previous ancestors must be known indiridually." . . . Then experiments may begin.

The introduction of the experimental method in biology will, he thinks, fill a want which has always been detrimental to the advance of transformist ideas.

"The prevailing belief that slow and gradual, almost invisible changes constitute the process of evolu- 
tion in the animal and vegetable kingdom, did not offer a strong stimulus to experimental research. One of the greatest objections to the Darwinian theory of descent arose from the length of time it would require if all evolution was to be explained on the theory of slow and all but invisible changes. This difficulty is at once met and fully surmounted by the hypothesis of periodical but sudden and quite noticeable steps. This assumption requires only a limited number of mutative periods, which might well occur within the time allowed by physicists and geologists for the existence of animal and vegetable life on the earth." This is not, however, the only benefit which the transformist ideas will derive from the application of the mutation theory. One of their weak points was that "the followers of the theory of descent were induced to deny the manifest fact that species are constant entities," in spite of all the observations pointing to the contrary. The notion of a "constant" species was radically opposed to the idea of a "variable" species.

The mutation theory gives a clew to the final combination of the two contending ideas. "A species is always uniformly variable or rather is not always uniformly mutable." (De Vries reserves the word variability for the phenomenon of individual fluctuation.) "Mutability is not a permanent feature but a periodic phenomenon, producing at times new qualities, 
and at other times leaving the plants unchanged during long successions of generations. All lines of the genealogic tree show alternatively mutating and constant species. Some lines may be mutating at the present moment; others may momentarily be constant. The mutating lines will probably sooner or later revert to the inactive state, while the powers of development now dormant may then become awakened on other branches. In a complete and systematic enumeration of the real units of nature, the elementary species and varieties are thus observed to be discontinuous and separated by definite gaps. There is no reason to suppose that the world is reaching the end of its development, and so we are to infer that the production of new species and varieties is still going on. In reality, new forms are observed to originate from time to time, both wild and in cultivation, and such facts do not leave any doubt as to their origin from other allied types, and according to natural and general laws." 1

De Vries decided to watch out for the actual appearance of the phenomenon and after experiments of eight years' duration he finally succeeded in observing in Linaria vulgaris a mutation which resulted in a new variety. It was another plant, however, of the genus $\boldsymbol{E}$ Enothera, which enabled him to make de-

${ }^{1}$ Species and Varieties. Their Origin by Nutation, by H. DE Vriss, 1906, passim, 
cisive observations and to formulate certain general rules or laws.

Enothera was introduced from America on several occasions into European gardens; it also grows wild, escaping cultivation, and several species of it have been listed. The one De Vries selected for his experiments is known as lamarchiana for the reason that Lamarck first described it after observing it in the garden of the Paris Museum where it was cultivated.

"This striking species was found in a locality near Hilversum, in the vicinity of Amsterdam, where it grew in some thousands of individuals. The first discovery of this locality was in 1886. This plant showed the long-sought peculiarity of producing a number of new species every year. Some of them were observed directly on the field, either as stems or as rosettes. 'The latter could be transplanted into my garden for further observation, and the stems yielded seeds to be sown under like control."

"Lamarck's evening-primrose is a stately plant, with a stout stem, attaining often a height of $\mathbf{1 . 6}$ meters and more. The main stem is surrounded by a large circle of smaller branches, growing upwards from its base so as often to form a dense bush. The flowers are large and of a bright yellow color; they open towards evening, as the name indicates." The new species produced were $O$. gigas, $O$. rubriner- 
¿is, O. oblonga and $O$. albida, which immediately became constant and transmitted all their characters to their off spring.

"The giant evening-primrose, though not taller in stature than $O$. lamarchiana, deserves its name because it is so much stouter in all respects. The stems are robust, often with twice the diameter of lamarckiana throughout. The internodes are shorter, and the leaves more numerous, covering the stems with a denser foliage. This shortness of the internodes extends itself to the spike, and for this reason the flowers and fruits grow closer together than on the parentplant. The fruits attain only half the normal size, but are broader and contain fewer, but larger seeds. The rubrinervis is in many respects a counterpart to the gigas, but its stature is more slender. The spikes and flowers are those of the lamarchiana, but the bracts are narrower. Red veins and red streaks on the fruits afford a striking differentiating mark, though they are not absolutely lacking in the parentspecies. A red hue may be seen on the calyx, and even the yellow color of the petals is somewhat deepened in the same way. Young plants are often marked by the pale red tinge of the mid-veins, but in adult rosettes, from lack of sunshine, this hue is often very faint. Both of these stout species have been found quite constant from the very first moment of their appearance. I have cultivated them 
from seed in large numbers, and they have never reverted to the lamarchiana.

"We may now take up a couple of forms, which are equally constant, but which are so obviously weak as to have no manifest chance of self-maintenance in the wild state. These are the whitish and the oblongleaved evening-primroses or the CEnothera albida and oblonga. CEnothera albida is a very weak species, with whitish, narrow leaves, which are evidently incapable of producing sufficient quantities of organic food.

" $O$. oblonga when very young has broader leaves, but in the adult rosettes the leaves become very narrow, but fleshy and of a bright green color. They are so crowded as to leave no space between them unoccupied; it always remains a small plant, reaching about half the height of that of lamarchiana." 2

From the observation of these various species and varieties of Enothera, De Vries formulated the following laws of mutation:

"I. The first law is, that new elementary species appear suddenly without intermediate steps."

"II. New forms spring laterally from the main stem. The current conception concerning the origin of species assumes that species are slowly converted into others. The conversion is assumed to affect all the individuals in the same direction and in the same 2 Pp. 521-540. 
degree. 'The whole group changes its character, acquiring new attributes. By intercrossing they maintain a common line of progress, one individual never being able to proceed much ahead of the others. The birth of the new species necessarily seemed to involve the death of the old one. On the contrary, the vast majority remains unchanged; thousands are seen exactly repeating the original prototype yearly, both in the native field and in my garden. There is no danger that lamarckiana might die out from the act of mutating, nor that the mutating strain itself would be exposed to ultimate destruction from this cause."

"Another phase of the opposition between the prevailing view and my own results seems far more inportant. According to the current belief the conversion of a group of plants growing in any locality and flowering simultaneously would be restricted to one type. In my own experiments several new species arose from the parental form at once, giving a wide range of new forms at the same time and under the same conditions."

"III. New elementary species attain their full constancy at once, that is, transmit all their characters to their progeny independently of any external condition."

"IV. Some of the new strains are evidently ele- 
mentary species, while others are to be considered as retrograde varieties."

The last statement requires a few explanations. De Vries takes great pains to define the word species and to delimit the notion of species. Species as commonly understood in classification (the Linnæan species) is, he thinks, too inclusive a unit, corresponding as it does to a complex group of forms. In the majority of cases it can be subdivided into a certain number of secondary units called varieties, but which it would be more fitting to call elementary species, reserving the word variety for lesser subdivisions.

Every new species which De Vries obtained in the course of his experiments on Enothera constituted therefore an "elementary. species" and its "varieties" were only subvarieties. This is not for De Vries a mere question of conventional nomenclature; to him the definition of species corresponds to something very real, for he belongs, as we stated elsewhere, to the school of biologists who believe that characters originate and are contained in material particles. According to whether those particles, which he designates as "specific units" are active or passive, the corresponding character may either appear or remain latent.

"Latency, from this point of view, must be one of the most common things in nature. All organisms 
are to be considered as internally formed of a host of units, partly active and partly inactive. Extremely minute and almost inconceivably numerous, these units must have their material representatives within the most intimate parts of the cells."

"Therefore we can consider the following as the principal difference between elementary species and varieties; that the first arise by the acquisition of entirely new characters, and the latter by the loss of existing qualities or by the gain of such peculiarities as may already be seen in other allied species."

Mutation can take place in the line of progression or in the line of retrogression according to whether characters have been acquired (have been awakened) or have been lost (have become latent).

Among the forms obtained by De Vries, some were, according to his standard, true species, while some others were regressive varieties, that is, they presented no other peculiarity but the passing of one certain character into latency.

"V. The same new species are produced in a large number of individuals. This is a rery curious fact. It embraces two minor points, viz: the multitude of similar mutants in the same year, and the repetition thereof in succeeding generations. Obviously there must be some common cause."

"VI. The relation between mutability and fluctuating variability has always been one of the chief 
difficulties of the followers of Darwin. The majority assumed that species arise by the slow accumulation of slight fluctuating deviations, and the mutations were only to be considered as extreme fluctuations, obtained, in the main, by a continuous selection of small differences in a constant direction."

"My cultures show that quite the opposite is to be regarded as fact. All organs and all qualities of lamarckiana fluctuate and vary in a more or less evident manner, and those which $I$ had the opportunity of examining more closely were found to comply with the general laws of fluctuation. But such oscillating changes have nothing in common with the mutations. Their essential character is the heaping up of slight deriations around a mean, and the occurrence of continuous lines of increasing deriations, linking the extremes with this group. Nothing of the kind is observed in the case of mutations. There is no mean for them to be grouped around and the extreme only is to be seen, and it is wholly unconnected with the original type. The offspring of $\mathrm{my}$ mutants are, of course, subject to the general laws of fluctuating variability. They vary, however, around their own mean, and this mean is simply the type of the new elementary species."

"VII. The mutations take place in nearly all directions. They do go, according to Darwin's view, in all directions, or at least in many. If these in- 
clude the useful ones, and if this is repeated a number of times, cumulation is possible; if not, there is simply no progression, and the type remains stable through the ages. Natural selection is continually acting as a sieve, throwing out the useless changes and retaining the real improvements." 3

While De Vries opposes his theory of the origin of species by sudden variations to the theory postulating the accumulation of slow variations, he nevertheless attributes an important rôle to natural selection. He considers selection, however, as being operative between species and not between individuals of the same species.

"Intraspecific selection produces the local races, the marks of which disappear as soon as the special external conditions cease to act. It is of very subordinate importance. The experience of breeders proves that selection according to a constant standard soon reaches a limit which it is not capable of transgressing. In order to attain further improvements the method of selection itself must be improved. Nature, as far as we know, changes her standards from time to time only in consequence of the migrations of the species, or of local changes of climate."

Selection between species is much more important whether it is natural or artificial. It constitutes the sieve through which certain species only can pass and B Pp. 558-574. 
which is sufficient to account for the most complex structures, the most perfect cases of adaptation. Interspecific selection chooses from several mutations, and consequently from the various new species, those that are to survive. Natural selection and artificial selection are absolutely similar in this respect and it is perfectly legitimate, all statements to the contrary notwithstanding, to draw a parallel between them.

The external environment influences the evolution of individuals through interspecific selection; it is alsc in all probability the environment which determines the appearance of a period of mutation; but the action of the environment can not accomplish more than this. The nature of mutations is in no way determined by external factors; their origin is germinal, congenital, and depends upon changes taking place within the sexual cells. The appearance of new characters, the awakening of latent characters or their passing into latency, are due to unknown internal causes acting within the germ cells.

This view, which minimises the influence of external factors, is a connecting link between De Vries and the Weismannians, in spite of the stand De Vries takes against the classical theory of natural selection. On the other hand, it separates De Vries distinctly from the Lamarckians.

Among the naturalists who have been converted to the mutation theory we may mention T. H. Morgan, 
who is one of its warmest partisans. He enumerates the advantages which the new conception presents as follows:

"1. Since the mutations appear fully formed from the beginning, there is no difficulty in accounting for the incipient stages in the development of an organ, and since the organ may persist, even when it has no value to the race, it may become further developed by later mutations and may come to have finally an important relation to the life of the individual."

"2. The new mutations may appear in large numbers, and of the different kinds, those will persist that can get a foothold. On account of the large number of times that the same mutations appear, the danger of becoming swamped through crossing with the original form will be lessened in proportion to the number of new individuals that arise."

"3. If the time of reaching maturity in the new form is different from that in the parent forms, then the new species will be kept from crossing with the parent form, and since this new character will be present from the beginning, the new form will have much better chances of surviving than if a difference in time of reaching maturity had to be gradually acquired."

"4. The new species that appears may be in some cases already adapted to live, in a different environment from that occupied by the parent form; and if 
so, it will be isolated from the beginning, which will be an advantage in avoiding the bad effects of intercrossing."

" 5 . It is well known that the differences between related species consists largely in differences of unimportant organs, and this is in harmony with the mutation theory, but one of the real difficulties of the selection theory."

"6. Useless or even slightly injurious characters may appear as mutations, and if they do not seriously affect the perpetuation of the race, they may persist." 4

L. Plate, who has written the most complete criticism of the mutation theory, refuted the foregoing, paragraph by paragraph, in the following terms:

"1. De Vries' theory does not account any more than the Darwinian theory does for the appearance of useful characters, as infinitesimal differential characters do not attain, on Morgan's own admission, the necessary degree of usefulness from the very beginning. Only a large number of mutations following one another in determined sequence can impart to a character the necessary degree of usefulness.

"2. The simultaneous appearance of the same mutation in a large number of individuals is a rery infrequent phenomenon and self-fecundation being exceptional in nature, intercrossing is unavoidable.

4 T. H. Morgax. Evolution and Adaptation, pp. 298-299. 
"Paragraphs 3 and 4 point out obstacles to this possible intercrossing which are as real in fluctuating variation as in mutation.

"Paragraphs 5 and 6, relative to indifferent or even slightly injurious characters, establish a fact which is not accounted for by mutation any more than by natural selection, the origin of variations. Both theories simply take them for granted. Neither in fluctuation nor in mutation, do isolated variations have any importance; what really counts is plural variations which are more likely to occur in fluctuation than in mutation." 5

Many other arguments have been presented by various authors for or against (more for than against), the theory of mutation, but we shall not refer to them. The claims sometimes made that the new doctrine furnished a general explanation of phylogenetic evolution and could supersede all other hypotheses is not well founded. The theory of mutation only points out one of the various lines followed by evolution. That evolution may follow this line is amply proved by De Vries' many and accurate experiments.

In one respect the new theory appears unsatisfactory: it does not account in any way for the general and important phenomenon of adaptation. De Vries does not seem to have attached any importance to this

5 L. Plate. Darwinismus contra Mutationstheorie, quoted in German in V. L. KellogG, Darwinism To-day, pp. 368-372. 
question. Another fact which makes one hesitate to accept mutation as a general explanation is the rarity of the cases observed. It is true that since De Vries' book was published many new observations have been made and new cases reported. De Vries himself confesses, however, that those cases are yet too few. His explanation of the fact is rational enough but would fit any other theory as well. When a mutation takes place in the wild state, he says, naturalists regard it as an old variety and take no account of it. Thousands of mutations may thus appear and disappear and never be noticed, at least, as mutations. On the other hand, the struggle for life wipes out easily all the individuals which diverge too far from the normal and are incapable of developing under certain conditions. This is true of mutations as well as of fluctuating variations, and as useful mutations are rare, many useless mutations must be wiped out in the struggle for life. If De Vries was able to observe a certain number of mutations, it is because he took all the precautions known to cultivation in order to preserve them.

The practical import of De Vries' observations is the concrete evidence they give that new species can appear and that their appearance may be due to other factors besides slow and gradual variations. 


\section{CHAPTER XXI}

\section{Résumé}

The present status of the question.-Differentiation and adaptation.-Theories of differentiation: mutation, orthogenesis, isolation.--Theories of adaptation: Darwinism and Lamarckism.-Natural selection, transmission of acquired characters.-The limits of adaptation.-Structure and function.Non-adaptive variations.-Increasing complexity of living things.-A possible solution of the question at issue.

THE questions we have examined in the course 1. of the foregoing chapters are many and varied, the theories reviewed are very different and sometimes irreconcilable; by surveying rapidly the field just covered, we will be able to derive a clear idea of the problems now wanting solution.

Two important phenomena mark the evolution of the organic world; one is the appearance of the different species, the differentiation of the various groups recognised in the usual classification of animals and plants, the increasing complexity of organisms, their evolution from the lowest to the highest forms; the other is the adaptation of living things to the conditions and necessities of their environment. 


\section{RÉSUMÊ}

The two processes, while simultaneous, differ entirely in their natures and are never superimposed. When we speak of higher and lower animals we do not mean to convey the idea that the former are better adapted than the latter to their conditions; it is indubitable, on the contrary, that protozoa thrive as well in their environment as vertebrates do in their own, and that the most insignificant parasite enjoys in its own sphere all the advantages possessed by higher animals which are obliged to exert all their faculties in order to preserve an existence beset by many dangers.

Whenever a species supersedes another species or appears simultaneously with another, it would be wrong to conclude that it is better adapted to its mode of life than the species from which it sprang. The criteria adopted in classification prove that, in establishing the distinctions between species or genera, no account is taken of the adaptive character of structures. Moreover, the element of structure itself is almost entirely disregarded when it comes to estimating the degree of relationship between species; a structural likeness may result, in many cases, from a convergence, from a similarity of functions, whereas the all-important fact is a common origin. In order to determine the phylogenetic origin of an organ, we do not seek in lower animals of the same type an organ which serves the 
same purpose, but an organ which has the same embryogenetic origin.

For instance, we do not seek the origin of the bird's wings in the insect's wings but in the anterior members of reptiles, in spite of the reptiles' widely different mode of locomotion. And if we list the whale with mammals, not with fishes, it is because we consider elements other than the whale's characters of adaptation to its environment.

We therefore face two distinct problems for which any theory that presumes to explain the entire processus of evolution should offer two distinct solutions. We fail to find any system that is inclusive enough to cover both points; every known system confines itself to the solution of one of the two problems. Some systems disregard the question of adaptation entirely. Such are De Vries' theory of mutation, Eimer's and Naegeli's theory of heterogenesis, Wagner's theory of geographical isolation, Romanes' theory of physiological selection. On the other side we find Darwin's theory which is solely a theory of adaptation, for it holds that natural selection fosters only useful variations; by describing the method of development of those variations it explains that of the differentiation of species.

The Lamarckian theory is generally characterised as a theory of adaptation, but a distinction should be made: it is an adaptation theory when it deals with 
active reactions of the organism, with the use and disuse of organs; when, however, it considers the direct action of climate, temperature or nutrition, it can account for any variations whatever. Adaptation in this case becomes a more obscure and more problematic phenomenon.

Let us first take the problem of adaptation and see whether it has been explained satisfactorily by any of the systems we have passed in review. The criticisms formulated against the idea that natural selection fosters infinitesimal individual variations and brings about, without the help of any other factor, the entire phylogenetic development, are so serious and based upon evidence so positive, that no biologist will ever again consider natural selection as the exclusive factor. Natural selection can of course destroy injurious variations, especially if they are very pronounced, but scientists agree that it cannot foster useful variations.

The development of useful organs is very easily explained by use which fosters their growth, but, though this theory is self-evident within the limits of the individual's life, it becomes more questionable when we consider the individual's offspring. The offspring cannot be benefited by any favourable result of organic activity in the parent unless this result is transmitted hereditarily. And it is precisely when we consider the characters due to use or disuse, 
in other words the characters which contribute most directly to adaptation, that we are hard put to it to explain the hereditary transmission of acquired characters. Roux's theory of functional stimulation beginning in organs with embryonic life, is the only theory which can throw a little light on the subject. Roux however offers a method for solving the problem rather than a solution. The question remains open.

Besides, whenever adaptation is being discussed, it is relevant to ask whether adaptation is ever as perfect in reality as it is theoretically believed to be. Is not the wonderful harmony, the accurate adaptation which we seem to observe everywhere, a mere illusion due to the fact that we only perceive one brute result, the survival of the animal or plant? We can hardly realise all the efforts made, sometimes in vain, all the injurious influences withstood in order to achieve survival. What we see is good overpowering evil and we cannot see anything else, for if the outcome had been different the organism would have perished. Moreover, starting from the idea that everything is adapted, we let our imagination run riot and very naturally we find what we are looking for. We must also remark that no animal bears passively the influence of its environment; if the environment is too unfavourable and the animal cannot adapt itself to it, it seeks another environment and frequently succeeds in finding one. 


\section{RESUME}

Observing the animal in its new environment we are apt to believe that it has been especially adapted to this environment. We might mention many organs, however, which have been preserved although they are not only useless but positively injurious. In his Études sur la nature humaine, Metchnikoff gives many examples of this anomaly : the hair on the human body whose folliculæ harbor microbes, the vermiform appendix, the seat of appendicitis, the large intestine easily affected by various infections, etc. There are even more striking "discrepancies," such as the lack of proportion between the pain felt in certain cases by the organism and the cause of that pain. "Insignificant causes," Metchnikoff writes, "unimportant sicknesses, like neuralgia, will sometimes inflict unbearable suffering. Parturition, a natural physiological phenomenon, is, in the majority of cases, accompanied by very acute pains which are absolutely. useless as a 'danger signal.',

"On the other hand, some of the most dangerous diseases, such as cancer' and nephritis, can develop for a long period of time without causing the slightest sensation of pain, with the result that the patient's attention is not attracted to them until it is too late to apply a remedy." 1

We also observe cases of faulty adaptation of instincts: insects are drawn to the flame of a lamp and

1 E. Metcinikoff. Etudes sur la nature humaine, 248-249. 
burned to death, few animals are able to detect poison in their food, rabbits often devour their young or abandon them, birds set on their nests although there may not be one egg left, etc., etc.

Thus far we have only mentioned injurious organs and instincts; many more cases could be instanced of indifferent organs and instincts. And, as the injurious and indifferent organs and instincts, put together, are probably more numerous than the useful ones, we must not judge too severely the phylogenetic theories which fail to solve the problem of adaptation.

Certain adaptations being taken for granted, there remains to be seen not only whether the results of adaptation can be transmitted to the offspring, but whether adaptation originates in the function or in the structure. This is the line of cleavage between Darwinians and Lamarckians. Does the mole possess paws adapted to burrowing because it had to burrow, or does the mole burrow because it has paws whose conformation makes that sort of work especially easy? No direct experimental proof is obtainable; the answer to this question must be subordinated to whatever system we adopt. Our knowledge concerning the insufficiency of natural selection (which by the way is based on structure) leads us to seek an explanation in functional stimulation whose action lasts during the entire life of the organism and also 
in the influence exerted upon the physiology of the organism by the various external factors.

As soon as we consider external factors we leave the domain of adaptive phenomena. We fail to see how factors like climate, temperature or nutrition could, by exerting their influence upon an animal or a plant, bring about such modifications as would facilitate the animal's or the plant's existence under given conditions. Cold may deepen the colouration of butterfly's wings and heat may increase the pigmentation of the human skin, but we fail to detect any usefulness in such changes. Those modifications may be useful in certain cases: when cold causes hair or feathers to turn white it may render a service to the animals inhabiting the Polar regions by enabling them to escape detection; but this is a pure coincidence from which we can draw no conclusion.

The influence of non-adaptive factors is the more far reaching as those factors, being dependent upon conditions of life which are common to a large number of individuals, bring about general variations which do not dwindle away as individual variations do. A general variation cannot become a factor in the transformation of species unless it be inherited; and it is precisely in variations of this kind that we find the most convincing evidence as to the transmission of acquired characters and it is to them that our tenta- 
tive explanation of heredity would apply most fittingly. This disposes in a relatively satisfactory manner of the question as to how those variations appear, acquire constancy and become the distinctive characters of species.

The next question which the theories of orthogenesis have endeavoured to solve is the following: why do certain forms, certain characters succeed one another, in the history of life, along a determined direction, without reiteration or retrogression. No satisfactory answer has ever been offered and it is doubtful whether our present state of knowledge can enable us to find one.

It may be also that the influence of certain factors outlasts whatever direct action of those factors we observe at the time and brings about changes whose connection with those factors we fail to perceive. It may be that the chemical constitution of the organism limits in some unknown way the action of those factors to one single mode, excluding all other modes, just as the eye reacts in always the same way upon all stimuli whatsoever. In this connection we must confine ourselves to mere hypotheses and as "internal evolutionary tendencies" and other verbal explanations of the same type explain nothing, we must confess that here again the question is still open.

The next problem to be solved is that of the gradual differentiation of beings, of their organic advance. 
We observe (although we must not overestimate the regularity of the processus) that higher forms make their appearance after and at the expense of lower forms, and that this evolutionary process is never reversible. As this evolution does not coincide with any progressive adaptation it cannot be explained through natural selection nor through the Lamarckian factors. We cannot account for it unless we go back to the origin of life, to the physico-chemical constitution of the cell. In the course of organic life the cell acquires new chemical substances and is submitted to new physical actions. None of those actions ceases without leaving some traces; their effects are, so to speak, stored up, while the chemical constitution of the cell-substance becomes more and more complex. The number of chemical substances it contains increases steadily, permitting a more and more raried histological differentiation and contributing to the growing complexity of the organism. This of course is a rather general explanation, and the problem will not be solved until we can really observe this increase in complexity and understand clearly how a certain chemical processus can give rise to a certain histological structure.

The problem of differentiation inevitably introduces another problem. We know that the plasticity of beings is in inverse ratio to their differentiation and that in every animal group it is the least differentiated, 
the least specialised, which give rise to new types. The conclusion is that a very high degree of differentiation would preclude the appearance of new variations and that, generally speaking, variability must be on the wane in the organic world.

Such is in fact the opinion of Rosa and of some other biologists. The question is very complex, for we have no set standard by which to measure the plasticity of organisms. We could remark that lower organisms do not die off after giving birth to higher organisms and that nothing prevents them, therefore, from producing new types. It is possible, on the other hand, that lower organisms have become differentiated enough to lose their plasticity, for differentiation and plasticity are not synonymous, and it would not be unreasonable to assume that a Vorticella, for example, might be as completely differentiated in spite of its simple structure as any of the higher organisms. This would explain why nearly all the main animal and vegetable groups arose in the earliest ages and why no new groups have appeared since.

What conclusion can we draw from our review of the various biological systems? While none of them offers a satisfactory solution of the problem of evolution, it is undeniable that the various factors of evolution which their authors mention play an important 
part. The action and interaction of the various factors, however, are so complex, that it is extremely difficult to determine precisely the exact part played by each one of them. And this is probably the reason why the authors of the various theories have yielded to the temptation of ascribing to some one factor a preponderant rôle and of underestimating the importance of the others.

That exclusiveness was a source of weakness. We personally think that the problem will be solved as soon as we succeed in determining accurately the part played by every single factor; and then, only one more thing will have to be discovered, that is, the actual processus of the transmission of acquired characters. Then we will have an answer ready for the most embarrassing objections. 


\section{Conclusion}

O science, even when its subject matter is as con1 crete and objective as that of geology or biology, can escape the influence of the social theories, ethical opinions, philosophical or religious conceptions of the day. On the other hand, every scientific idea, too broad to be confined within the narrow limits of a few isolated cases, is bound to exert, either directly or through the intermediary of some other science, a distinct influence upon the discussion of the problems, material, ethical, social or philosophical, which are foremost at the time in the minds of men.

It is not our purpose to enlarge upon the philosophical and social bearing of the Lamarckian and of the Darwinian theories; we merely wish to point out certain interesting instances of their application outside of the domain of biology.

The leading idea of Lamarckism, the influence of the environment, seems to have affected more and more deeply in the course of the past fifty years all our psychological, ethical and social conceptions. The notion of innate has been gradually superseded by the notion of acquired elements. We need not multiply examples: they will come readily to the reader's mind 338 
when he compares our present mental attitude to that of thinkers living fifty years ago. One of the most striking, from a practical point of view, is the gradual substitution of the determinist point of view for the belief in free will. If man is a creature of his environment, all our ideas on society and on education, all our methods for attaining what seems to us right are bound to undergo a radical change.

It may seem strange to mention Lamarck in connection with this very modern line of thought, for he failed to exert any influence in this direction; but we find in his writings a negation of free will and an affirmation of the personal irresponsibility of man, a product of his environment. ${ }^{1}$ Such was the conclusion of his transformist theories. His contemporaries were not ripe for accepting his conceptions, and they were even less likely to draw from them such conclusions. It is to Darwin, to the stir and excitement created in every mind by the publication of his books that credit is due for the rise and the rapid progress made by the new ideas.

We must, however, draw a sharp line between the transformist side of the Darwinian theories and their selectionist side. While Darwinian transformism has perhaps contributed more to the emancipation of the human mind than any other scientific theory, the

1 La Philosophie zoologique et le système analytique des connaissances positives de l'homme, passim. 
theory of natural selection is far from having given results as beneficial. Universally adopted by biologists, the idea of natural selection and of the struggle for life became rapidly popular and was applied in ways which its originator had certainly never dreamt of.

By struggle for life Darwin meant broadly the struggle which living things have to wage against the conditions surrounding them, climate, soil, individuals of the same and of other species; this conception was narrowed until it only meant a struggle between individuals, especially individuals of the same species. Darwin considered this struggle as one of the main factors of evolution; certain Darwinians and the general public began to regard it as the only factor; it became a mere matter of individual competition.

At the same time the original conception lost all but its essential elements and acquired a rather brutal meaning. It was construed in its simplest, most literal sense: a fight to the death, by tooth and nail, in which nothing counted but brute force. One can well imagine what further applications were found for this idea. Under our present social system, in which competition between individuals is a constant occurrence and in which the triumph of those best armed for the fray is the general rule, the theory of natural selection and of the survival of the fittest 
found a ready welcome, for it justified the present state of affairs and furnished a refutation, based upon scientific observation, of all the equalitarian and humanitarian demands.

To those who happened to feel, now and then, a little uneasy at the thought of their own selfish lives, this new theory furnished a scientific vindication of their attitude: if the weak are crushed, they said, it is in accordance with nature's law and for the benefit of the race!

The responsibility for such a distorted interpretation does not rest entirely with the public; the most eminent naturalists were often at fault. Huxley, one of the earliest adherents of Darwinism and one of the cleverest exponents of the Darwinian theory, showed himself very bold in his application of it to social questions, especially in a lecture he delivered in 1888 on the struggle for life and its meaning for man.

A gross misinterpretation of the Darwinian principles has led certain writers to condemn charitable organisations for the assistance of the sick, the infirm or the old, to repudiate all social solidarity, and to advocate a mode of life which, under the name of scientific progress, would lower us to the level of savage tribes.

Hence a distressing dilemma: shall we obey the noblest sentiments, the highest human aspirations which none of us, unless blinded by selfish considera- 
tions, is willing to sacrifice, or shall we bow to a scientific truth which cannot be disregarded by anyone who is accustomed to think scientifically?

We personally contend that every individual has a perfect right to follow the path which he judges right, even if his actions are not justified from any scientific point of view. Scientific theories are not immutable and what seems to be, to-day, a rigorously exact conclusion, may, to-morrow, in the light of new facts or of new conceptions, appear erroneous. Moreover, it would be absurd to hold out to us animal life as an example to imitate, for evolution has lifted us to a higher plane in a great many respects and has created for us a much more complex mode of existence.

The leading exponents of transformism never dreamt that their theories could be made to justify attempts at lowering man's moral status. On the contrary we see Lamarck placing solidarity at the basis of social life. He expresses himself as follows in his Système analytique des connaissances positives de l'homme: " "In the relations between individuals or between the various societies growing out of their groupings, the harmony between mutual interests is the principle of good, while disharmony between those interests is the principle of evil."

And he revolted against the inequality due to the

2 Quoted by Marcel LaNdriRT: Préoccupations métaphysiques, sociales and morales, Ch. XXII. 
institution of private property and against the oppression of the masses by the minority.

Darwin considered the question from a different point of view. If man is an animal species descended from other species, his psychical life must have developed as gradually as his physical constitution and we should find in the animal kingdom rudiments of our ethical and social instincts. And the facts prove that such is the case, that there is no fundamental difference between man and the higher animals from the point of view of intellect, sentiments, emotions, social instincts and moral sense, the last two being identical. "The social instincts lead an animal to take pleasure in the society of its fellows, to feel a certain amount of sympathy with them, and to perform various services for them."

These instincts and the life in common which develops them are beneficial to the species: "With those animals which were benefited by living in close association, the individuals which took the greatest pleasure in society would best escape various dangers; while those that cared least for their comrades, and lived solitary, would perish in greater numbers."

Darwin quotes from Brehm and other naturalists many facts showing the extent to which mutual aid exists among animals. Some of them post sentinels to warn the herd of possible danger; in herds of mammals the strongest individuals, the males, place them- 
selves on the front rank to defend the others; wolves lunt in packs; pelicans fish in concert. "The Hamadryas baboons turn over stones to find insects, and when they come to a large one, as many as can stand round turn it over together and share the booty." Here is a curious case told by Brehm and cited by Darwin: "An eagle seized a young Cercopithecus, which, by clinging to a branch, was not at once carried off ; it cried loudly for assistance, upon which the other members of the troop, with much uproar, rushed to the rescue, surrounded the eagle, and pulled out so many feathers that he no longer thought of his prey, but only how to escape. This eagle, as Brehm remarks, assuredly would never again attack a single monkey of a troop." 3

Feelings of sympathy and pity are sometimes expressed very clearly by animals. Darwin states that monkeys, male and female, always adopt the orphaned progeny of their kindred and care for them very solicitously, and that ravens and pelicans have been known to feed their blind fellows.

A large number of similar cases are cited in "The Descent of Man." As usual, Darwin gathers all the available information before drawing a conclusion. His conclusion is that man's animal origin is proved by the history of moral and social sentiments. What is of special significance to us is that, after reciting 3 The Descent of Man, Part I, Vol. II, pp. 139-144. 
the evidence as to the psychical bonds which unite men and the animals, Darwin stated that nature's law is not merciless strife, but solidarity and mutual aid.

It is evident that Darwin's followers have wandered away from orthodox Darwinism. It is hard to understand why naturalists like Wallace should, in wrestling with this problem, draw a sharp line between man and the rest of the animal world. Wallace points out that ever since man became a separate species in the animal kingdom, he has added instincts of solidarity and sympathy to the weapons of fight characteristic of other animal species. It is not upon physical characters but upon these instincts that natural selection is based, as far as man is concerned; adaptation in man is not physical but ethical and intellectual. This implies, from Wallace's point of view, that the life and death struggle is the sole law of the rest of the organic world and that the feelings of solidarity and sympathy we observe in man have no phylogenetic origin. Wallace is convinced that man, by the superiority of his intelligence and of his moral sentiments, has raised himself above the laws that rule the animal world. Man is in a class by himself and this belief leads Wallace to draw purely spiritualistic conclusions. ${ }^{4}$

The question thus presented could not be solved satisfactorily and this artificial difficulty is responsiblc

4 A. R. Waluace. Natural Selection, p. 332 and following. 
for the misinterpretations of the selectionist idea which we have mentioned.

Fortunately, many scientists have followed Darwin's advice and endeavoured to find a solution no longer inspired by metaphysical or spiritualistic considerations or traditions but derived solely from the results of observations and experiments which should be the only basis of biological conclusions.

Psychologists have tried to find in the animal kingdom the origin of the various human sentiments and they have thus established the science of comparative psychology which is as yet in its infancy but has already furnished valuable indications. Ribot, for instance, holds the view that ethical feelings result from life in common and that social feelings are observable in animal societies. Approaching the question from another side, he finds the concrete origin of our ethical feelings and of our altruistic impulses in the unavoidable tendency of our organism to extend the field of its activity, to spend its energy not only upon destructive efforts which leave only a feeling of discomfort, but in constructive, beneficent endeavour, which is accompanied by unmixed enjoyment. ${ }^{5}$ This view is also held in philosophy by Guyau, who is the author of a scientific system of morals. ${ }^{6}$ In both Ribot's and Guyau's writings we feel the 5 Tн. Rпот. La psychologie des sentiments, Ch. VIII; Les sentiments moraux et sociaux.

6 M. Gurau. Esquisse d'une morale sans obligation ni sanction. 
direct influence of Darwin from whose works they quote copiously.

Some sociologists have followed the same path and, in establishing the foundations of comparative history and of the comparative study of human institutions, have felt the need of giving to their new-born science a biological basis. Many of those sociological systems start from an absolutely wrong conception. Spencer's theory, for instance, is based upon an alleged analogy between society and the organism and is inspired by metaphysical considerations. Its weakest point is that it ignores the distinction between the division of physiological labour and the division of social labour; while it makes every effort to set itself on a biological foundation, it is influenced by political and social considerations and by a desire to justify the present social system.

Other scientists have followed a better method: they have tried to learn some lessons as to our social life, not from the life of isolated individuals, but from their observation of animal associations; this has enabled them to formulate very important and deep-searching criticisms against a too narrow application of the principle of natural selection. In his book on "Mutual Aid a Factor of Evolution," P. Kropotkin has very clearly presented this point of view which coincides, he says, with the theories of many Russian authors and in particular with those of the zoologist Kessler. 
"Wherever natural conditions are unfavourable," Kropotkin writes, "the climate too rigorous, food too scarce, wherever life triumphs with difficulty over the forces of destruction, it is not a struggle between individuals of the same species which we observe but, on the contrary, mutual aid, which becomes an important factor in the preservation of life and the evolution of the species. The study of the animal world reveals everywhere the existence of a social life not only among ants and bees but even among animals like crabs whose groupings are not as noticeable nor as permanent. Among the vertebrates, birds are most notable for their social instincts. There are associations of birds of prey for hunting, of herons for fishing, societies of parrots, meetings preceding migrations, etc. The shrewdest and cleverest are always eliminated in favour of those who appreciate best the advantages of social life and of mutual aid. The odds are very uneven between a beast of prey armed with the most perfect weapons and other animals that lack those advantages. But the issue of the fight may at times be very different from what it would be if individual death-and-life struggle were nature's law. We quote from Kropotkin the following episode related by the famous Russian ornithologist, Sievertzoff. ${ }^{7}$

"Watch, for example, one of the numberless lakes 7 Sievertzoff. Periodical Phenomena, Moscow, 1855 (in Russian). 
that dot the Russian or Siberian steppes. Its shores are peopled with myriads of aquatic birds belonging to at least a score of different species, all living in perfect peace-all protecting one another. For sereral hundred yards from the shore the air is filled with gulls and terns as with snowflakes on a winter day. Thousands of plovers and sand coursers run along the water-edge looking for food, whistling and enjoying life. Farther out, a duck is rocking himself on the crest of each wavelet, while flocks of casarki are wheeling above the lake. Exuberant life swarms everywhere.

"And now come the robbers, the strong, shrewd birds, that are ideally fitted for preying on the other feathered species. We can hear their hungry, angry, dismal cries, as for hours in succession they watch the opportunity of snatching from that living mass one single unprotected individual. As soon as they venture a little nearer, however, their approach is signalled by dozens of volunteer sentries and hundreds of gulls and sea swallows turn to repel the aggressor. Maddened by hunger, the robber abandons his usual precautions; he suddenly dashes into the living mass; but attacked from all sides, he is driven to retreat. From sheer despair he throws himself upon the wild ducks, but those intelligent and social birds quickly gather in flocks and fly away if the aggressor is an erne; or they dive under the water if it is a falcon; or they 
whip up a cloud of spray and blind him if it is a kite. And while life continues to swarm on the lake, the robber flies away uttering angry cries and tries to find some carrion or a young bird or field mouse that has not yet learnt to heed the danger warnings of its kindred. In the face of an exuberant life, the robber, ideally armed, is reduced to feeding upon refuse." Thus selfish, individual struggle compares with solidary action.

Association, Kropotkin adds, began with the dawn of animal life; it is a consequence of the very physiological constitution of certain invertebrates such as bees and ants; it becomes more conscious or purely social with birds and mammals. It plays in their existence a part at least as important as the struggle between the various classes, and certainly greater than intraspecific struggle and competition. The fittest survive, but who are the fittest? Those who have acquired habits of mutual aid?

Among the various adaptations observable in the animal kingdom, many aim precisely at preventing intraspecific competition. The storing up of food by ants, the migration of birds or beavers, the winter sleep which begins when competition for food would become terrific, the changes of food, are as many means employed by nature to do away with competitive struggle. Natural selection always asserts itself and is a mighty factor, but how does its action make 
itself felt? 'Through the survival of those who know best how to make use of their aptitude for social life, which, in the universal struggle, becomes one of the most efficient weapons.

We may add that two Russian zoologists, Professors Menzbir and Brandt, confirmed Kropotkin's general thesis at the time when it was published in various magazine articles (anonymously, for the Russian censure did not allow him to sign them) and brought forth many facts they had observed personally in support of his contention. ${ }^{8}$

The conclusions to be drawn from the foregoing are much too broad to be confined within the limits of biological problems; in Kropotkin's book two chapters only are devoted to mutual aid among animals; the rest of the book treats of the application of this doctrine to human society among the wild races, the barbarians, in the mediæval cities, and in modern communities.

This novel application of biological ideas to social questions is well worth mentioning. Besides. jt. $r$.1stitutes an important contribution to t... study of the great problem of evolution. It points to a connection, to a phylogenetic transition between the various manifestations of human life (even those which metaphysicians considered as admitting only of a spiritualist interpretation) and the phenomena of animal life from which they are derived. This materialistic

8 Mexzbir. Darwinism in Biology (in Russian). 
origin of our highest aspirations gives them a more solid basis than any free-will theory ever gave them. Above all, it imparts to them the strength to resist the encroachment of selfish interests that pretend to be based upon scientific deductions. 




\section{PLEASE DO NOT REMOVE CARDS OR SLIPS FROM THIS POCKET}

\section{UNIVERSITY OF TORONTO LIBRARY}

BiolMed 
